TECHNICAL REPORT N-76-6

\title{
DEVELOPMENT AND EVALUATION OF CORRUGATED METAL FIGHTING HOLE COVER DESIGNS
}

\author{
by \\ James W. Ball \\ Weapons Effects Laboratory \\ U. S. Army Engineer Waterways Experiment Station \\ P. O. Box 63I, Vicksburg, Miss. 39180 \\ May 1976 \\ Final Report
}

Approved For Public Release; Distribution Unlimited

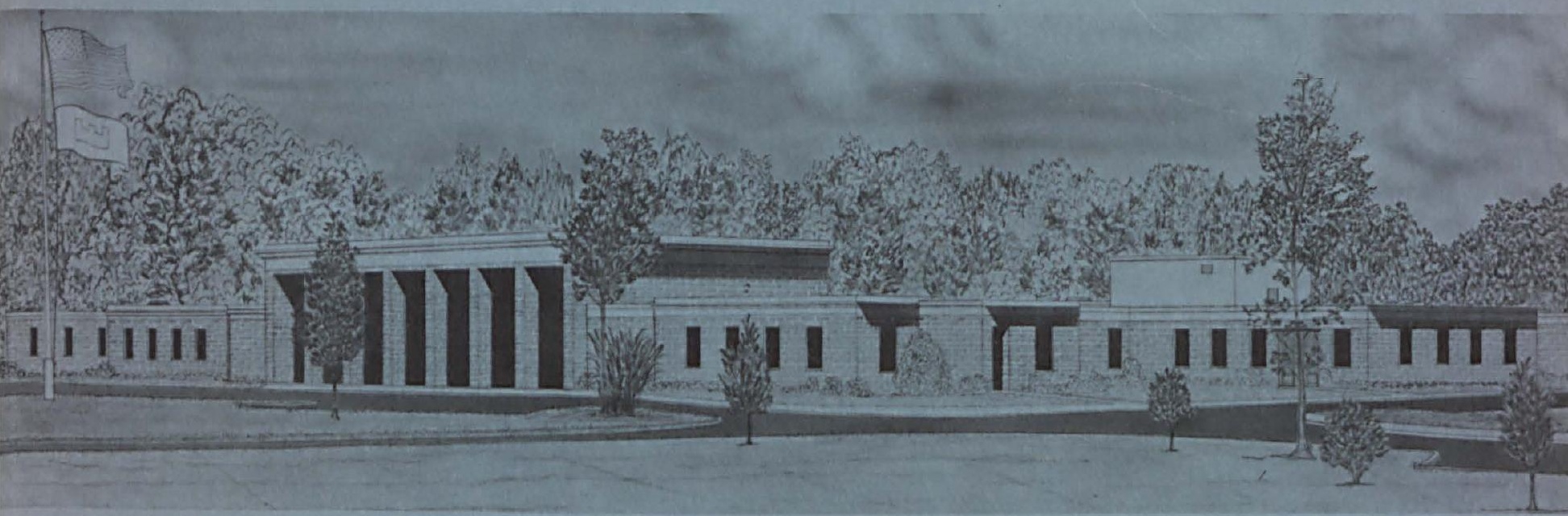

Prepared for Office, Chief of Engineers, U. S. Army

Washington, D. C. 20314

Under Project No. 4A762719AT30, Task 0I 


\begin{tabular}{|c|c|}
\hline REPORT DOCUMENTATION PAGE & $\begin{array}{l}\text { READ INSTRUCTIONS } \\
\text { BEFORE COMPLETING FORM }\end{array}$ \\
\hline $\begin{array}{l}\text { 1. REPORT NUMBER } \\
\text { Technical Report } \mathrm{N}-76-6\end{array}$ & 3. RECIPIENT'S CATALOG NUMBER \\
\hline $\begin{array}{l}\text { 4. TITLE (and Subulto) } \\
\text { DEVELOPMENT AND EVALUATION OF CORRUGATED METAL } \\
\text { FIGHTING HOLE COVER DESIGNS }\end{array}$ & $\begin{array}{l}\text { 5. TYPE OF REPORT \& PERIOD COVERED } \\
\text { Final REPORt - Jul 73-Jun } 75 \\
\text { 6. PERFORMING ORG. REPORT NUMBER }\end{array}$ \\
\hline $\begin{array}{l}\text { 7. AUTHOR(a) } \\
\text { James W. Ball }\end{array}$ & 8. CONTRACT OR GRANT NUMBER(A) \\
\hline $\begin{array}{l}\text { 9. PERFORMING ORGANIZATION NAME AND ADDRESS } \\
\text { U. S. Army Engineer Waterways Experiment Station } \\
\text { Weapons Effects Laboratory } \\
\text { P. O. Box } 631 \text {, Vicksburg, Miss. } 39180\end{array}$ & $\begin{array}{l}\text { 10. PROGRAM ELEMENT, PROJECT, TASK } \\
\text { AREA \& WORK UNIT NUMBERS } \\
\text { Project } 4 \text { A762719AT30 } \\
\text { Task } 01\end{array}$ \\
\hline $\begin{array}{l}\text { 11. CONTROLLING OFFICE NAME AND ADDRESS } \\
\text { Office, Chief of Engineers, } U, S \text {. Army }\end{array}$ & $\begin{array}{r}\text { 12. REPORT DATE } \\
\text { MaY } 1976 \\
\end{array}$ \\
\hline Washington, D. C. 20314 & $\begin{array}{l}\text { 13. NUMQER OF PAGES } \\
89\end{array}$ \\
\hline 14. MONITORING AGENCY NAME ADORESS(II dilforent from Controlline Offico) & $\begin{array}{l}\text { 15. SECURITY CLASS. (of thie report) } \\
\text { Unclassified }\end{array}$ \\
\hline & $\begin{array}{l}\text { 15.. DECLASSIFICATION/DOWNGRADING } \\
\text { SCHEDULE }\end{array}$ \\
\hline
\end{tabular}

\section{DISTRIBUTION STATEMENT (of thio Roport)}

Approved for public release; distribution unlimited.

17. DISTRIBUTION STATEMENT (ot the sbatract onterod In Block 20, if difforent from Report)

18. SUPPLEMENTARY NOTES

19. KEY WORDS (Continue on roverse sldo II necoseary and identify by block number)

Bunkers (Fortifications) Protective structures

Corrugated metal shells Subsurface structures

Expedient construction

Multiple Intersecting Cylindrical Shelis

20. ABSTRACT (Continuo an revorse side It necessary and identify by block number)

The purpose of this study was to develop criteria for the design and use of earth-covered metal shells for rapidly emplaceable fighting bunkers. Fighting bunker dimensions were determined from bunkers commonly used by $U$. $S$. forces in Korea and Vietnam. An initial concepts study verified that the bunker shell to most efficiently support the earth and explosion loads and meet the minimum dimensional requirements could be made from Multiple Intersecting Cylindrical Shells (MICS). Corrugated steel shells of various thicknesses, corrugation dimensions, and joining methods were designed with the MICs concent and (cont'd) 
20. ABSTRACT (Continued).

evaluated in laboratory static tests and field explosion tests. A fighting bunker shell was designed and tested that: (a) can be fabricated in battlefield rear areas or by small vendors from standard corrugated steel culvert sections, (b) weighs approximately 300 pounds, (c) can be installed over an unlined (in most soils) fighting hole by non-engineer troops without mechanized equipment, and (d) when properly covered with earth will defeat the effects of direct hits of the contact bursts of large mortars and medium artillery rounds. 
The investigation reported herein was conducted by personnel of the Weapons Effects Laboratory (WEL), U. S. Army Engineer Waterways Experiment Station (WES), for the Office, Chief of Engineers, Department of the Army, as part of "Research for Protective Structures and Theater of Operations," Project 4A762719AT30, Task 01. The requirement is "Qualitative Construction Requirements," items 1.01.001(4), 1.07.002, and 1.07.003. The technical monitor was Mr. R. H. Barnard.

This investigation was accomplished during the period July 1973 through June 1975 under the general supervision of $\mathrm{Mr}$. W. J. Flathau, Chief of WEL, and Mr. J. T. Ballard, Chief of the Structures Division, WEL. The investigation was conducted and this report prepared by Mr. J. W. Ball.

The assistance and cooperation of many persons were instrumental in the successful completion of this investigation. Particular appreciation is extended to Messrs. E. H. Case, J. E. Larson, and J. A. Conrad, Jr., of the Engineering and Construction Services Division, WES, for their skill in the layout and fabrication of the test structures. Also, to Mr. J. L. Scott, WEL, for his capable assistance during the field tests and Mr. J. R. Harris of the Scientific Illustration and Graphics Branch, Publications and Graphic Arts Division, WES, for his excellent assistance in many phases of producing this final report.

The Director of WES during the investigation and the preparation and publication of this report was COL G. H. Hilt, CE. Technical Director was Mr. F. R. Brown. 
PREFACE-

CONVERSION FACTORS, U. S. CUSTOMARY TO METRIC (SI) UNITS OF MEASUREMENT-_-

CHAPTER I INTRODUCTION-C_- 6

1.1 Background-_- 6

1.2 Objective-_-C-

1.3 Scope-n- 7

CHAPTER 2 DESIGN DEVELOPMENT- 10

2.1 Requirements 10

2.2 Materials Available-_an 10

2.3 Initial Concept- 11

2.3.I Discussion- II

2.3.2 Multiple Intersecting Cylindrical Shell__._._._. Il

2.3.3 Aperture Beams_a 13

CHAPTER 3 LABORATORY TEST- 24

3.1 Objective-1 24

3.2 Test Procedures-_- 24

3. 3 Test Results-_____n 24

3. 4 Design Improvements-_a 26

CHAPTER 4 FIELD TESTS AT BIG BLACK TEST FACIIITY________ 34

4.1 Selection of Test Charges- 34

4.2 Phase I Test Series-_- 35

4.2.1 Test Procedures___. 35

4.2.2 Installation- 35

4.2.3 Results and Discussion-_._. 37

4.3 Phase II Test Series-_- 39

4.3.1 Description of Test Structure___ 39

4.3.2 Test Procedures-_- 40

4.3.3 Installation- 40

4.3.4 Results and Discussion-_ 41

4.4 Phase III Test Series- 42

4.4.1 Description of Test Structure-_a 42

4.4.2 Test Procedure-1 43

4.4.3 Installation-_._. 44

4.4.4 Results and Discussion- 44 
5.1 Selected Designs-_ 81

5.2 Recommendations-__n_- 83

TABLES

4.1 Installation Time, Big Black Field Test

(Phase I) - 47

4.2 Installation Time, Big Black Field Test

(Phase II) 48

4.3 Weight of Phase II Test Structure-_____________ 49

4.4 Weight of Phase III Test Structure-_-___- 50

4.5 Installation Time, Big Black Field Test

(Phase III) - _._. 51

5.1 Cost of Materials for the Phase II Test 84

5.2 Cost of Materials for the Phase III Test. 85

FIGURES

1.1 Concrete fighting bunker-_- 8

1.2 "C"-shell fighting bunker-_______ 9

2.1 Sectional properties of 6- by 2 -inch corrugated steel plates-a 14

2.2 Sectional properties of 3 - by 1 -inch corrugated steel sheets-_a 15

2.3 Sectional properties of $2-2 / 3-$ by $1 / 2-i n c h$ corrugated steel sheets-_- 16

2.4 Common sizes of 6- by 2-inch corrugated plates-a-n-_- 17

2.5 Concrete fighting bunker-_- 18

2.6 Multiple Intersecting Cylindrical Shell (MICS) -

2.7 Layout and cutting scheme of MICS quarter-sections-_-_- 20

2.8 Connection scheme of MICS quarter-sections-_-_-_-_-_ 21

2.9 Aperture beam and fabrication 22

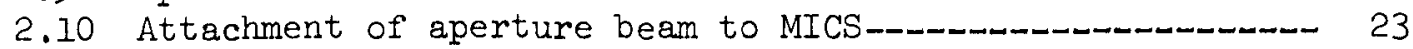

3.1 Static test configuration-_ 27

3.2 Sandbag loading configuration-_ 28

3.3 Deflection gage locations-a 31

3.4 Vertical downward and inward lateral displacement

3.5 Vertical downward displacement of aperture beam versus layers of sandbags-_.__ 32

3.6 Revised aperture beam- 33

4.1 Charge sizes and locations for Phase I test series-an- 52 
4.2 Installation of the Phase I test structure at BBTF

4.3 Hand-tools used in erecting Phase I test structure with the exception of three shovels and two wheelbarrows- 57

4.4 Damage resulting from Phase I test series Round 1-_ 58

4.5 Damage resulting from Phase I test series, Round 2- 59

4.6 Damage resulting from Phase I test series, Round 3- 61

4.7 Detailed design drawings of Phase II test structure-_- 65

4.8 MICS and typical aperture beam used in Phase II test series-_-_- 66

4.9 Charge sizes and locations of Phase II test series_-_._._. 67

4.10 Various stages of installation of Phase II test structure-_- 68

4.11 Damage resulting from Phase II test series, Round I-_- 70

4.12 Damage resulting from Phase II test series, Round 2-___ 71

4.13 Detailed design drawings of Phase III test structure-_- 73

4.14 Charge sizes and locations for Phase III test series-_- 74

4.15 Various stages of installation of Phase III test structure-_. 75

4.16 Damage resulting from Phase III test series, Round 1-n_.._ 77

4.17 Damage resulting from Phase III test series, Rounds 2 and 3-_._. 78

4.18 Damage resulting from Phase III test series, Round 4-_- 79

5.1 Detailed design drawings of Phase II test structure-------- 86

5.2 Detailed drawings of Phase III test structure_._........ 87

5.3 Utilization of remaining corrugated material for fabrication of additional quarter-sections of MICS-_-_-_ 88 
CONVERSION FACTORS, U.S, CUSTOMARY TO METRIC (SI) UNITS OF MEASUREMENT

U. S. customary units of measurement used in this report can be converted to metric (SI) units as follows:

\begin{tabular}{llll}
\multicolumn{1}{c}{ Multiply } & \multicolumn{1}{c}{ By } & & \multicolumn{1}{c}{ To Obtain } \\
\cline { 1 - 1 } inches & 0.0254 & & metres \\
feet & 0.3048 & metres \\
square feet & 0.09290304 & square metres \\
pounds (mass) & 0.4535924 & kilograms \\
pounds (mass) per cubic foot & 16.01846 & & kilograms per cubic \\
& & & metre
\end{tabular}


CHAPTER 1

INTRODUCTION

\subsection{BACKGROUND}

Development of a corrugated metal fighting hole cover has been under consideration since the U. S. Army Engineer Command in Vietnam asked the U. S. Army Engineer Waterways Experiment Station (WES) to conduct a quick feasibility study in early 1968. The results of that study indicated that such a bunker was feasible, however (a) because of the nature of the abrupt buckling failure which such structures experience, a prototype should be load-tested prior to mass production, (b) substantial tooling costs would be necessary for production and (c) little protection was provided by the shell unless it was covered with earth. The corrugated-bunker idea was abandoned at that time in favor of the 6inch-*thick concrete parapet fighting bunker shown in Figure 1.1. The concrete bunker was selected because it provides protection from mortar fragments immediately upon being installed and it could be fabricated with almost no lead time. WES tested a similar version of this parapettype bunker at Ft. Benning, Ga., in 1968 (Reference 1).

Again, in May 1972, It. Gen. Frank A. Camm sent the Office, Chief of Engineers, a document entitled "Concept for C-shell fighting bunker." In this document the advantages of such a structure were enumerated and an artistic concept was presented (Figure 1.2). WES surveys of the field fortifications used in Vietnam indicated that the reinforced concrete version of this bunker was commonly used and well liked (Reference 2). A corrugated-metal version of this bunker can be handled and installed by ron-engineer troops and can provide an excellent means of decreasing the vulnerability of or upgrading key fighting hole positions.

* A table of factors for converting U. S. customary units of measurement to metric (SI) units is given on page 5 . 
The objective of this investigation was to develop criteria for the design and use of earth-covered metal shells for rapidly emplaceable fighting bunkers, and, further, to demonstrate the logistic and construction effort and the protection provided by a recommended bunker design.

\subsection{SCOPE}

Three corrugated metal fighting hole covers were fabricated and tested at WES. These designs were based on the "C"-shell concept (Figure 1.2) furnished by Lt. Gen. Frank A. Camm, U. S. Army. Each fighting hole cover consisted of four quarter-sections that, when connected, formed a square base with sides made of circular curved arch sections. This concept is designated the Multiple Intersecting CyIindrical Shell (MICS). Each MICS design, along with corrugated metal aperture beams, was tested at the WES Big Black Test Facility (BBTF) against statically detonated 4- and 10-pound spherical TNT charges.

The first MICS design and its aperture beams were fabricated from 12-gage or 0.1046 -inch (uncoated thickness) galvanized steel plates with corrugations of 6-inch pitch and 2-inch depth. The four quarter-sections of MICS were connected with steel plates, straps, and bolts. This bunker was statically tested and the design refined before it was installed at the BBTF for blast testing (Phase I test series).

As a direct result of the Phase I test series, a second MICS design was fabricated from uncoated steel plates. Structurally, these steel plates were identical to those used in the first bunker. The connections for the curved plates were changed. Results of the explosive tests at BBTF (Phase II test series) revealed this bunker design to be the optimum of the two bunkers fabricated.

The third MICS design was fabricated from 16-gage or 0.0598-inch (uncoated thickness) galvanized steel plates with corrugation of 3-inch pitch and 1-inch depth. Aperture beams were identical to that used in the first two bunkers. The quarter-sections of this MICS design were welded together.

The three bunker designs will be discussed in greater detail in the following chapters. 

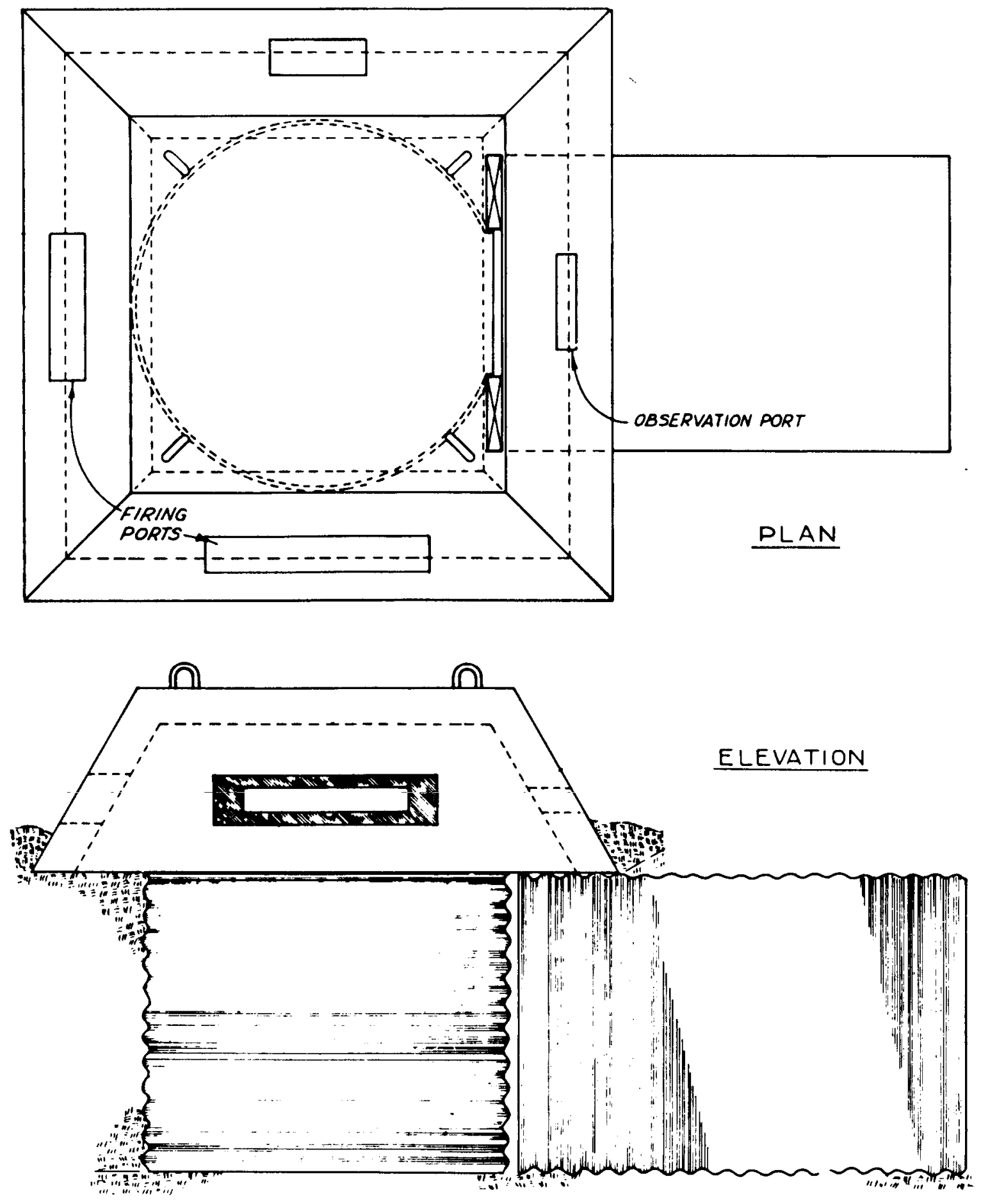

Figure 1.1 Concrete fighting bunker. 


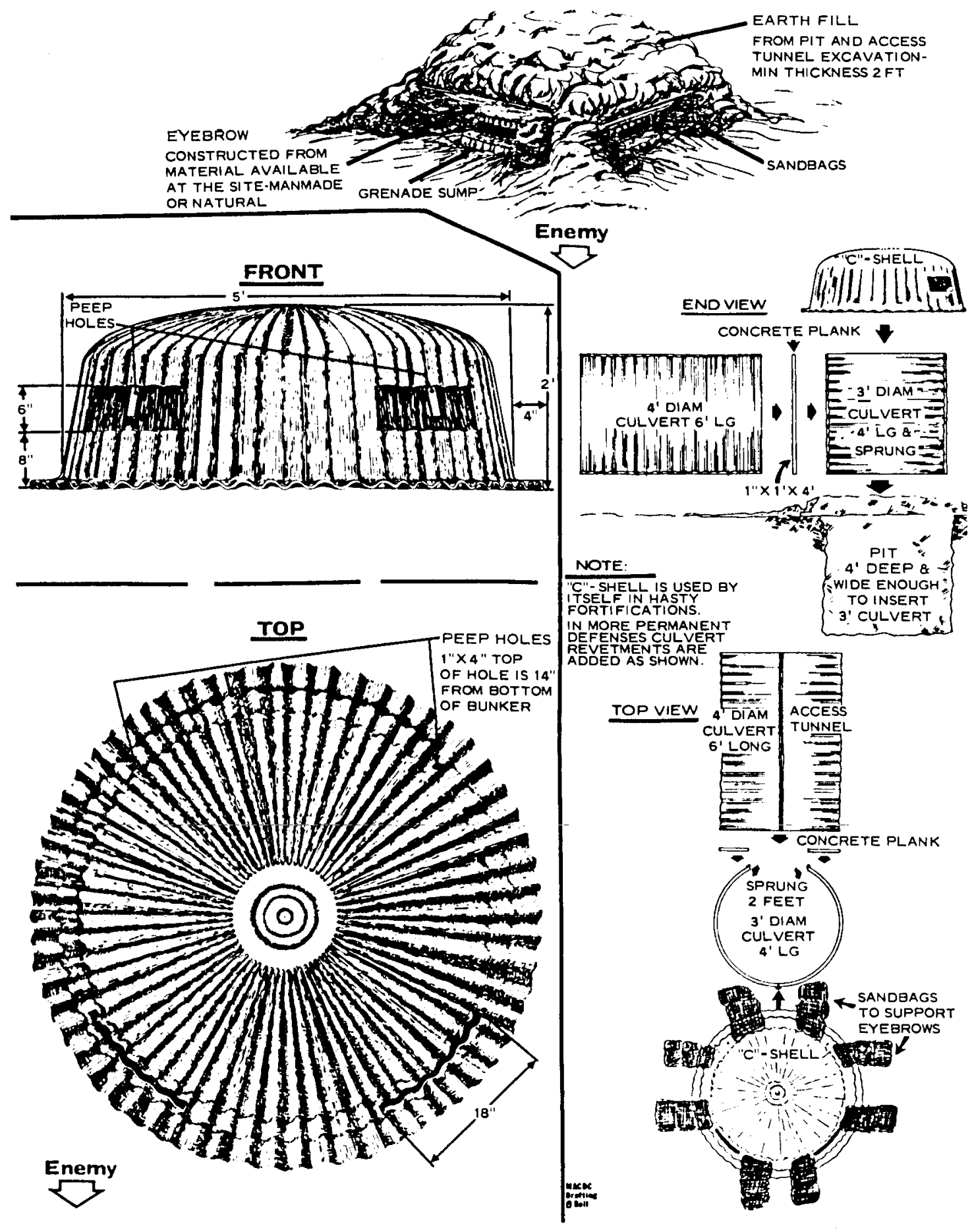

Figure 1.2 "C"-shell fighting bunker. 


\section{CHAPTER 2}

\section{DESIGN DEVELOPMENT}

\subsection{REQUIREMENTS}

During the development of the fighting hole cover, requirements that were considered include:

1. Protection. The cover should provide a high degree of protection against rifle and machine-gun fire, air-burst artillery, and, to some extent, direct hits by $81-\mathrm{mm}$ and 4.2-inch mortars and 105-mm artillery shells. It should also protect its occupants from the weather.

2. Fabrication Feasibility. The cover design should be based on existing fabrication techniques and standard materials. Development of new hardware (dies, molds, etc.) was not considered.

3. Functional Factors. This cover design must provide adequate space for two- and/or three-man fighting teams. Its aperture should accommodate rifle, machine gun, and $M-79^{\prime} s$, and provide fields of fire that are necessary for the success of a tactical operation.

4. Transportability. It is desirable that the cover be air (helicopter) and/or truck transportable and light enough to be handled on the ground by personnel without lifting equipment.

5. Constructability. Since mechanical equipment is often unavailable to forward area combat troops, it is desirable that the cover be installable (excavation, assembly, and soil cover) by hand labor.

6. Cost. Material and fabrication costs should compare with other type covers that provide the same protection without the loss of logistical and construction advantages.

\subsection{MATERIALS AVAILABLE}

Corrugated steel rather than timber, reinforced concrete, noncorrugated steel, etc., was selected for the MICS designs because it results in a stronger, simpler, and lighter structure. Continuous corrugated plate structures withstand the effects of localized blast loads much better than do plate and beam structures.

Three corrugation patterns are commonly used for the construction of drainage pipes and pipe arches: (1) 6-inch pitch and 2-inch depth 
(Figure 2.1), (2) 3-inch pitch and 1-inch depth (Figure 2.2), and (3) 2-2/3-inch pitch and 1/2-inch depth (Figure 2.3). The 6-inch-pitch and 2-inch depth corrugated plates are the standard of the American Association of State Highway Officials (Reference 3). These corrugated steel plates are available in uncoated thicknesses ranging from 1- to l2-gage (0.2758- to 0.1046-inches), respectively. These plates are fabricated in five common widths (Figure 2.4) in nominal lengths of 10 and 12 feet and can be rolled to various radii. The 6-inch-pitch and 2-inch-depth corrugations run at right angles to the length of the plate.

The 3-inch-pitch and 1-inch-depth sheets, along with the 2-2/3-inchpitch and 1/2-inch-depth sheets, are commonly available in uncoated thicknesses ranging from 8- to 16-gage ( 0.1644 to 0.0598 inches), respectively. The 3-inch-pitch and 1-inch-depth sheets, along with the 2-2/3-inch-pitch and 1-inch-depth sheets (unlike the 6-inch-pitch and 2-inch-depth corrugated plates) have corrugations munning in the direction perpendicular to the width of the plate. Also, these sheets are produced only in one common width of $25-1 / 2$ and 25-5/8 inches, respectively.

\subsection{INITIAL CONCEPT}

\subsubsection{Discussion. Efforts were made to dimension the corrugated} shell into as small a target area as possible, yet provide enough room to accommodate two- to three-man fighting teams and their equipment. The fighting hole dimensions selected were identical to those used for the concrete trapezoidal fighting hole cover (Figure 2.5). The size of the fighting hole was a factor in determining the dimensions of the fightirg hole cover. The fighting hole depth of 4 feet provides a convenient firing-shelf height for the U. S. soldier.

\subsubsection{Multiple Intersecting Cylindrical Shell. The MICS (Figure} 2.6) is composed of four quarter-sections that, when connected, form a base that is 7 feet 9 inches square (inside dimensions) with sides formed by curved circular sections of 4 feet radius and a crown height of 3 feet. When the MICS is placed over the excavated fighting hole (5 feet in diameter and 4 feet deep), a vertical clearance of 7 feet at the 
crown and approximately 6 feet at the extreme perimeter of the pit is provided inside for personnel. Also, a firing shelf with a minimum width of 1 foot 4 inches is provided at each firing port.

Four apertures are provided in MICS for firing ports. Aperture dimensions are identical to those of the concrete trapezoidal fighting hole cover shown in Figure 2.5, i.e., 2 feet long and 8 inches high. In the original design, the bottom of each aperture was 8 inches (measured vertically) from the bottom of MICS. The aperture openings in the recommended design extend to the bottom of the MICS and can be adjusted for a given weapon and field of fire by the addition of bagged soil in front of the opening. Besides serving as firing ports, the aperture openings are large enough ( 24 inches wide by 16 inches high) to serve as emergency exits when the bagged soil is removed.

Each quarter-section of MICS was fabricated from a standard corrugated plate (designated N8 in Figure 2.4) that was 10 feet long and had been rolled to a 4-foot radius. Corrugated plates of 6-inch pitch and 2 -inch depth were selected initially since this pattern was the strongest standard material available (Figures 2.1-2.3). These plates were of 12-gage or 0.1046-inch thickness (uncoated). This gage material is the lightest material available for this size corrugation that can be rolled to a 4-foot radius without appreciable error.

An inside and outside sheet metal template was used to mark each side of the shell prior to flame cutting. The outside surface of the curved corrugated plate was marked first (Figure 2.7a). Likewise, the inside template was placed on the inside surface of the corrugated plate, and the intersection of the corrugated crests with the template was marked (Figure 2.7b). Straight lines were then drawn between the marked points, which, in effect, produced a zigzag line that was cut with a cutting torch (Figure 2.7c) to produce the desired quarter-section. Graphical determination of the sheet metal templates used in the final selected designs is discussed in Chapter 5.

Adjacent quarter-sections of MICS were bolted together to permit field erection (Figure 2.8). Two steel plates, 3 by 4 by $1 / 4$ inches 
thick, along with 3/8-inch cap screws were used to connect adjacent sections at each seam (Figure 2.8a). Two steel straps, 16 inches long $I$ inch wide by $1 / 4$ inch thick, along with 3/8-inch cap screws were used to connect the adjacent sections at the crown of MICS (Figure $2.8 \mathrm{~b}$ ).

2.3.3 Aperture Beams. The soil cover for the apertures is supported by trapezoidal corrugated metal beams (Figure 2.9a). These four beams were fabricated from two 10-feet-long standard plates (designated N8 and N3 in Figure 2.4) that were bolted together. A torch was used to cut the trapezoidal pattern of the aperture beam (Figure 2.9b). This pattern consisted of the short and long side of the two parallel sides being 3 and 8 feet long, respectively, with a 2-foot 6-inch width. These dimensions resulted in a 45-deg flare of the nonparallel sides. Five equally spaced holes were burned into the closest corrugated crest of the 3-foot side to allow attachment with $3 / 4$-inch bolts to a 5 - by 5 - by 5/16-inch steel angle that was 3 feet 6 inches long (Figure 2.10a). Each angle was then attached above the aperture of each quarter-section of MICS with 3/4-inch bolts. Figure 2.10b shows the holes in MICS; Figure 2.10c shows the steel angle attached to MICS and the resulting embrasure formed by sandbags supporting the nonparallel sides of the aperture cover. It is important to note that the geometry of the embrasure desired is dependent only on the sandbag arrangement. 


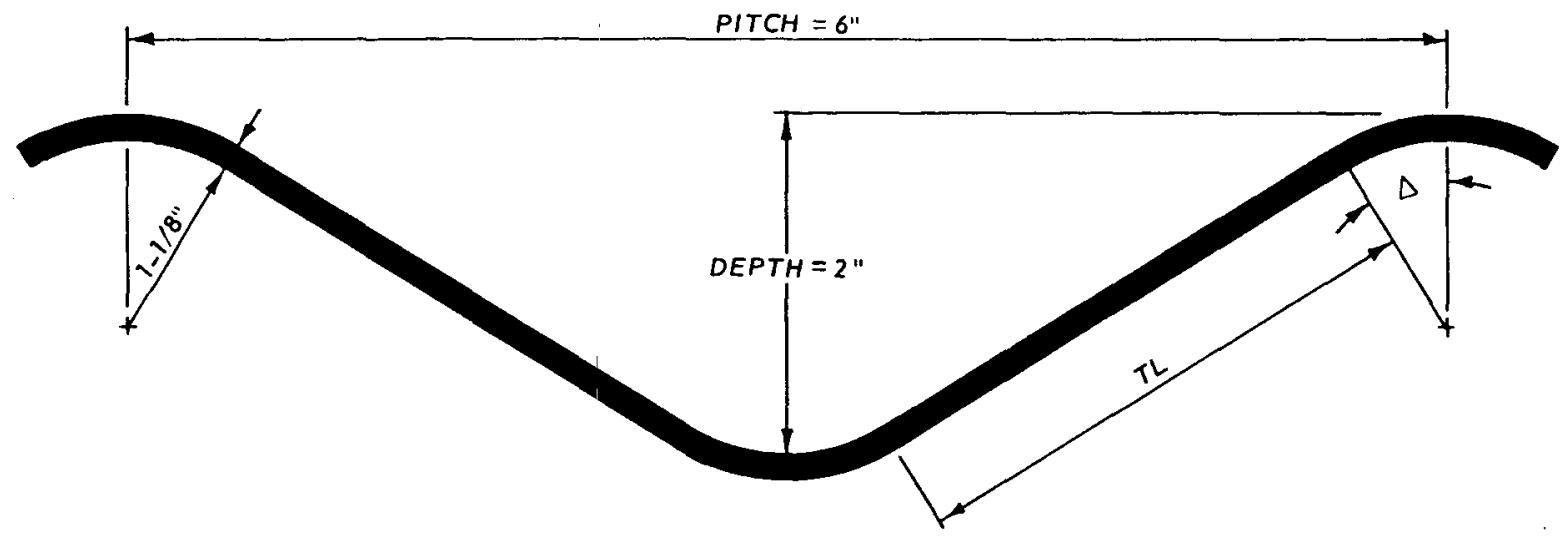

$\stackrel{\leftarrow}{\leftarrow}$

\begin{tabular}{|c|c|c|c|c|c|c|c|c|c|}
\hline GAGE & $\begin{array}{c}\text { SPECIFIED } \\
\text { THICKNESS } \\
\text { IN. }\end{array}$ & $\begin{array}{c}\text { UNCOATED } \\
\text { THICKNESS } \\
T \\
\text { IN. }\end{array}$ & $\begin{array}{c}\text { AREA OF } \\
\text { SECTION } \\
\text { A } \\
\text { SQ IN./FT }\end{array}$ & $\begin{array}{c}\text { TANGENT } \\
\text { LENGTH } \\
\text { TL } \\
\text { IN. }\end{array}$ & $\begin{array}{c}\text { TANGENT } \\
\text { ANGLE } \\
\triangle \\
\text { DEGREES }\end{array}$ & $\begin{array}{c}\text { MOMENT OF } \\
\text { INTERIA(a) } \\
\text { IN. }{ }^{4} / F T\end{array}$ & $\begin{array}{c}\text { SECTION } \\
\text { MODULUS(a) } \\
S \\
\text { IN. }{ }^{3} / \mathrm{FT}\end{array}$ & $\begin{array}{c}\text { RADIUS OF } \\
\text { GYRATION } \\
r \\
\text { IN. }\end{array}$ & $\begin{array}{l}\text { DEVELOPED } \\
\text { WIDTH } \\
\text { FACTOR } \\
\text { (b) }\end{array}$ \\
\hline 12 & 0.109 & 0.1046 & 1.556 & 1893 & 44.47 & 0.725 & 0.689 & 0.682 & 1.240 \\
\hline 10 & 0.138 & 0.1345 & 2.003 & 1.861 & 44.73 & 0.938 & 0.879 & 0.684 & 1.241 \\
\hline 8 & 0.168 & 0.1644 & 2.449 & 1.828 & 45.00 & 1.154 & 1.066 & 0.686 & 1.242 \\
\hline 7 & 0.188 & 0.1838 & 2.739 & 1.807 & 45.18 & 1.296 & 1.187 & 0.688 & 1.242 \\
\hline 5 & 0.218 & 0.2145 & 3.199 & 1.773 & 45.47 & 1.523 & 1.376 & 0.690 & 1.243 \\
\hline 3 & 0.249 & 0.2451 & 3.658 & 1.738 & 45.77 & 1.754 & 1.562 & 0.692 & 1.244 \\
\hline 1 & 0.280 & 0.2758 & 4.119 & 1.702 & 46.09 & 1.990 & 1.749 & 0.695 & 1.245 \\
\hline
\end{tabular}

a. PER FOOT OF PROJECTION ABOUT THE NEUTRAL AXIS. TO OBTAIN A, I, OR S PER INCH OF WIDTH, DIVIDE THE ABOVE VALUES BY 12.

b. DEVELOPED WIDTH FACTOR MEASURES THE INCREASE IN PROFILE LENGTH DUE TO CORRUGATING.

Figure 2.1 Sectional properties of 6 - by 2-inch corrugated steel plates . 


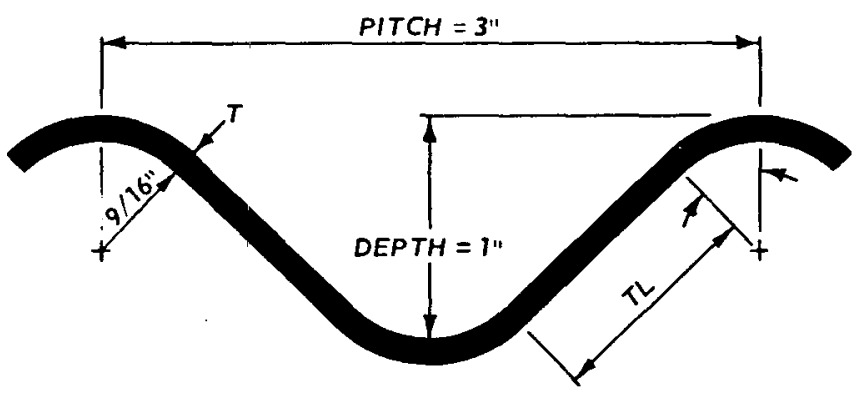

v

\begin{tabular}{|c|c|c|c|c|c|c|c|c|c|}
\hline GAGE & $\begin{array}{c}\text { SPECIFIED } \\
\text { THICKNESS } \\
\text { IN. }\end{array}$ & $\begin{array}{c}\text { UNCOATED } \\
\text { THICKNESS } \\
T \\
\text { IN. }\end{array}$ & $\begin{array}{c}\text { AREA OF } \\
\text { SECTION } \\
\text { A } \\
\text { SO IN./FT }\end{array}$ & $\begin{array}{l}\text { TANGENT } \\
\text { LENGTH } \\
\text { TL } \\
\text { IN. }\end{array}$ & $\begin{array}{c}\text { TANGENT } \\
\text { ANGLEE } \\
\Delta \\
\text { DEGREES }\end{array}$ & $\begin{array}{c}\text { MOMENT OF } \\
\text { INTERIA(a) } \\
1 \\
\text { IN. }{ }^{4} / F T\end{array}$ & $\begin{array}{c}\text { SECTION } \\
\text { MODULUS(a) } \\
\text { S } \\
\text { IN. }{ }^{3} / F T\end{array}$ & $\begin{array}{c}\text { RADIUS OF } \\
\text { GYRATION } \\
\text { I } \\
\text { IN. }\end{array}$ & $\begin{array}{c}\text { DEVELOPED } \\
\text { WIDTH } \\
\text { FACTOR } \\
\text { (b) }\end{array}$ \\
\hline $\begin{array}{l}16 \\
14\end{array}$ & $\begin{array}{l}0.064 \\
0.079\end{array}$ & $\begin{array}{l}0.0598 \\
0.0747\end{array}$ & $\begin{array}{l}0.890 \\
1.113\end{array}$ & $\begin{array}{l}0.938 \\
0.922\end{array}$ & $\begin{array}{l}44.60 \\
44.87\end{array}$ & $\begin{array}{l}0.1039 \\
0.1306\end{array}$ & $\begin{array}{l}0.1961 \\
0.2431\end{array}$ & $\begin{array}{l}0.3417 \\
0.3427\end{array}$ & $\begin{array}{l}1.240 \\
1.241\end{array}$ \\
\hline 12 & 0.109 & 0.1046 & 1.560 & 0.889 & 45.42 & 0.1855 & 0.3358 & 0.3448 & 1.243 \\
\hline 10 & 0.138 & 0.1345 & 2.008 & 0.855 & 46.02 & 0.2421 & 0.4269 & 0.3472 & 1.244 \\
\hline 8 & 0.168 & 0.1644 & 2.458 & 0.819 & 46.65 & 0.3010 & 0.5170 & 0.3499 & 1.246 \\
\hline
\end{tabular}

a. PER FOOT OF PROJECTION ABOUT THE NEUTRAL AXIS. TO OBTAIN A, OR S PER INCH OF WIDTH, DIVIDE THE ABOVE VALUES BY 12.

b. DEVELOPED WIDTH FACTOR MEASURES THE INCREASE IN PROFILE LENGTH DUE TO CORRUGATING.

Figure 2.2 Sectional properties of 3- by l-inch corrugated steel sheets . 


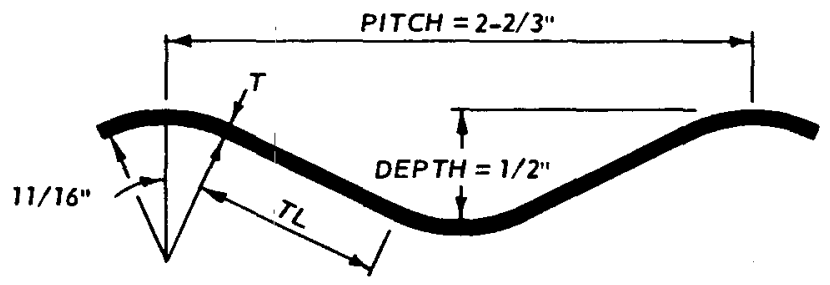

\begin{tabular}{|c|c|c|c|c|c|c|c|c|c|}
\hline GAGE & $\begin{array}{c}\text { SPECIFIED } \\
\text { THICKNESS } \\
\text { IN. }\end{array}$ & $\begin{array}{c}\text { UNCOATED } \\
\text { THICKNESS } \\
T \\
\text { IN. }\end{array}$ & $\begin{array}{c}\text { AREA OF } \\
\text { SECTION } \\
\text { A } \\
\text { SQ IN./FT }\end{array}$ & $\begin{array}{c}\text { TANGENT } \\
\text { LENGTH } \\
\text { TL } \\
\text { IN. }\end{array}$ & $\begin{array}{c}\text { TANGENT } \\
\text { ANGLE } \\
\triangle \\
\text { DEGREES }\end{array}$ & $\begin{array}{c}\text { MOMENT OF } \\
\text { INTERIA(a) } \\
\vdots \\
\text { IN. } 4 \text { FT }\end{array}$ & $\begin{array}{c}\text { SECTION } \\
\text { MODULUS(a) } \\
\text { S } \\
\text { IN. }{ }^{3} / F T\end{array}$ & $\begin{array}{c}\text { RADIUS OF } \\
\text { GYRATION } \\
r \\
\text { IN. }\end{array}$ & $\begin{array}{l}\text { DEVELOPED } \\
\text { WIDTH } \\
\text { FACTOR } \\
\text { (b) }\end{array}$ \\
\hline $\begin{array}{l}16 \\
14\end{array}$ & $\begin{array}{l}0.064 \\
0.079\end{array}$ & $\begin{array}{l}0.0598 \\
0.0747\end{array}$ & $\begin{array}{l}0.775 \\
0.968\end{array}$ & $\begin{array}{l}0.770 \\
0.760\end{array}$ & $\begin{array}{l}25.74 \\
26.86\end{array}$ & $\begin{array}{l}0.0227 \\
0.0287\end{array}$ & $\begin{array}{l}0.0812 \\
0.09988\end{array}$ & $\begin{array}{l}0.1712 \\
0.1721\end{array}$ & $\begin{array}{l}1.080 \\
1.080\end{array}$ \\
\hline 12 & 0.109 & 0.1046 & 1.356 & 0.740 & 27.11 & 0.0411 & 0.1360 & 0.1741 & 1.080 \\
\hline 10 & 0.138 & 0.1345 & 1.744 & b.720 & 27.37 & 0.0544 & 0.1714 & 0.1766 & 1.081 \\
\hline 8 & 0.168 & 0.1644 & 2.133 & b.699 & 27.65 & 0.0687 & 0.2069 & 0.1795 & 1.081 \\
\hline
\end{tabular}

a. PER FOOT OF PROJECTION ABOUT THE NEUTRAL AXIS. TO OBTAIN A, I, OR S PER INCH OF WIDTH, DIVIDE THE ABOVE VALUES'BY 12.

b. DEVELOPED WIDTH FACTOR MEASURES THE INCREASE IN PROFILE LENGTH DUE TO CORRUGATING.

Figure 2.3 Sectional properties of $2-2 / 3$ by $1 / 2$-inch corrugated steel sheets. 

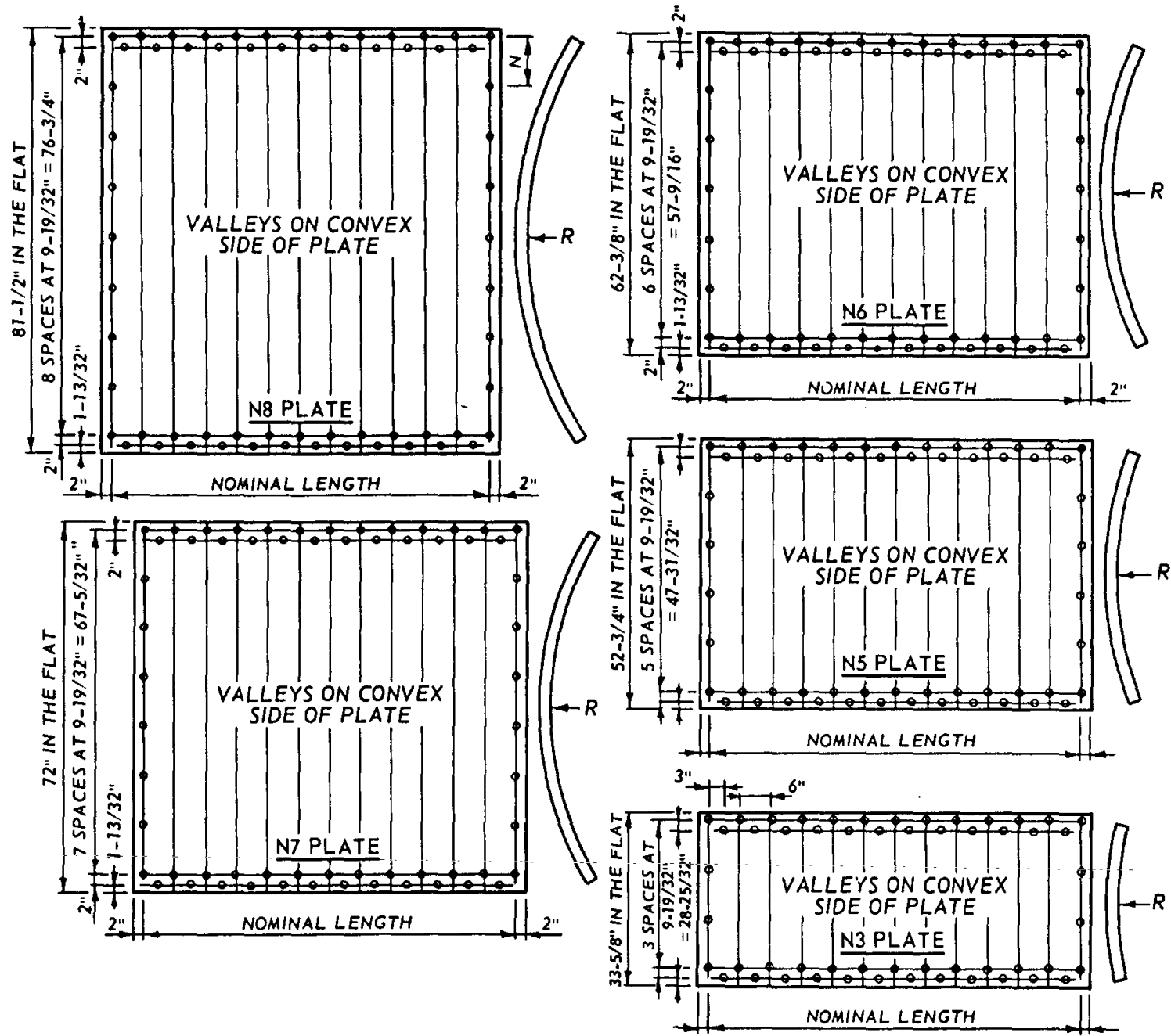

GENERAL NOTES:

1. N-NUMBER REPRESENTS THE NUMBER OF 9-19/32-IN. SPACES BETWEEN CIRCUMFERENTIAL BOLT HOLES IN EACH END.

2. PLATES ARE SHOWN PUNCHED FOR 4 BOLTS PER FT OF LONGITUDINAL SEAM. THEY MAY BE PUNCHED FOR 6 OR 8 BOLTS PER FT IF REQUIRED.

3. STANDARD BOLTS USED ARE $3 / 4$ IN. IN DIAMETER.

4. NOMINAL LENGTHS ARE 10 AND 12 FT.

Figure 2.4 Common sizes of 6 - by 2 -inch corrugated plates. 


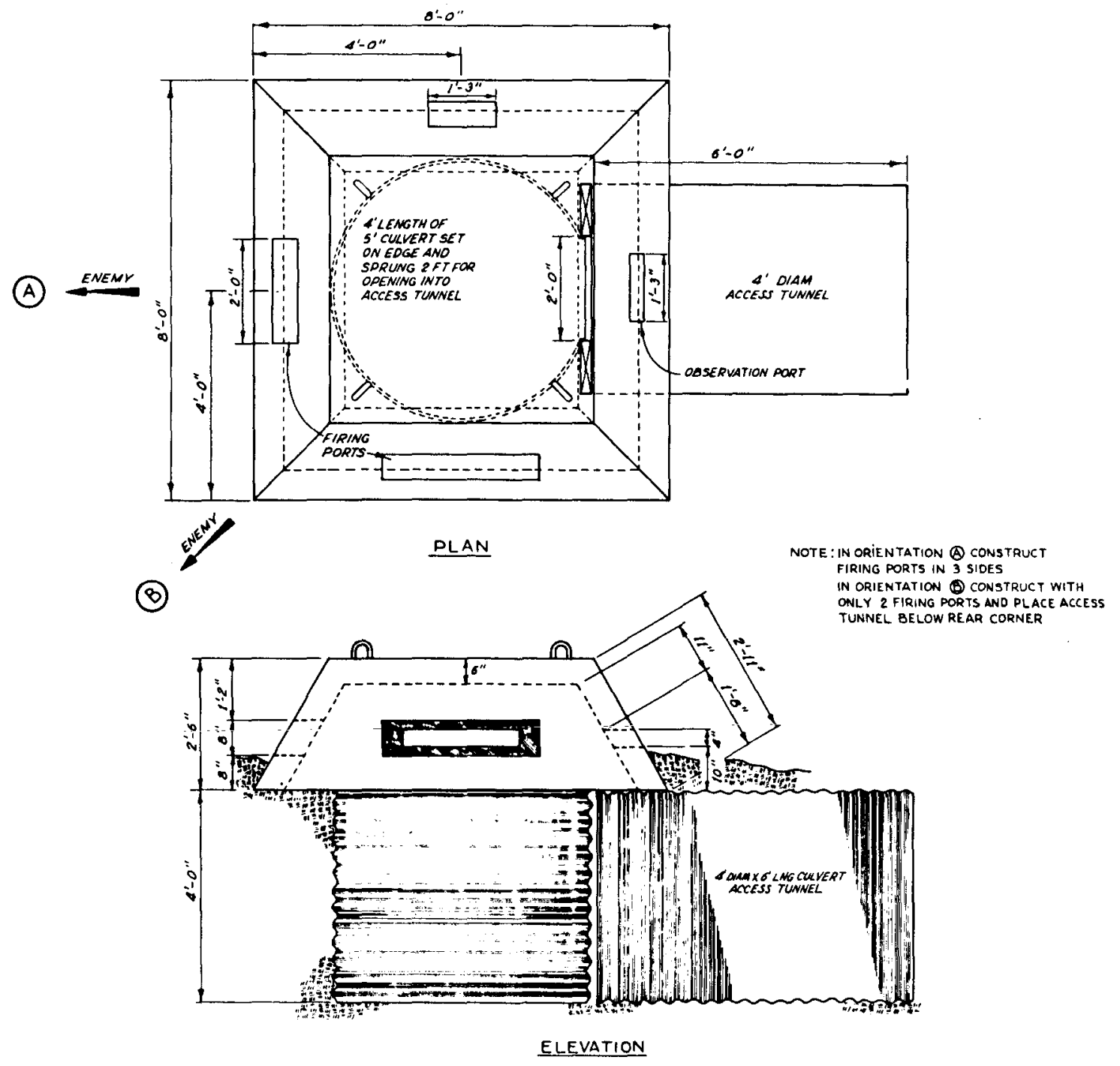

Figure 2.5 Concrete fighting bunker. 

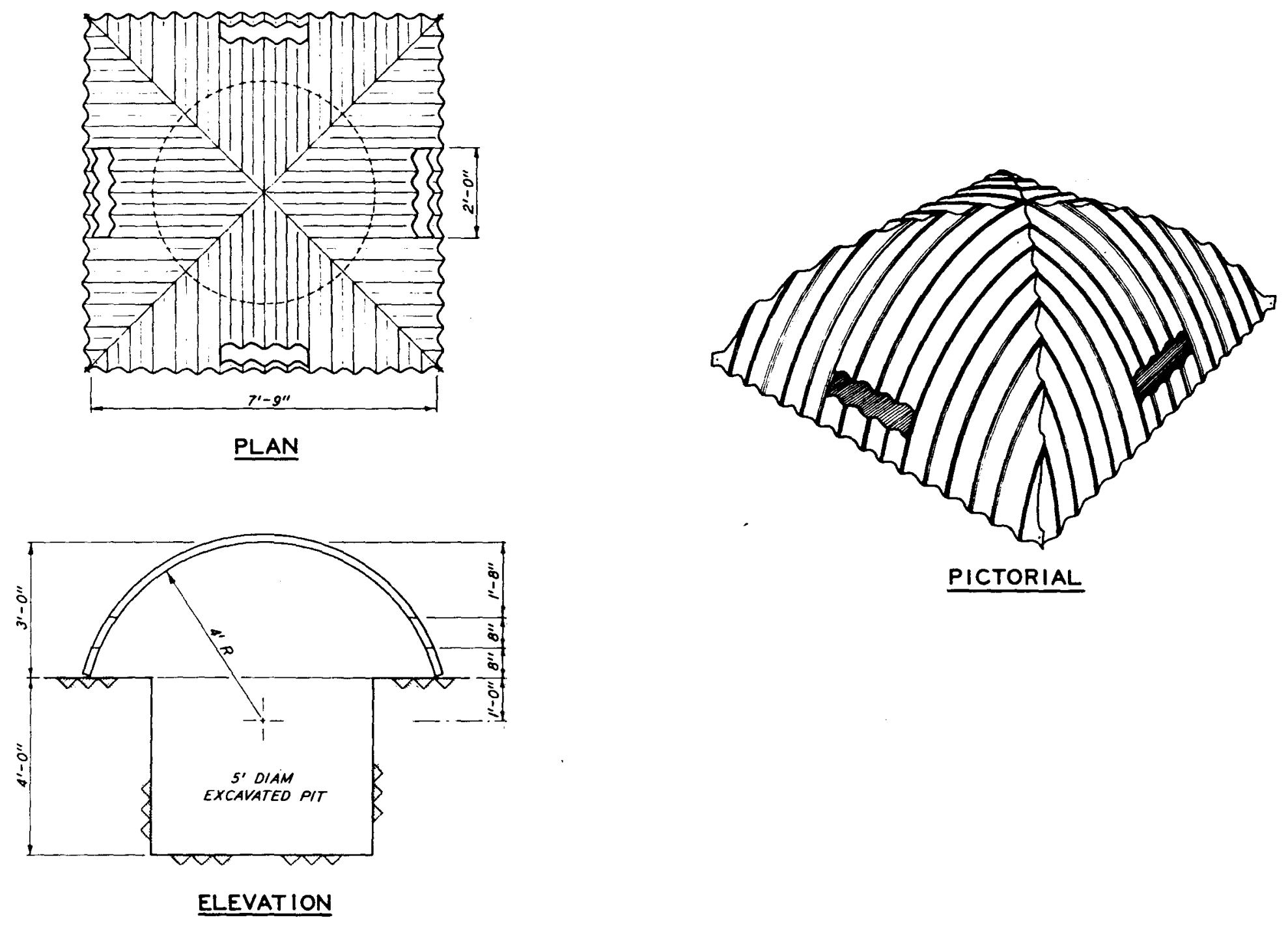

Figure 2.6 Multiple Intersecting Cylindrical Shell (MICS). 


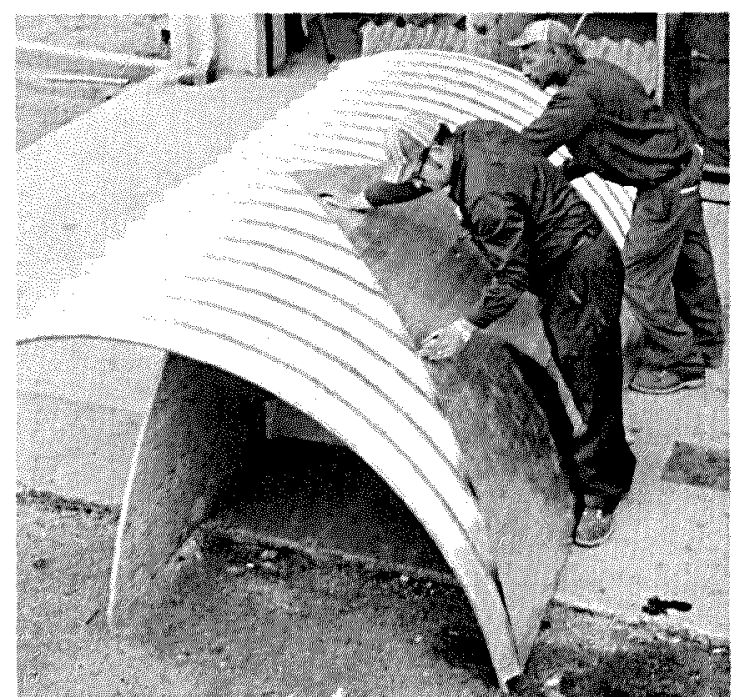

a. Marking the intersection of the outside template with the corrugated crests

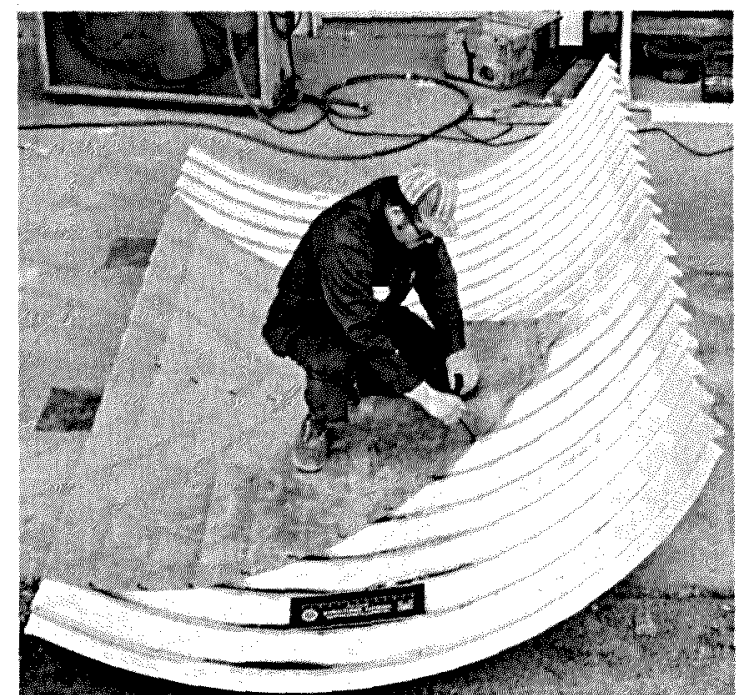

b. Marking the intersection of the inside template with the corrugated crests

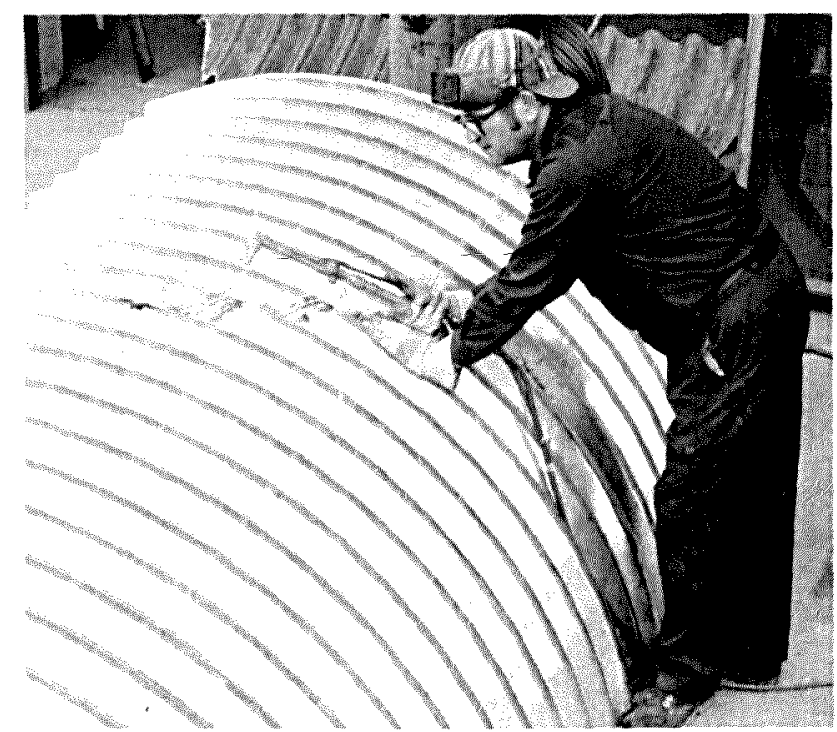

c. Cutting out the quarter-section

Figure 2.7 Layout and cutting scheme of MICS quarter-sections. 


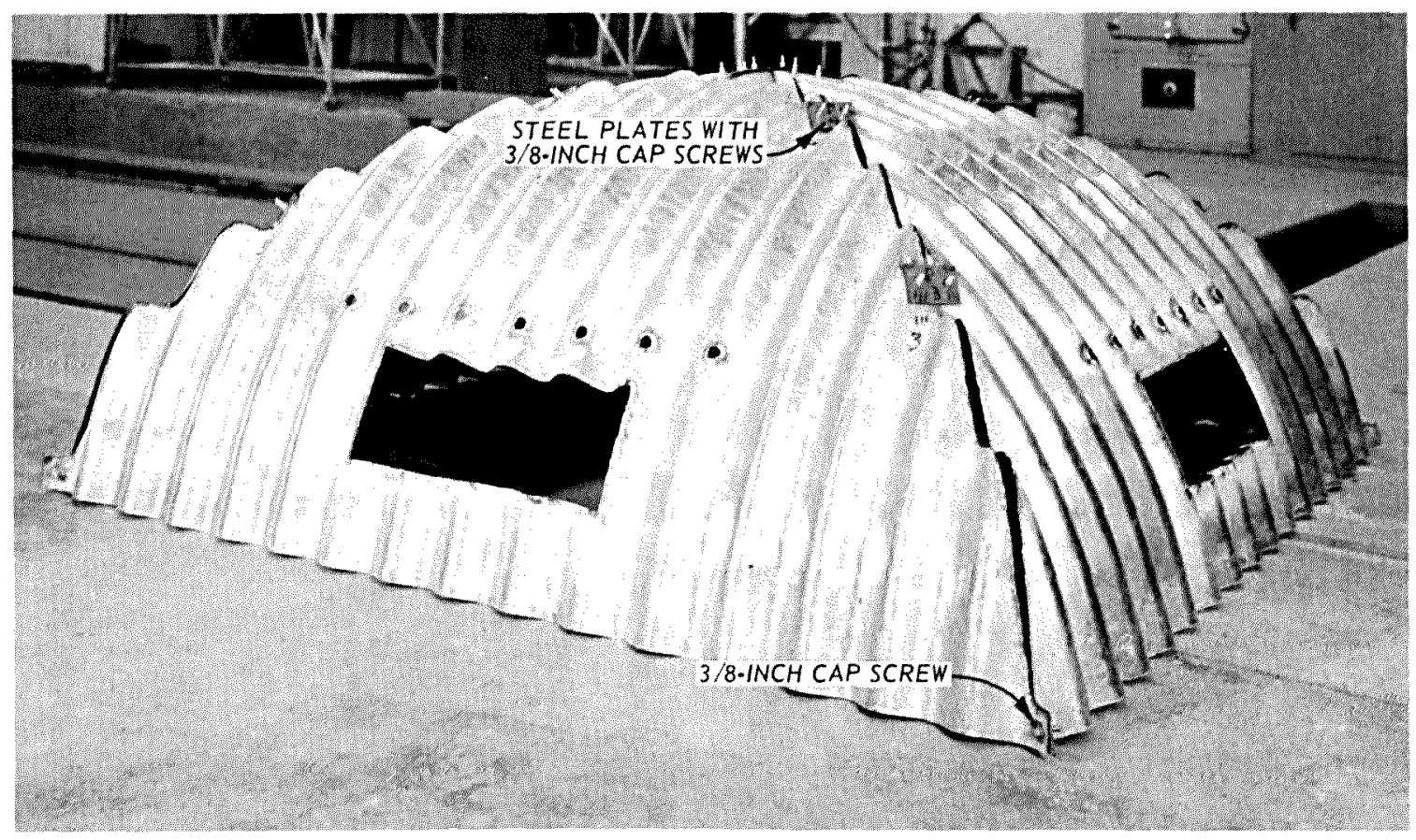

a. Typical connection at seam of two adjacent quarter-sections

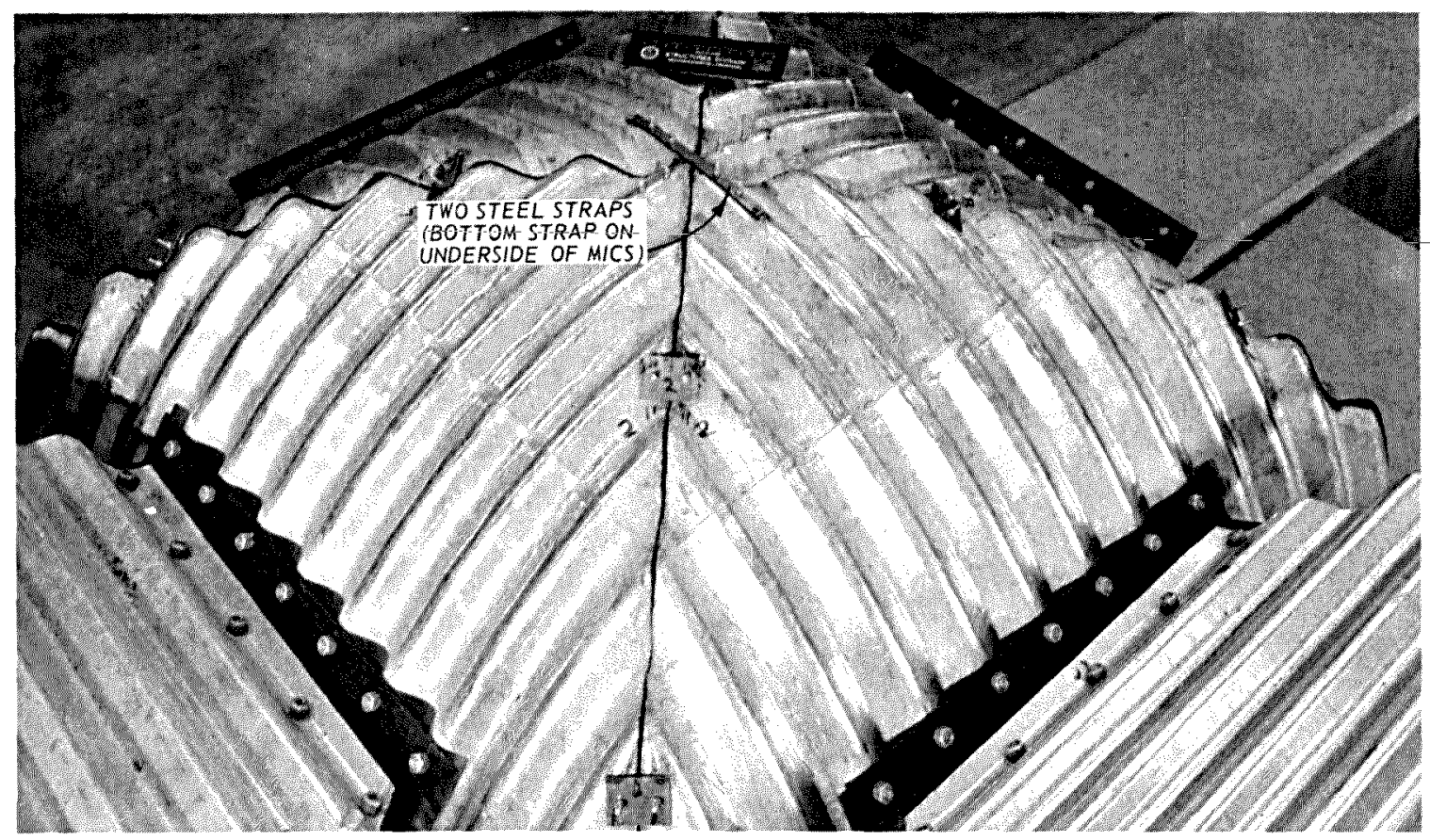

b. Steel straps at crown of MICS

Figure 2.8 Connection scheme of MICS quarter-sections. 


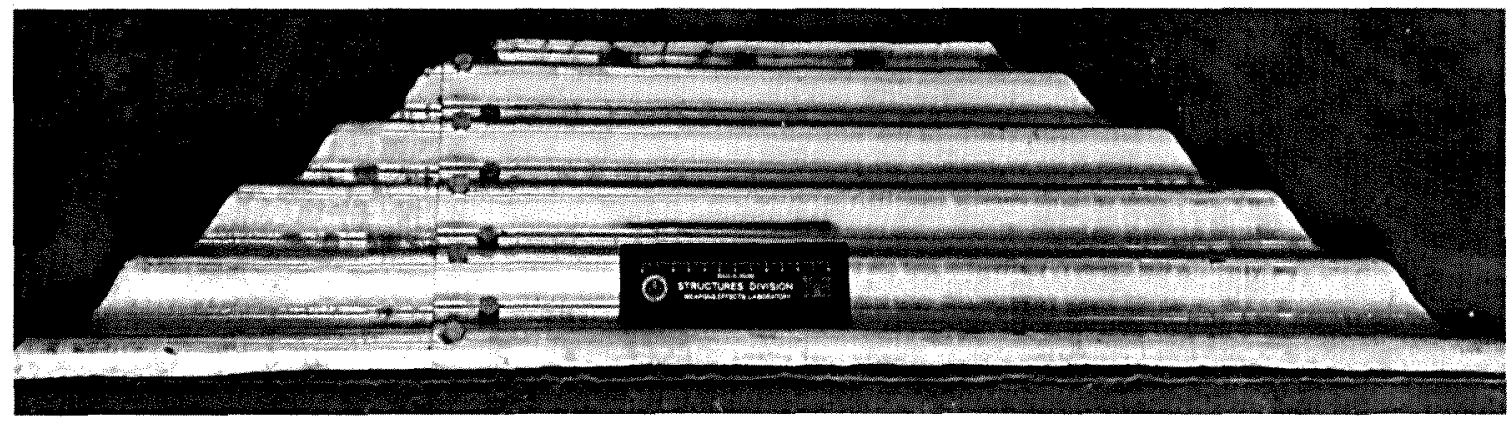

a. Aperture beam

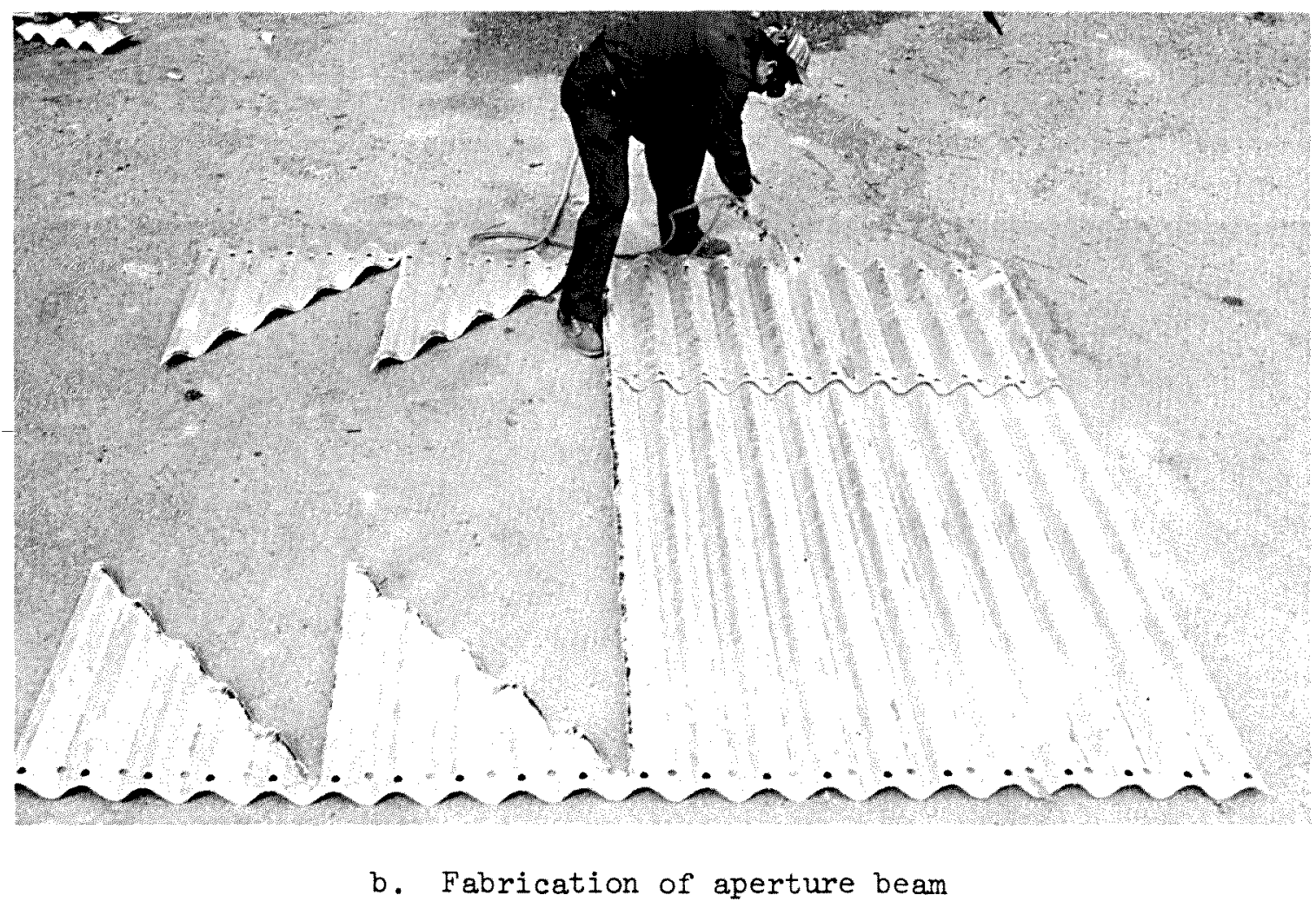

Figure 2.9 Aperture beam and fabrication. 


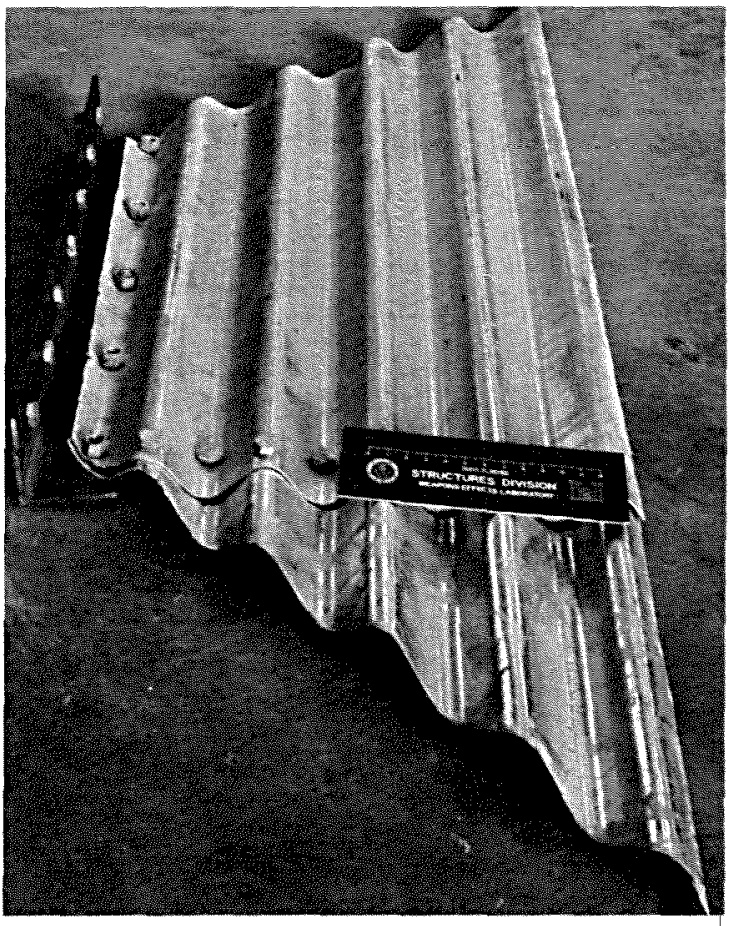

a. Aperture beam bolted to steel angle

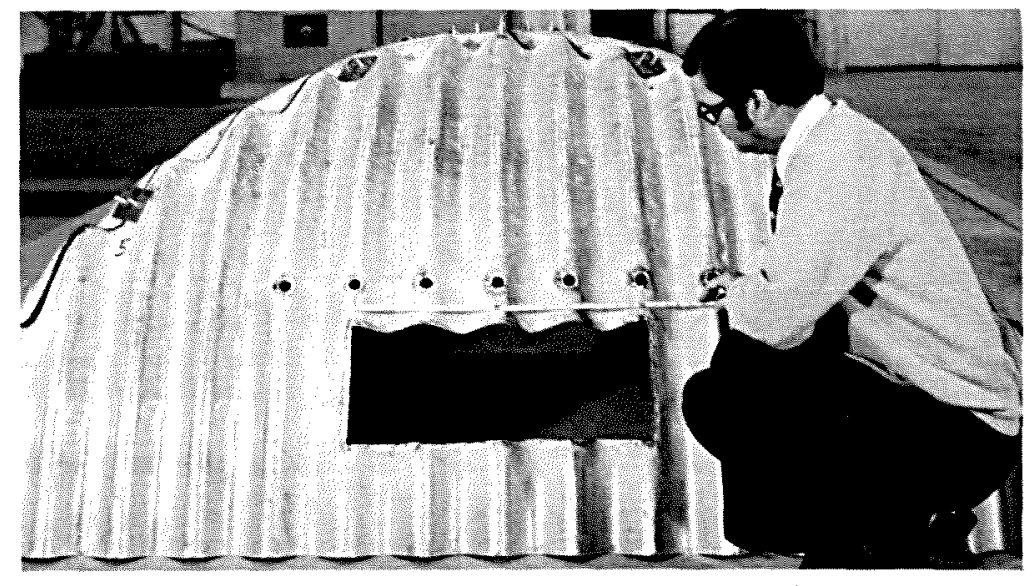

b. Holes above aperture

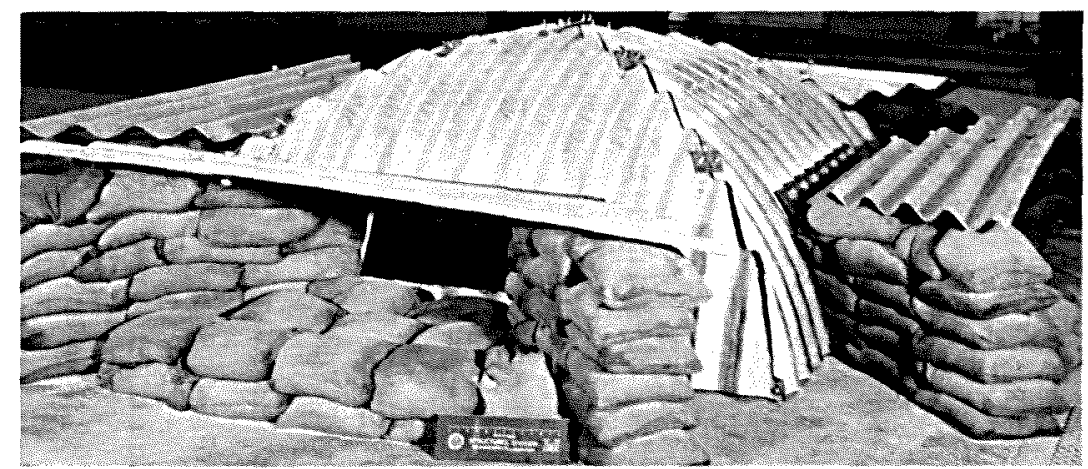

c. Aperture beam attached to MICS and resulting embrasure 
CHAPTER 3

LABORATORY TEST

\subsection{OBJECTIVE}

The objective of the laboratory test was to verify the static soil load capacity of the corrugated steel bunker shell and to determine needed design improvements prior to the field tests.

\subsection{TEST PROCEDURES}

The initial MICS design as described in Chapter 2 was assembled on a rigid concrete-and-steel bridge base (Figure 3.1). The aperture beams were bolted to the shell and supported by sandbags (Figure 3.1a). The entrance to the interior of the shell was between the steel bridges and under one of the apertures, as in the field with the initial design concept (Figure 3.1b).

Displacements were read and recorded using dial gages following the placement of each layer of sandbags. The sandbags were filled with dry sand and weighed an average of 45 pounds each. Nine layers of sandbags were placed on the structure. The loading configuration for each layer of sandbags is shown in Figure 3.2. Placement of the sandbags for each layer was begun at the bottom of MICS and continued to its crown. Displacement measurement locations are shown in Figure 3.3. These measurements included (a) the vertical displacement of the crown of MICS, (b) lateral displacement of one quarter-section of MICS, (c) vertical displacement of an aperture beam along its center line and (d) vertical displacement of the same aperture beam near its sandbag support. Vertical displacements of the aperture beam were not recorded until after the first layer of sandbags had been placed. This was due to the fact that the weight of one layer of sandbags was necessary for the aperture beams to come in contact with the supporting sandbags.

\subsection{TEST RESULTS}

Very little displacement was noted during the static test. Figure 3.4 shows the measured displacement of MICS and Figure 3.5 shows the 
measured displacement of the aperture beams. The maximum crown displacement of MICS and the maximum inward lateral displacement of the quartersection of MICS were 0.075 and 0.012 inches, respectively. The direction of the measured lateral displacement of the quarter-section was toward the center of MICS, and its load-displacement curve was linear up to five layers of sandbags. The inward displacement of the quarter-section was believed to have been a direct result of the sandbag loading procedure, i.e. from the bottom of MICS to its crown. The sandbags covering the side of the quarter-section were causing an inward displacement that was linear until after five layers of sandbags were placed; at that point, the vertical load over the crown tended to push out the side of the quarter-section, thus retarding the inward displacement. This decrease in the rate of displacement was evident up to seven layers of sandbags, at which point no further increase in displacement was noted.

The displacement of the aperture beam was uniform up to five layers of sandbags, i.e., the displacement at its center was almost identical to the displacement at the edge supported by sandbags. Therefore, it was concluded that the displacement was due to the compression of its sandbag support. For each layer of sandbags placed after five layers, an insignificant difference of the two displacements was noticed. This difference was a maximum of 0.02 inches and occurred after nine layers of sandbags had been placed on the structure. The displacements-at the center of the aperture beam and at the edge of the sandbag support after nine layers of sandbags had been placed were 0.53 and 0.51 inches, respectively. Therefore, it was concluded that the displacement of the aperture beam due to the compression of its sandbag support was 0.51 inches and only 0.02 inches of center-line deflection was due to bending. During the static tests, the sandbags supporting the aperture beam were placed with their long dimensions parallel to the non-parallel ends of the beam (Figure 3.1a). The long dimensions of the supporting bags were placed perpendicular to the non-parallel ends of the beam for subsequent tests. This method is preferred since it produces a stronger, more durable bunker. 


\subsection{DESIGN IMPROVEMENTS}

As a direct result of the static test, the original design was improved. These improvements included (a) the elimination of the steel angle that was used to connect the aperture beam to MICS, (b) the removal of the shell material below the aperture, and (c) the orientation of the sandbags used to support the aperture beams. The elimination of the steel angles for aperture beam connections was accomplished by bolting the aperture beam directly to MICS. This procedure resulted in a revision of the dimensions and the location of the bolt holes in the original aperture beam. The revised aperture beam is shown in Figure 3.6. The 3-foot 6-inch dimension was necessary so that the same number of bolts could be used to connect the aperture cover to MICS as was used in connecting the steel angle to MICS. The 8-foot 5-inch dimension is the total width of the two standard plates (designated N8 and N3 in Figure $2.4)$ when bolted together. These dimensions, together with a 2-foot6-inch-width, result in approximately a 45-deg flare of the nonparallel sides. The bolt holes of the revised aperture beams were located in the tangent section of the corrugated material nearest the 3-foot-6-inchside to allow attachment directly to MICS. The vertical increase of the aperture dimension was provided by removing the corrugated steel directly below the original MICS aperture. The revised MICS apertures provide an aditional vertical clearance of 8 inches for a total of 16 inches. This revision provided a more versatile aperture opening in each quarter-section. The increased aperture provides a crawl-in entrance when needed. Also, sandbags may be used to adjust the dimensions of the aperture opening as desired by troops in the field. The sandbags used to support the aperture beam should be placed with their long dimension perpendicular to the non-parallel ends of the aperture beam. 


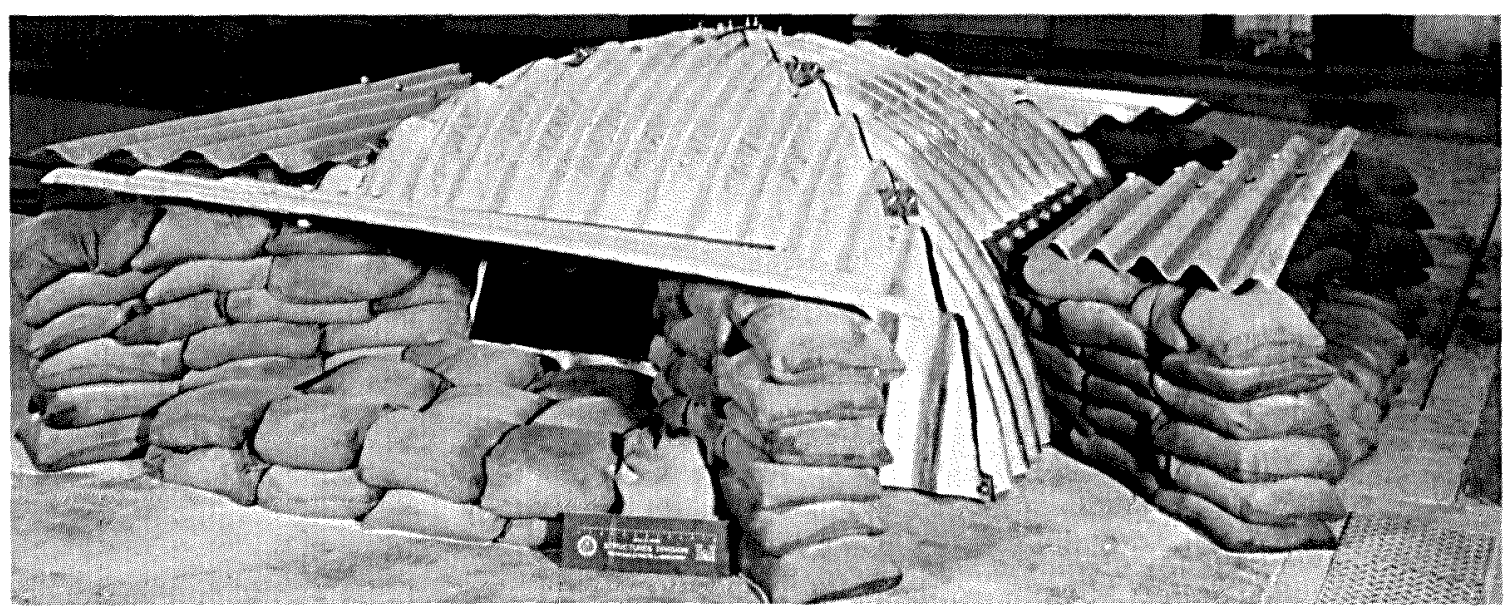

a. Test structure with six layers of sandbags supporting the aperture beams

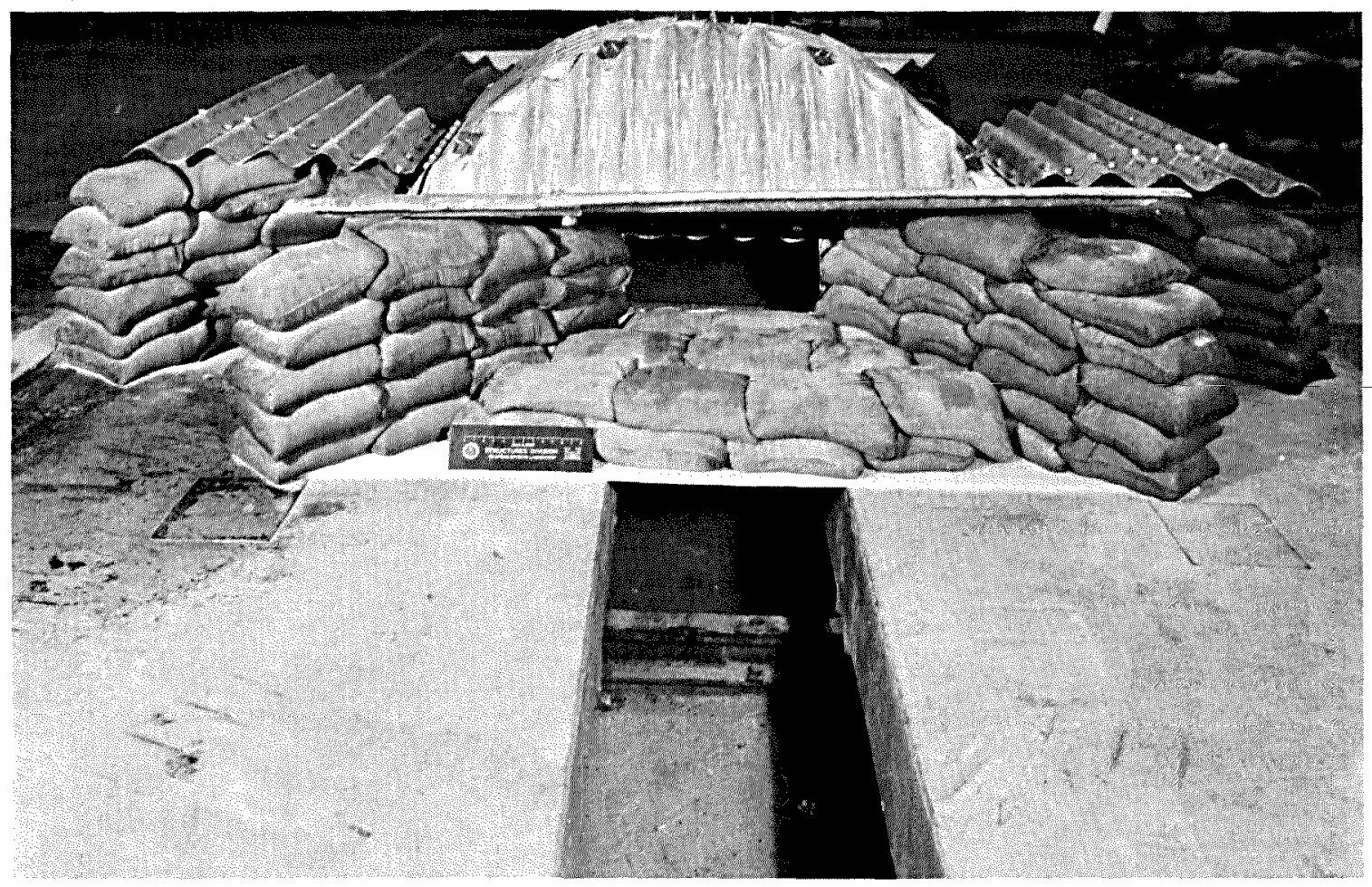

b. Test structure showing the 2-ft-wide entrance

Figure 3.1 Static test configuration. 


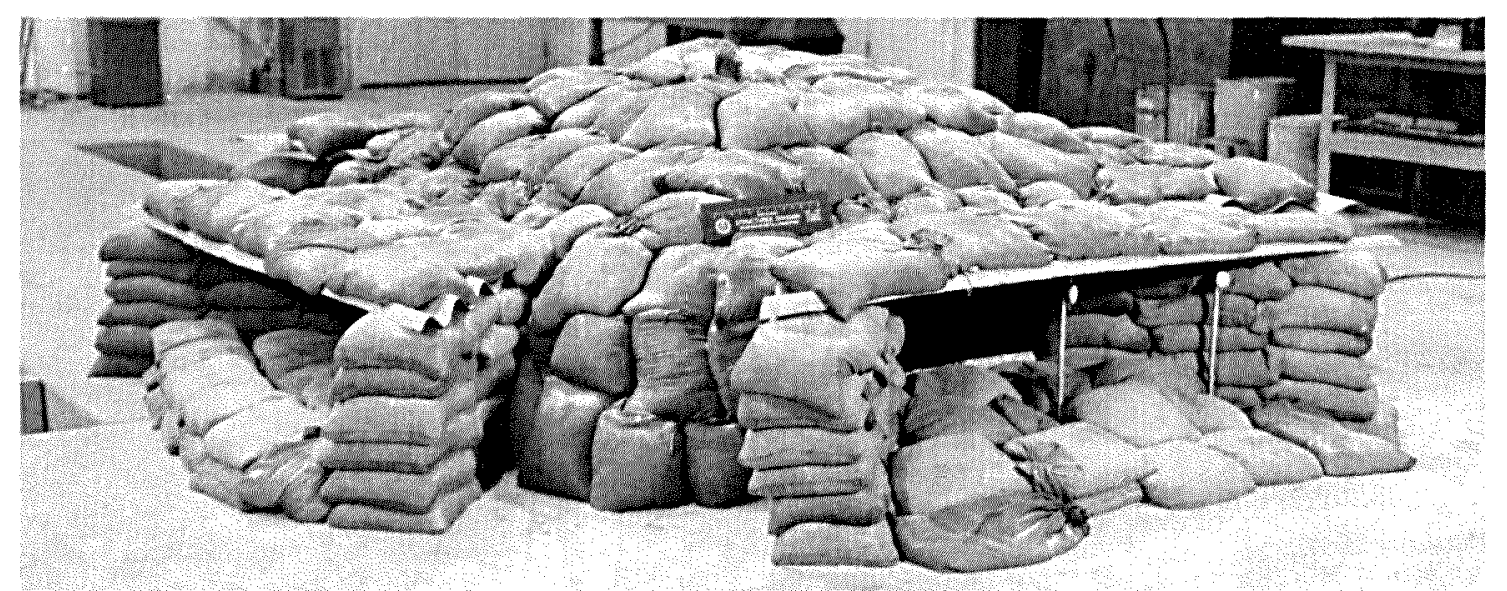

a. One layer of sandbags

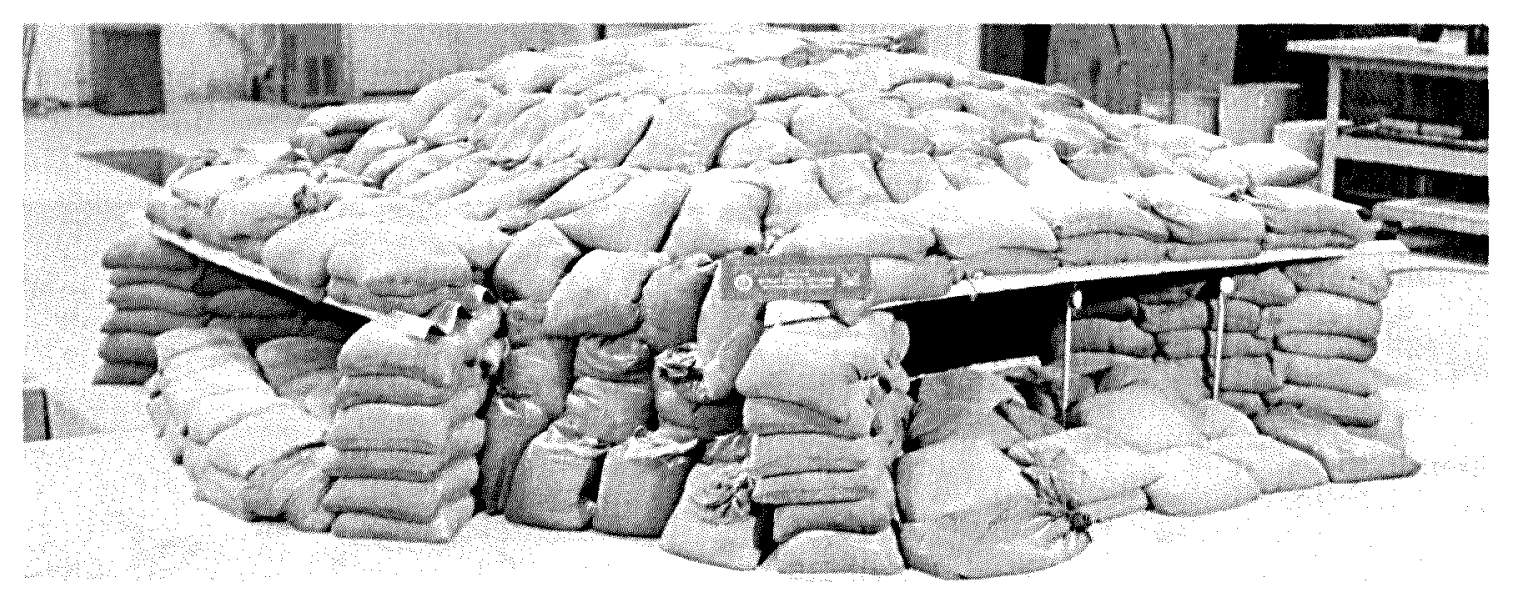

b. Two layers of sandbags

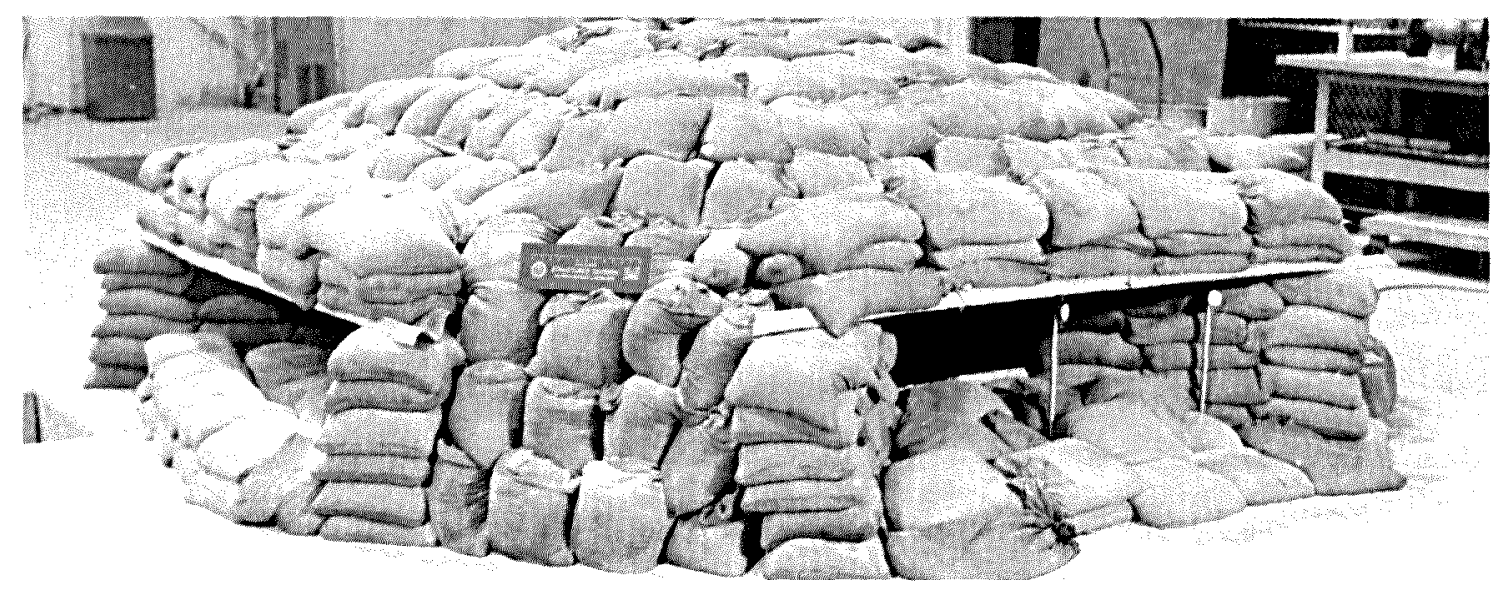

c. Three layers of sandbags

Figure 3.2 Sandbag loading configuration (sheet 1 of 3 ). 


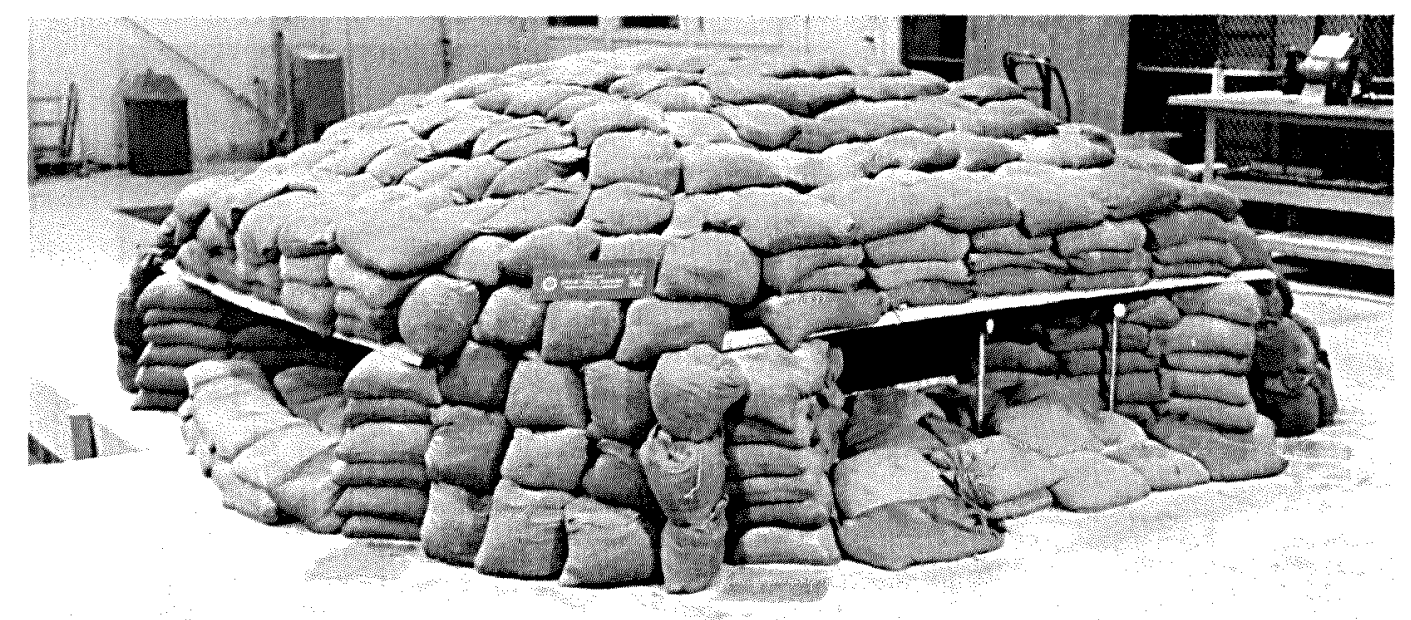

d. Four layers of sandbags

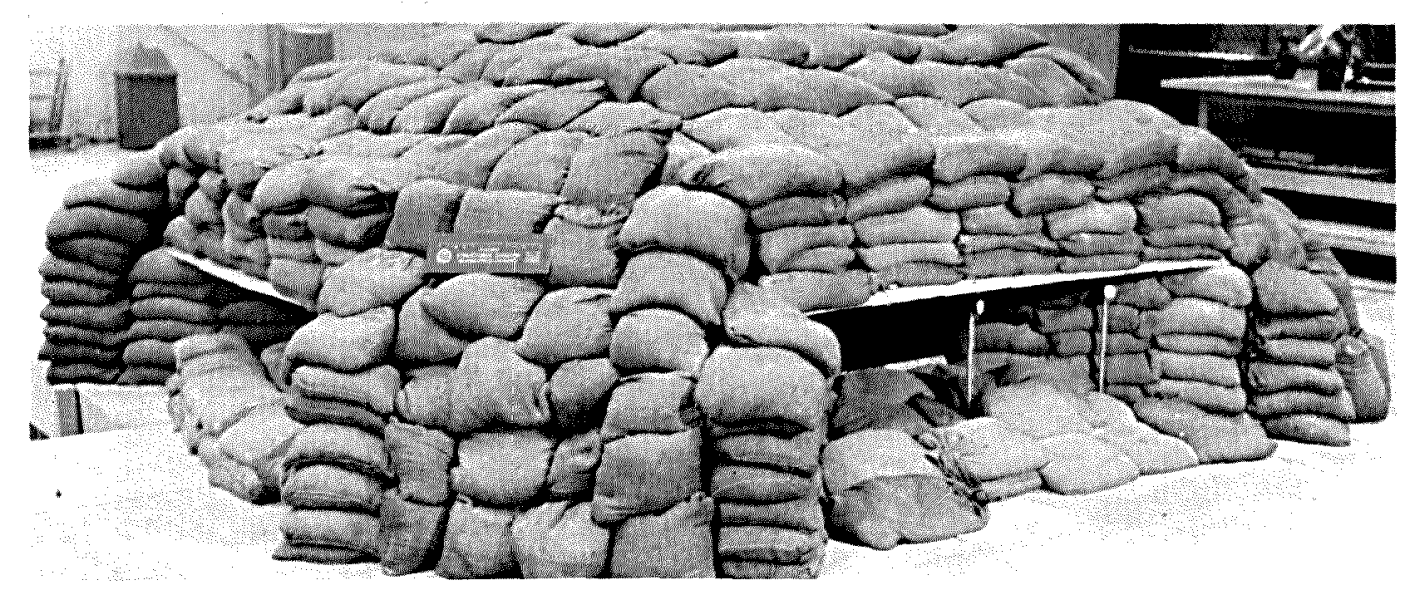

e. Five layers of sandbags

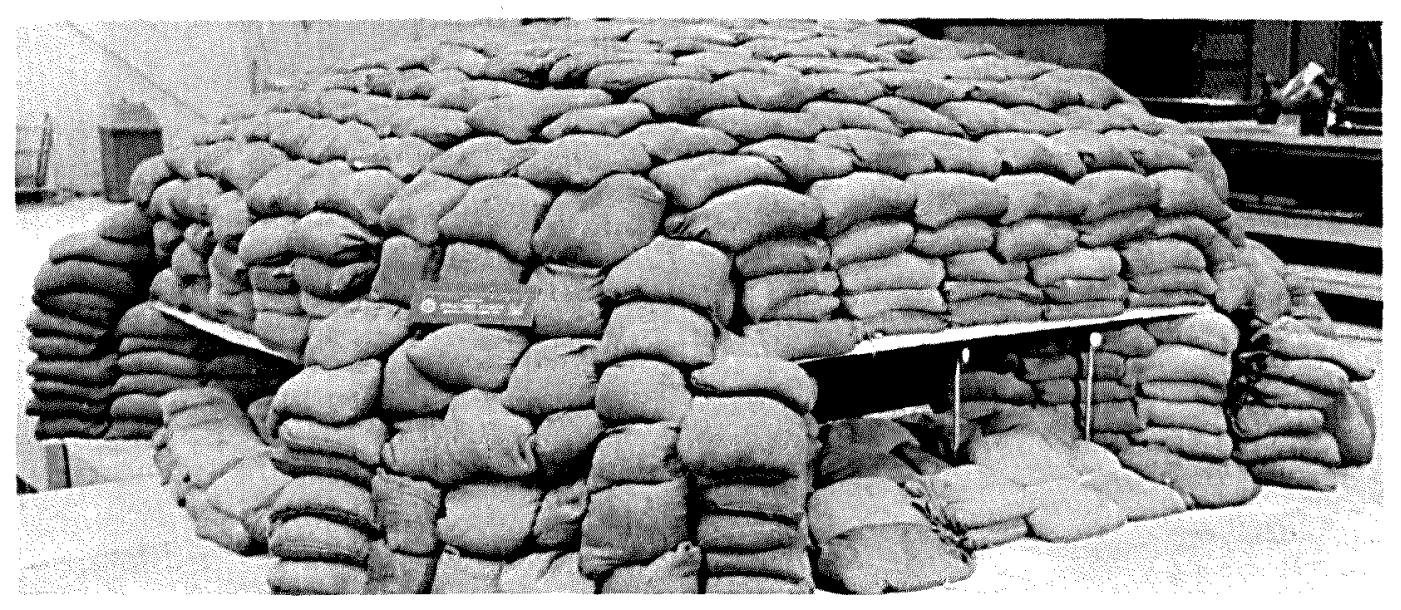

f. Six layers of sandbags

Figure 3.2 (Sheet 2 of 3 ). 


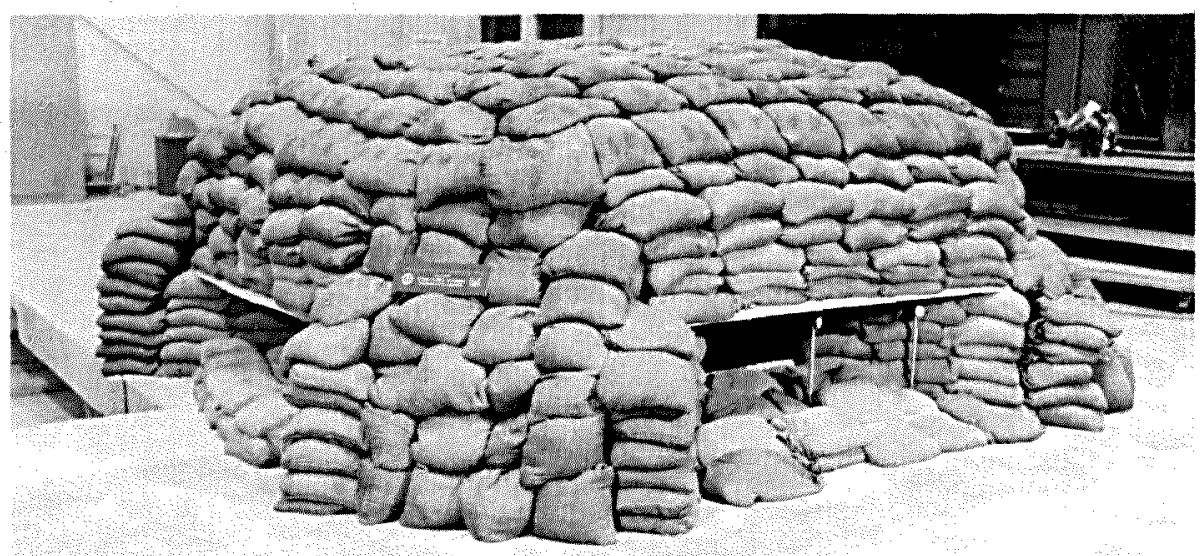

8. Seven layers of sandbags

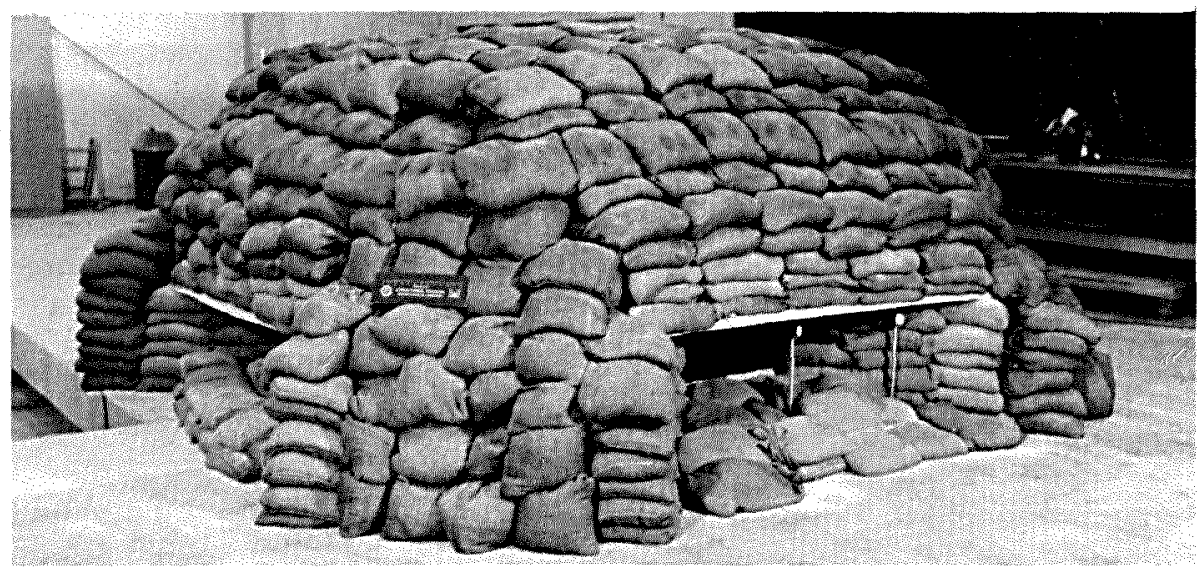

h. Eight layers of sandbags

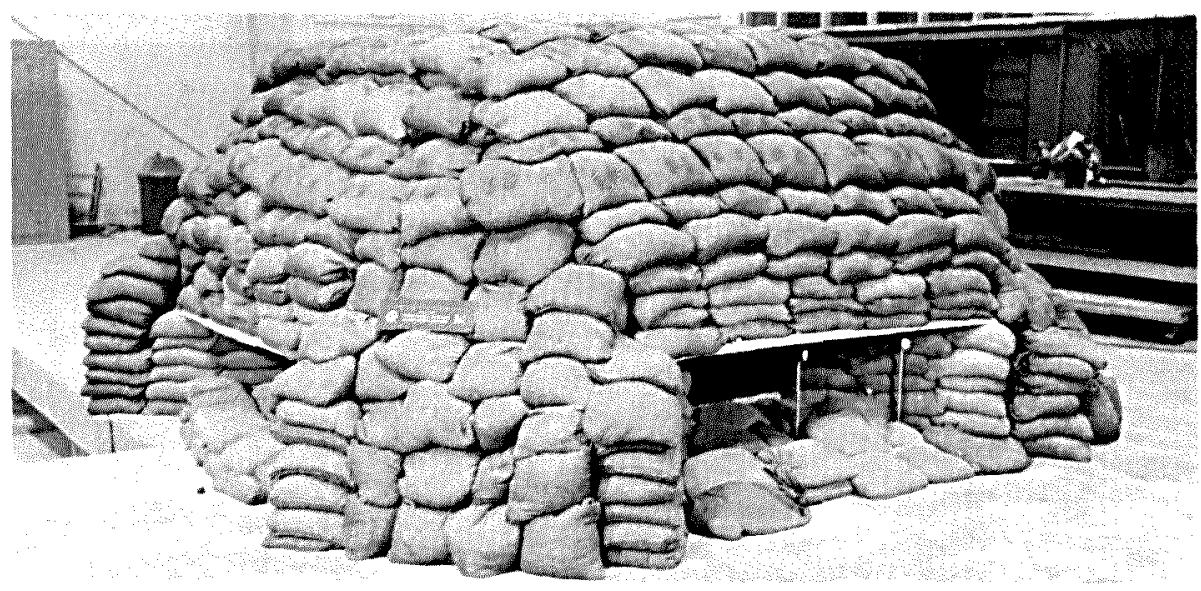

i. Nine layers of sandbags

Figure 3.2 (Sheet 3 of 3 ). 

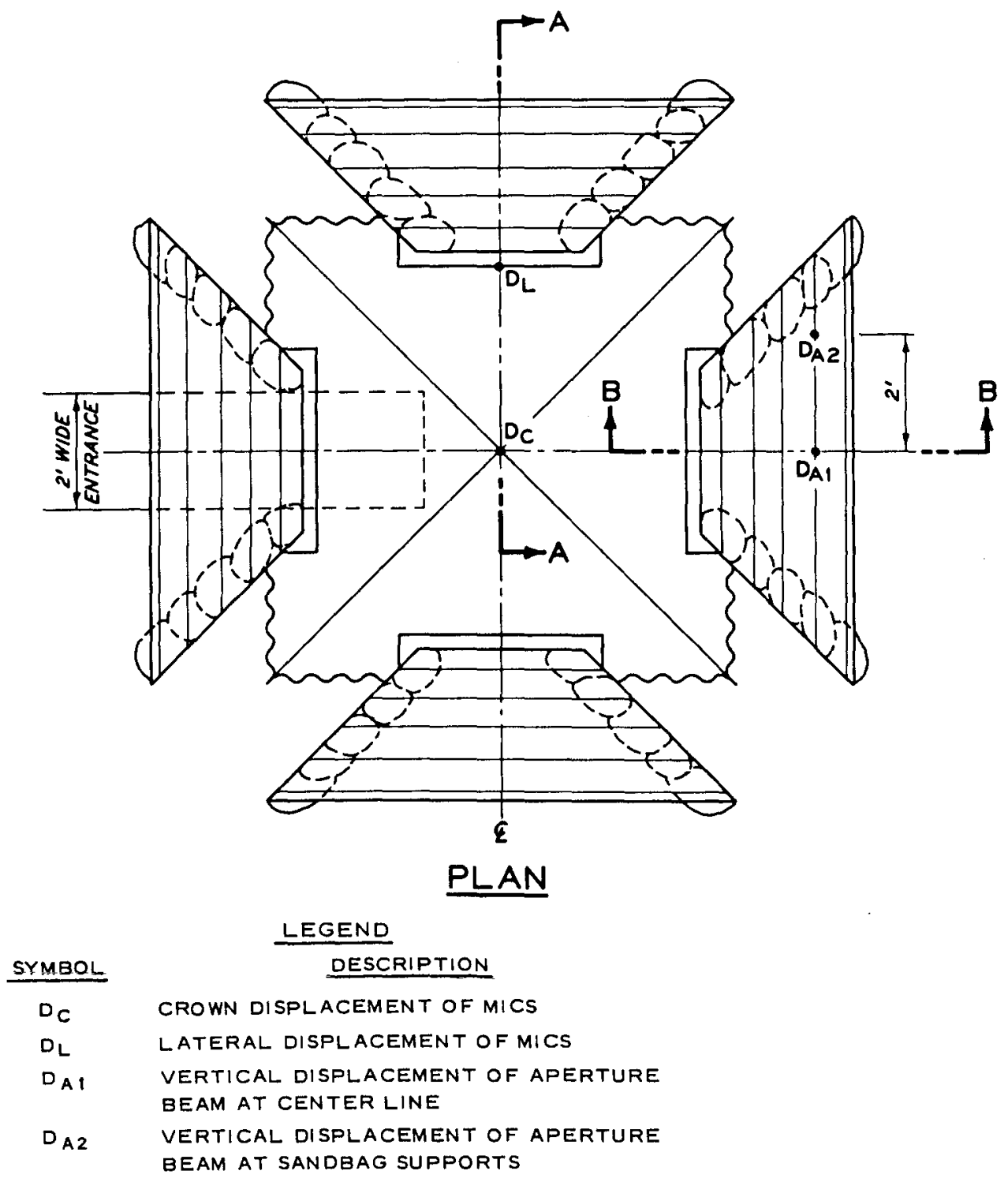

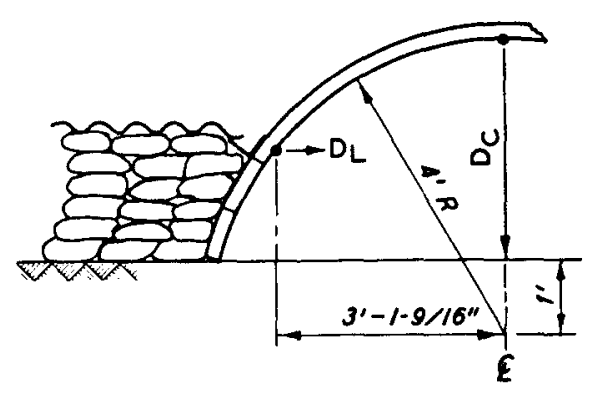

SECTION A-A

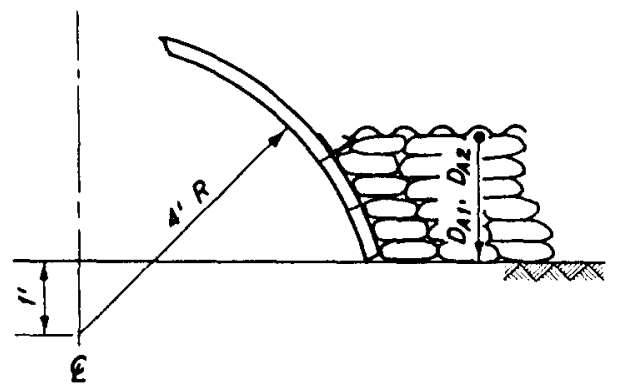

SECTION B-B

Figure 3.3 Displacement gage locations. 


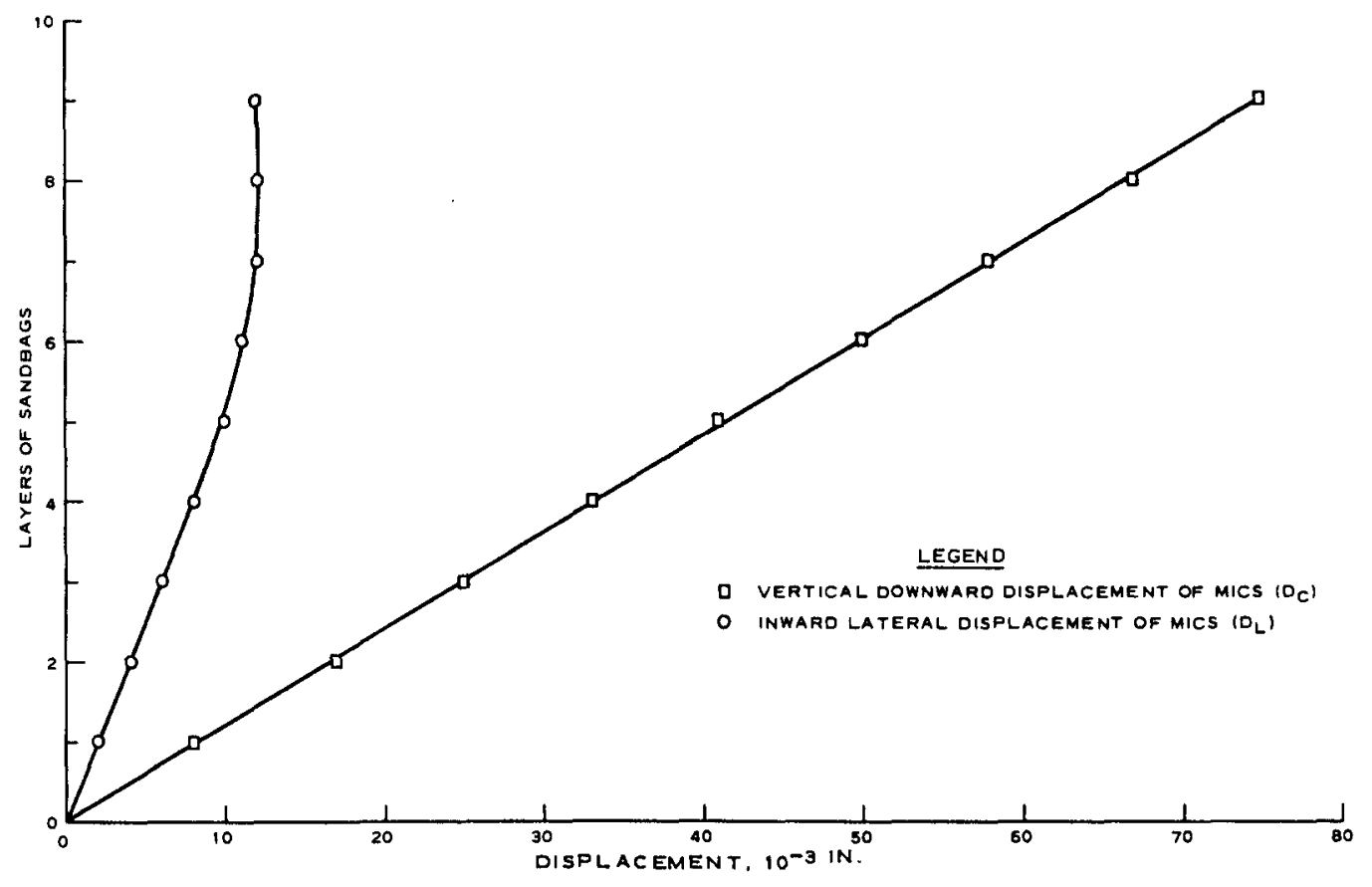

Figure 3.4 Vertical downward and inward lateral displacement of MICS .

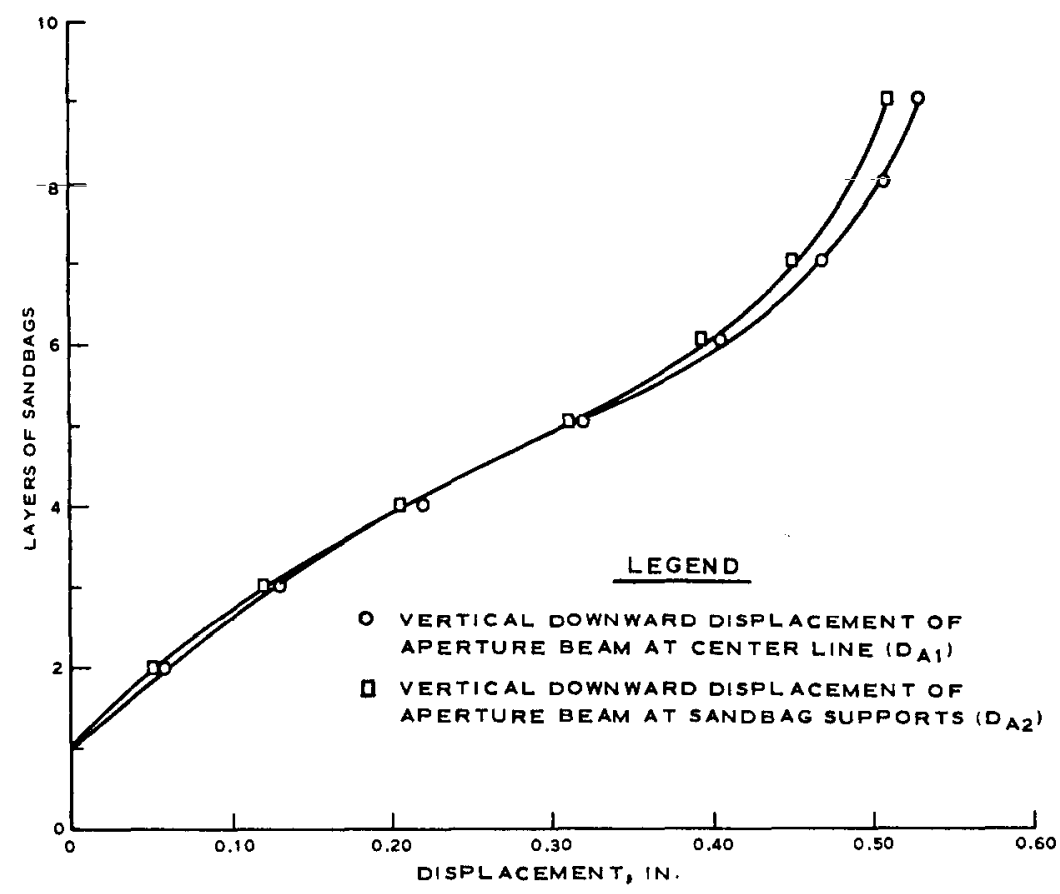

Figure 3.5 Vertical downward displacement of aperture beam versus layers of sandbags. 


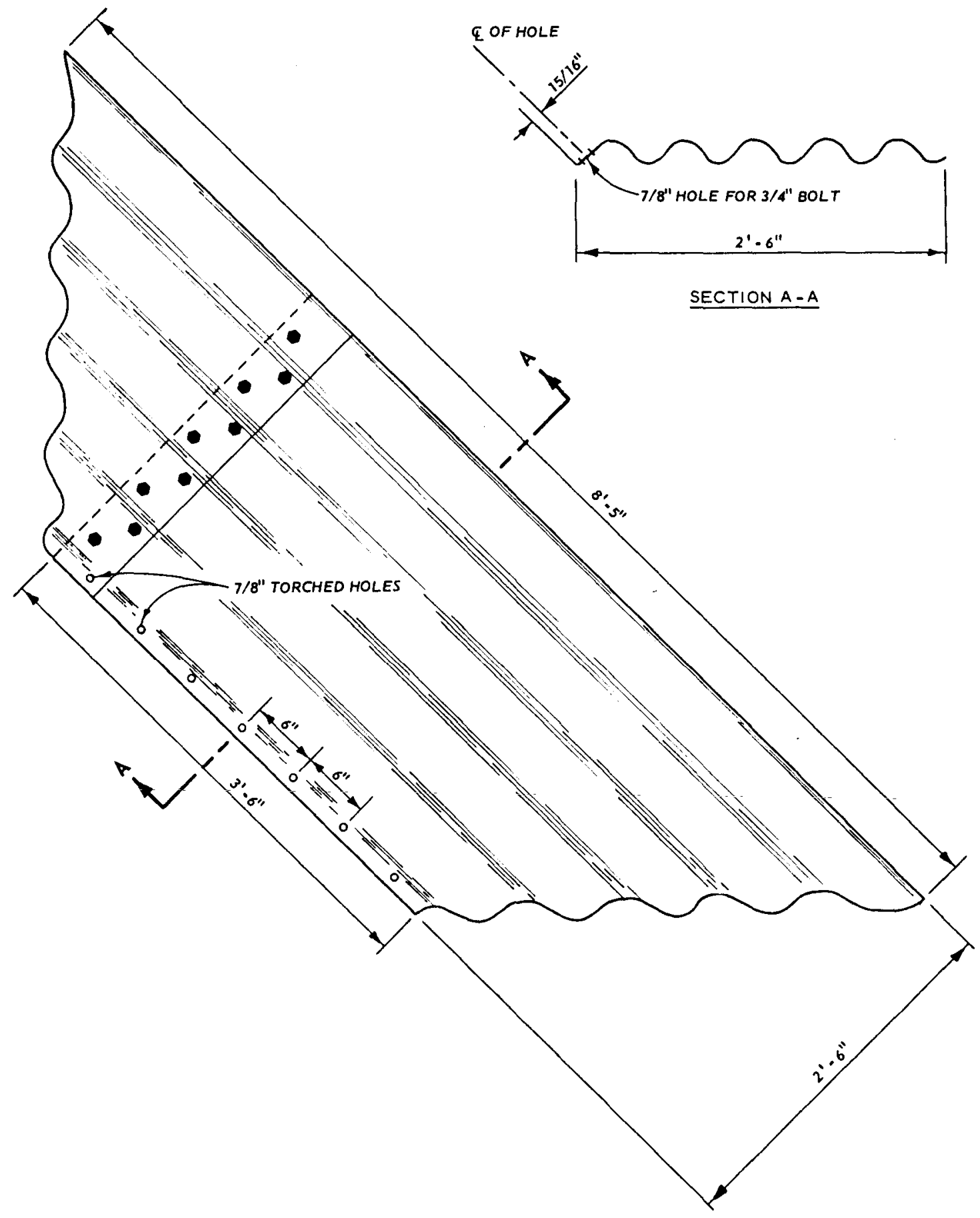

Figure 3.6.' Revised aperture beam 
CHAPTER 4

FIELD TESTS AT BIG BLACK TEST FACILITY

Field tests at the BBTF were conducted to determine the time and effort required to install each test structure and to determine its vulnerability to the blast effects of high-explosive (HE) detonations.

The field tests were conducted in three phases. Each phase consisted of the installation of a separate test structure that had been revised using the results of previous tests.

\subsection{SELECPION OF TEST CHARGES}

It was desired to determine the response of the bunkers to the blast effects of contact bursts, i.e. superquick fuzed small and medium HE mortar and artillery rounds. Spherical TNT charges were used to simulate these effects.

The use of spherical TNT charges is desirable because: (1) the blast effect is more repeatable than that of standard ammunition, (2) TNT can be cast in any weight, and (3) safety distances are minimized and special ranges are not required since there are no case fragments produced. Spherical TNT charges have been used to simulate the blast or shock damage of conventional weapons (References 1 and 4 ). This simulation is based on the hypothesis that, if craters formed by spherical TNT charges are similar to those of conventional weapons, the shock wave propogated through the soil cover media should be similar.

The following tabulation (taken from Reference 4 ) shows the requirements necessary for TNT simulation of live-fire mortar and artillery craters. This tabulation shows the crater resulting from the detonation of a 4-pound spherical TNT charge is similar to that resulting from the detonation of an $81-\mathrm{mm}$ mortar round when the center of gravity of the TNT charge is placed 4.5 inches above the ground surface. Likewise, it shows that the detonation of a 10-pound TNT charge when half buried forms a crater similar to that resulting from the detonation of a $105-\mathrm{mm}$ artillery round. 


\begin{tabular}{|c|c|c|c|c|c|c|}
\hline \multirow[b]{2}{*}{ Weapon } & \multirow[b]{2}{*}{$\begin{array}{l}\text { Crater } \\
\text { Depth } \\
\text { ft }\end{array}$} & \multirow[b]{2}{*}{$\begin{array}{c}\text { Crater } \\
\text { Radius } \\
\text { ft } \\
\end{array}$} & \multicolumn{4}{|c|}{ TNT Simulation (Spherical Charges) } \\
\hline & & & $\begin{array}{c}\text { Weight } \\
1 \mathrm{~b} \\
\end{array}$ & Configuration & $\begin{array}{l}\text { Crater } \\
\text { Depth } \\
\text { ft }\end{array}$ & $\begin{array}{c}\text { Crater } \\
\text { Radius } \\
\text { ft }\end{array}$ \\
\hline $\begin{array}{l}81-m m \\
\text { mortar }\end{array}$ & 0.45 & 2.20 & 4 & $\begin{array}{l}\text { Center of gra- } \\
\text { vity } 4.5 \text { in. } \\
\text { above surface }\end{array}$ & 0.45 & 1.75 \\
\hline $\begin{array}{l}\text { 4.2-inch } \\
\text { mortar }\end{array}$ & 0.65 & 2.00 & 4 & $\begin{array}{l}\text { Surface tan- } \\
\text { gent }\end{array}$ & 0.65 & 1.85 \\
\hline $\begin{array}{l}\text { 105-mm } \\
\text { howitzer }\end{array}$ & 1.30 & 3.25 & 10 & Half buried & 1.30 & 3.20 \\
\hline
\end{tabular}

For test purposes 4- and 10-pound spherical TNT charges were selected and half buried. The half-buried 10-pound charge simulates the blast loading of the 105-mm artillery round; the half-buried 4-pound charge conservatively simulates the blast loadings of the $4.2-$ inch and $81-\mathrm{mm}$ mortar rounds.

\subsection{PHASE I TEST SERIES}

4.2.1 Test Procedures. The modified bunker discussed in Chapter 3 was tested in Phase I. A three-man workcrew with only hand-tools performed the test installation. The structures were covered with dense dry sand (Unified Soil Classification, SP). Three spherical TNT charges were detonated to determine the vulnerability of the bunker. The charge sizes and location for this phase of testing are shown in Figure 4.1. All charges were buried with their center of gravity tangent to the top surface of the sand cover. Following the detonation of each round, the resulting damage was surveyed and documented with photographs, as needed. The structure was then covered to the original depth of sand prior to the detonation of each succeeding round. The bunker was modified prior to the detonation of Round 3 due to the results of Round 2. Results of Round 2 and the modification are discussed in Section 4.2.3.

4.2.2 Installation. Excavation of the fighting hole (Figure 4.2a) was accomplished by a three-man workcrew with shovels. As the soil was 
excavated from the fighting hole, it was used to level the bunker foundation site. The resulting fighting hole was 5 feet in diameter and 4 feet deep. A 2-foot-long and 2-foot-wide entrance was excavated to the fighting hole.

Following the excavation of the fighting hole and the delivery of the structural components of the bunker by way of pickup truck, the three-man workcrew erected the bunker over the fighting hole. The four quarter-sections of MICS were positioned around the perimeter of the fighting hole first (Figure 4.2b). Then two quarter-sections were attached to a steel strap with two 3/8-inch bolts loosely connecting the strap to each quarter-section (Figure 4.2c). The final connection of the crown involved the attachment of the last two quarter-sections of MICS (Figure 4.2d). This required one man inside the fighting hole with two men outside the bunker to position and attach these quarter-sections to the second steel strap with two 3/8-inch bolts loosely connecting the strap to each quarter-section. Following the connection at the crown, adjacent quarter-sections were loosely attached at the bottom with 3/8-inch bolts (Figure 4.2e). The adjacent quarter-sections were then moved into position and connected with two steel plates and two 3/8-inch bolts (Figure 4.2f). After tightening all connections, the erection of MICS was completed (Figure $4.2 \mathrm{~g}$ ).

The final step of assembling the prefabricated bunker components was the attachment of the aperture beams to MICS (Figure 4.2h). Each beam was attached with seven $3 / 4$-inch bolts.

Following the assembly of the prefabricated components (Figure 4.2i), sandbags were placed under each aperture beam to provide support (Figure 4.2j). Also, a layer of sandbags was placed along the outside edge of the aperture beams to weight the beams for firm contact with the sandbag supports. Other sandbags were placed along the seams to prevent soil leaking into the bunker.

Placement of mortar sand (SP) (Figure 4.2k) to a depth of 30 inches completed the bunker (Figure 4.2l). The specific gravity and average moisture content of the mortar sand were 2.65 and 5 percent, respectively. 
Dry and wet densities of the mortar sand was determined to be 78 and 82.5 pcf, respectively.

4.2 .3 Results and Discussion. Installation time is summarized in Table 4.1. A total time of $7-1 / 2$ hours was expended for the threeman crew to dig the fighting assembly and cover the bunker. This time was determined after taking into consideration the delays due to photographs, lunch periods, etc. The total time expended did not include the time required for transporting the bunker, men, and tools required to the field, nor did it include the time involved in filling the approximately 220 sandbags used in conjunction with the bunker. The filled sandbags from the static tests were used. The tools used in erecting the bunker, with the exception of three shovels and two wheelbarrows, are shown in Figure 4.3. The shovels were used to excavate the fighting hole and, in conjunction with the wheelbarrows, to place the sand cover.

4.2.3.1 Round 1. There was no significant blast damage to the bunker as a result of the 4-pound spherical TNI charge detonated above its crown. It was noted that the bunker had punched into the ground 2 to 3 inches. However, this was not a result of the blast load only, but was also due to the dead load of the bunker and the sand cover since no footing was used under the shell.

The apparent crater formed was a dished-out area approximately5-1/2 feet in diameter (Figure 4.4a). Level surveys before and after the shot revealed that 2 feet of sand was moved from the center of the dished-out area. The resulting crater had four peaks, each peak located at the corner of the bunker where the sand cover was continuous to the ground. A saddle formed between the peaks had a depth of approximately 2-3/4 inches in its center (Figure 4.4b). A mound of sand 4 to 6 inches high was deposited in front of each firing port (Figure 4.4c). This sand was assumed to have been displaced from above each aperture cover where the slope of the sand cover was possibly steeper than that of the corner of the bunker where the sand cover was continuous to the ground.

4.2.3.2 Round 2. The apparent crater formed by the detonation of the 4-pound TNT sphere on the side of MICS appeared to be 6 feet in 
diameter (Figure 4.5a) and 8-1/2-inches deep (Figure 4.5b). However, the actual crater diameter and depth were impossible to establish due to the backslide of loose sand.

It was observed after removing the sand cover that the quartersection of MICS above which the 4-pound charge of TNT had been centered was depressed in relation to the other quarter-sections (Figure 4.5c). This depression was a maximum of 2 inches (measured vertically) and occurred between the connection plates at the bottom of MICS and the crown of the bunker. Further examination revealed that this depression was a result of high stresses that occurred around the bolt holes used to connect the adjacent sections. Figure $4.5 \mathrm{~d}$ shows the metal around a bolt hole that was deformed due to its resistance to the blast load on the quarter-section. In spite of the depression of the loaded quartersection, sand was prevented from entering MICS by the sandbags placed over the seams of the adjacent section.

It was concluded that the weakest part of the bunker was the connection of the adjacent sections and that a 10-pound charge placed on the side of MICS would result in a catastrophic failure.

4.2.3.3 Round 3. As a result of Round 2, the two seams formed by the intersection of the north quarter-section with the east and west quarter-sections were stiffened inside by the addition of steel plates at locations where steel plates were used outside for the detonation of Rounds 1 and 2 .

The apparent crater formed by the detonation of the 10-pound charge appeared to be 7 feet in diameter (Figure 4.6a) and 9 inches deep (Figure 4.6b). However, the actual crater diameter and depth were impossible to determine due to the backslide of loose sand. Visual observation revealed that the aperture opening could not be used as an escape hatch and its use as a firing port was severely restricted (Figure $4.6 \mathrm{c}$ ). There was no indication inside the bunker of sand passing through the seams of the quarter-section; the sandbags used to cover the seams had blocked the sand from entering the bunker.

It was observed after removing the sand cover that the quarter-section 
of MICS above which the 10-pound charge of TNT had been centered was depressed in relation to the other quarter-sections of MICS (Figure 4.6d). The crown end of the loaded quarter-section was displaced 5 inches (vertical) (Figure 4.6e) with its connecting steel strap bent and the nut end of one of its 3/8-inch bolts pulled through the corrugated metal. Shear failure occurred around the two sets of connecting plates located nearest the crown of the bunker. Figure $4.6 f$ shows the typical shear failure that occurred around one set of connecting plates. The aperture beam had a permanent set that was a maximum of 7-3/4-inches along its center line (Figure 4.6g). The soil was removed from the base of the bunker, and it was observed that the base had punched into the ground approximately 7 inches near the aperture of the quarter-section where the 10-pound charge was centered (Figure 4.6h). This, of course, was a cumulative result of all three rounds.

It was concluded that the bunker design was weakest at the connections that joined the adjacent sections, and that some type footing was needed at the bunker base to prevent it from punching excessively into the soil, thus reducing the vertical height of the aperture openings and reducing their effectiveness as firing ports and emergency exits.

\subsection{PHASE II TEST SERIES}

4.3.1 Description of Test Structure. Detailed design drawings of this structure are shown in Figure 4.7. The MICS and aperture beams for this test series were fabricated from uncoated corrugated steel. The MICS (Figure 4.8a) is identical to the one tested in the Phase I test series, with the exception of modifications made as a direct result of those tests. Those modifications included (a) the addition of steel plate connectors along each seam formed by the intersection of two adjacent quarter-sections, (b) the addition of two inside steel straps that connect the quarter-sections at the crown, and (c) the addition of steel channel footings to prevent the quarter-sections from punching into the ground surface. The additional steel plate connections resulted in a total of seven sets (one inside and one outside) of plates along each seam formed by the intersection of two adjacent quarter-sections. 
Likewise, the adition of two steel straps results in a total of four straps (two outside and two inside) being used to connect the quartersections at the crown.

The aperture beams were identical to those used in the Phase I test series except they were fabricated from nongalvanized steel plates. Also, the two seams formed by overlapping the N8 and N3 steel plates from which the aperture beams were fabricated were welded instead of bolted. This resulted in aperture beams that were more stackable. Figure $4.8 \mathrm{~b}$ shows a typical aperture beam used in this test series. 4.3.2 Test Procedures. As in the Phase I test series, a threeman workcrew with only hand-tools performed the test installation. Two 10-pound spherical TNT charges were detonated to determine the vulnerability of the bunker. The charge locations for this test phase are shown in Figure 4.9. As before, all charges were buried with their center of gravity tangent to the top surface of the sand cover. Also, as before, the resulting damage was surveyed and documented with photographs, when needed, following the detonation of each round.

4.3.3 Installation. The three-man workcrew and components of the bunker were carried to the field in a pickup truck (Figure 4.10a). The components, were unloaded (Figure $4.10 \mathrm{~b}$ ) and placed adjacent to the same fighting hole used for the Phase I test series. Footings consisting of 4-inch steel channels and the four quarter-sections of MICS were placed around the perimeter of the fighting hole first (Figure 4.10c). Then two quarter-sections with their base inside the channel footings were connected to a steel strap located on the outside of the quartersections with two 3/8-inch cap screws loosely connecting the crown strap to each quarter section (Figure 4.10d). The final two quarter-sections with their base inside the channel footings were loosely bolted to a second crown steel strap located outside of the quarter-sections and lapped over the first strap. Following the crown attachment of the quarter-sections to the two outside steel crown straps, the nuts of the bolts connecting each crown strap were removed and an inside steel strap was attached directly beneath each outside crown strap. Following the 
connection at the crown, adjacent quarter-sections were loosely attached at the bottom of MICS with 3/8-inch cap screws. The adjacent quarter-sections were then moved into position to permit attachment to steel plates. Seven sets of steel-plate connectors were used at each of the four seams formed by the four quarter-sections. The erection of MICS was completed after tightening all connections.

Attachment of the aperture beams, placement of the sandbags, and sand cover were identical to the procedure used for the Phase I test series discussed in Section 4.2.2. Properties of the mortar sand (SP) used for cover were the same used for the Phase I test series, i.e. moisture content was 5 percent and dry and wet densities were 78 and 82.5 pef, respectively.

4.3.4 Results and Discussion. Installation time was not recorded for each phase of the installation. This was due to the fact that the fighting hole used for the Phase II test series was the same used for the Phase I test series. Also, other phases of installation of the Phase II test series, other than the erection of MICS, were identical to the Phase I test series. An additional 30 minutes was required to erect MICS for the Phase II test series. This was due to the additional 48 steel plate connectors and two steel straps that were used to connect the four quarter-sections. Therefore, the total time expanded for the three-man crew to instaII the Phase II test structure was 8 hours. A summation of the installation time of the Phase II test structure (Table 4.2) is identical to that of Phase I (Table 4.1) except for the additional 30 minutes required to erect the modified MICS.

There were no component parts of the Phase II test structure that could not be lifted by two men. The heaviest component part was a quartersection of MICS that weighed 106 pounds. Table 4.3 shows the weight of the Phase II test structure.

4.3.4.1 Round I. There was no visible damage to the bunker as a result of the 10-pound spherical TNT charge detonated above its crown. The crater (Figure 4.1la) was geometrically similar to that of the 4-pound crown shot (Round 1) of the Phase I test series, only larger. The apparent crater was 7 feet in diameter and had four peaks, each 
located at each corner of the bunker where the sand cover was continuous to the ground. The saddle formed between the peaks was $3-1 / 2$ inches deep at its center (Figure 4.IIb). As with previous rounds (Phase I), a mound of sand was deposited in front of each firing port. The firing ports were unaffected by the detonation (Figure 4.1lc). The steel channel footings were quite effective in preventing the quarter-sections of MICS from punching into the ground surface.

4.3.4.2 Round 2. The apparent crater formed by the detonation of the 10-pound charge on the side of MICS appeared to be 7 feet in diameter (Figure 4.12a) and 9-1/2 inches deep (Figure 4.12b). However, the actual crater dimensions were impossible to determine due to the backslide of loose sand.

It was apparent after removing the sand cover that the additional steel plates and straps used to connect the quarter-sections prevented the distortion evident during the Phase I test series. It was observed that the quarter-section of MICS above which the 10-pound charge was centered was slightly depressed in relation to the adjacent quartersections. This depression, a maximum of 1 inch measured vertically (Figure 4.12c), occurred between the crown and the steel-plate connectors nearest the crown. The aperture beam above which the 10-pound charge was centered sustained a permanent set that was a maximum of $11-1 / 2$ inches along its center line (Figure 4.12d). Despite this failure, and due to the steel channel footings that prevented the loaded quarter-section from punching into the ground surface, the embrasure could still be used as an emergency exit and/or as a firing port that would not require a vertical angle.

\subsection{PHASE III TEST SERIES}

4.4.1 Description of Test Structure. A detailed design drawing of the Phase III test structure is shown in Figure 4.13. Like the Phase II test structure, it consisted of a MICS, aperture beams, and steel channel footings. The weight of the component parts of this test structure is presented in Table 4.4 .

The MICS was fabricated from galvanized, corrugated steel sheets. 
The sheets were of 16-gage or 0.598 inches thickness (uncoated) and had a 3-inch pitch and a l-inch depth corrugation. Since the width of each corrugated panel was only 25-1/2 inches (see Section 2.2), each quarter-section of the MICS was cut from five sheets, 6 feet 3 inches long, that had been rolled to a 4 -foot radius with their circumferential joints welded in $1-1 / 2$ inch lengths at 6 -inch spacings. Unlike the 12-gage, 6- by 2-inch corrugated MICS, only an outside sheet metal template was used as the cutting pattern for each quarter-section of MICS. Graphical determination of the outside sheet metal template is shown in the design drawing presented in Figure 4.13. The aperture dimensions were identical to those of the 12-gage, 6- by 2-inch corrugated MICS, i.e. 2 feet wide and 16 inches high (measured vertically). Unlike the 12-gage, 6- by 2-inch corrugated MICS, the four quarter-sections were welded together to form the MICS. A 1-1/2-inchdiameter (inside) steel ring $1 / 4$ inch thick was welded to the crown of the MICS for lifting purposes. This steel ring was not intended for test purposes but was used for the attachment of a load cell in determining the weight of MICS; therefore, it is not included in the design drawing shown in Figure 4.13. Thirteen 1/2-inch bolt holes were punched above the apertures of each quarter-section for attachment of each aperture beam. Like the Phase II test structure, the MICS was supported by steel channel footings; however, instead of being 4 incheswide, they were 3 inches wide.

The aperture beams were identical to those used in the Phase II test series with the exception of the prepunched holes for attachment to each quarter-section. Thirteen 1/2-inch bolt holes spaced on 3-inch centers were punched into the tangent section nearest the 3-foot 6-inch side of the aperture beam to match those of each quarter-section of MICS and to allow 3/8-inch cap screws to attach an aperture beam to each quarter-section of MICS.

4.4.2 Test Procedure. A three-man workcrew with hand-tools performed the test installation. Four spherical TNT charges were detonated to determine the vulnerability of the bunker. The charge sizes and locations for Phase III are shown in Figure 4.14. All charges were buried with their center of gravity tangent to the top surface of the sand cover. 
Following the detonation of each round, the resulting damage was surveyed and documented with photographs. The structure was then covered with the original depth of sand prior to the detonation of each succeeding round.

4.4.3 Installation. Excavation of the fighting hole was accomplished by a three-man workcrew with shovels. This fighting hole was similar to that used for the Phase I and II test series discussed in Section 4.2.2. Following the excavation of the fighting hole and the delivery of the bunker components the three-man workcrew erected the bunker over the fighting hole (Figure 4.15). First, the 3-inch steel channel footings were placed around the perimeter of the fighting hole (Figure 4.15a). The MICS was then lifted by the workcrew and its base placed inside the channel footings (Figure 4.15b). Attachment of the aperture beams (Figure 4.15c), placement of the sandbags (Figure 4.15d), and placement of the sand cover (Figure 4.15e) were identical to the procedure used for the Phase I and II test series, with the exception that sandbags were not required along the seams formed by the intersection of the adjacent quarter-sections .

\subsubsection{Results and Discussion. Phase III installation time is} summarized in Table 4.5. A total time of 6 hours and 30 minutes was expended for the three-man crew to install the bunker. Again, this time was determined after taking into consideration the delays due to photographs, lunch periods, etc. The total time expended did not include the time required for transporting the bunker, men, and tools required to the field, nor did it include the time involved in filling the sandbags used in confunction with erecting the bunker. Approximately 160 sandbags would be required. The tools used in erecting the bunker consisted of three shovels, two wheelbarrows, and a 1/2-inch ratchet with a 9/16-inch shallow well socket. The shovels were used to excavate the fighting hole and, in conjunction with the wheelbarrows, to place the sand cover. The 1/2-inch ratchet and 9/16-inch shallow well socket were used to attach the aperture beams to the MICS.

All component parts of the Phase III test structure could be lifted by three men. The heaviest component part of this structure was the 
MICS which weighed 300 pounds. Table 4.4 shows the weight of the Phase III test structure.

4.4.4.1 Round 1. There was no visible damage to the bunker as a result of the 4-pound spherical TNT charge detonated above its crown. The apparent crater (Figure 4.16a) was similar to that of Round 1 of the Phase I test series (Section 4.2.3.1). Also, like Round 1 of the Phase I test series, a mound of sand was deposited in front of each firing port (Figure $4.16 b$ ).

4.4.4.2. Round 2. Other than the displacement of some of the sand cover, there was no visible damage to the bunker as a result of the 4-pound spherical TNT charge detonated on the side of MICS. The apparent crater (Figure 4.17a) appeared to be similar to that of Round 2 of the Phase I test series (Section 4.2.3.2).

4.4.4.3. Round 3. Other than displacement of some of the sand cover, there was no visible damage to the bunker as a result of the 10-pound spherical TNT charge detonated above its crown. The crater formed (Figure 4.17b) was similar to that of the 10-pound crown shot (Round 1) of the Phase II test series (Section 4.3.4.1). Also, as with Round 1 of the Phase II test series, a mound of sand was deposited in front of each firing port.

4.4.4.4. Round 4. The apparent crater (Figure 4.18a) of the 10-pound charge on the side of MICS was similar to that of Round 2 of Phase II test series (Section 4.3.4.2). It was apparent, after removing the sand, that the aperture beam above which the 10-pound charge was centered sustained a permanent set of $11-1 / 2$ inches along its center line (Figure 4.18b). This was equal to the permanent set sustained by the aperture beam due to Round 2 of the Phase II test series. The embrasure formed by the damaged aperture beam could still be used as an emergency exit and/or as a firing port that would not require a vertical angle. It was also observed after removing the damaged aperture beam that a permanent set of 5-1/4 inches had occurred at the center line of the quarter-section of MICS about which the 10-pound charge had been centered (Figure 4.18c). It was also evident that the center corrugation of the two adjacent quarter-sections to the loaded quarter-section had been compressed due to 
the 10-pound shot. Also evident was the distortion of the adjacent seams (Figure 4.18a) due to the high stresses developed in resisting the loaded quarter-section. It is believed that, if the quarter-sections were bolted together as in the Phase II test structure, the bunker would have been neutralized. 
Phase of the

Installation
Time Required ${ }^{\mathrm{a}}$

(Three-man crew)
Excavation

Erecting MICS

Attachment of aperture beams

Placement of sandbags $b$

Placement of sand cover
2 hours

1 hour

30 minutes

1 hour

3 hours

Total Time Expended 7 hours 30 minutes $^{c}$

a. Time was determined after taking into consideration the delays due to photographs, lunch periods, etc.

b. The time required for the placement of sandbags does not include the time required to fill the sandbags, nor does it include the time involved in transporting the filled sandbags to the field.

c. The total time expended does not include the time required for transporting the bunker, men, and tools required to the field. 
TABLE 4.2

INSTALLATION TIME, BIG BLACK FIELD TEST (PHASE II)

Phase of the

Time Required ${ }^{a}$

Installation

(Three-man crew)

Excavation

Erecting MICS

Attachment of aperture beams

Placement of sandbags $b$

Placement of sand cover
2 hours

1 hour 30 minutes

30 minutes

1 hour

3 hours

Total Time Expended 8 hours $^{c}$

a. Time was determined after taking into consideration the delays due to photographs, Iunch periods, etc.

b. The time required for the placement of sandbags does not include the time required to fill the sandbags, nor does it include the time involved in transporting the filled sandbags to the field.

c. The total time expended does not include the time required for transporting the bunker, men, and tools required to the field. 
Weight of Required Component Parts

Ibs

Multiple Intersecting Cylindrical

Shell (MICS)

Corrugated quarter-section

3- by 4- by 1/4-inch steel place

1/4-inch by 1-inch by 1-foot 4-inch steel strap

3/8-inch-diameter $16 \mathrm{NC}$ by $1-3 / 4-$ inch cap screw/w nut

3/8-inch-diameter $16 \mathrm{NC}$ by $1-1 / 2-$ inch cap screw/w nut $\begin{array}{rr}4 & 424 \\ 56 & 42\end{array}$

4

6

56

$1-5 / 16$

8

Total weight of MICS

$473-1 / 2$

\section{Aperture Beams}

2-feet 6-inch by 3-feet 6-inch

by 8 -feet 5 inch corrugated cover

3/4-inch-diameter $10 \mathrm{NC}$ by 1-1/4-inch

cap screw/w nut

344

28

14

Total weight of aperture covers and connectors

Channel Footings

C4 by 5.4 by 7 -feet 2 -inch steel channel 3

116

C4 by 5.4 by 2 -feet 6 -inch steel channel 2

Total weight of channel footings

Total Weight of Phase II Test Structure

143

$974-1 / 2$

$a_{\text {Sandbags are not included in this table }}$ 
Description of Component Parts ${ }^{a}$
Required Number of Component Parts
Weight of Required Component Parts

Ibs

Multiple Intersecting Cylindrical

Shell (MICS)

Total weight of MICS

300

Aperture Beams

2-feet 6 -inch by 3 -feet 6 -inch by

8-feet 5-inch corrugated cover

4

344

3/18-inch-diameter -16 NC by 1-inch

cap screw/w nut

52

$1-1 / 4$

Total weight of aperture beams

and connectors

$345-1 / 4$

Channel Footings

C3 by 4.1 by 7 -feet 2 -inch steel channel 3

C3 by 4.1 by 2 -feet 6 -inch steel channel 2

212

Total weight of channel footings 109

Total Weight of Phase III Test Structure 754-1/4

$a_{\text {Sandbags are not included in this table }}$ 
TABLE 4.5

INSTALLATION TIME, BIG BLACK FIELD TEST (PHASE III)

Phase of the

Installation

Time Required ${ }^{a}$

(Three-man crew)

Excavation

2 hours

Erecting MICS

5 minutes

Attachment of aperture beams

30 minutes

Placement of sandbags $b$

55 minutes

Placement of sand cover

3 hours

Total Time Expended

6 hours 30 minutes ${ }^{c}$

a. Time was determined after,taking into consideration the delays due to photographs, lunch periods, etc.

b. The time required for the placement of sandbags does not include the time required to fill the sandbags, nor does it include the time involved in transporting the filled sandbags to the field.

c. The total time expended does not include the time required for transporting the bunker, men, and tools required to the field. 

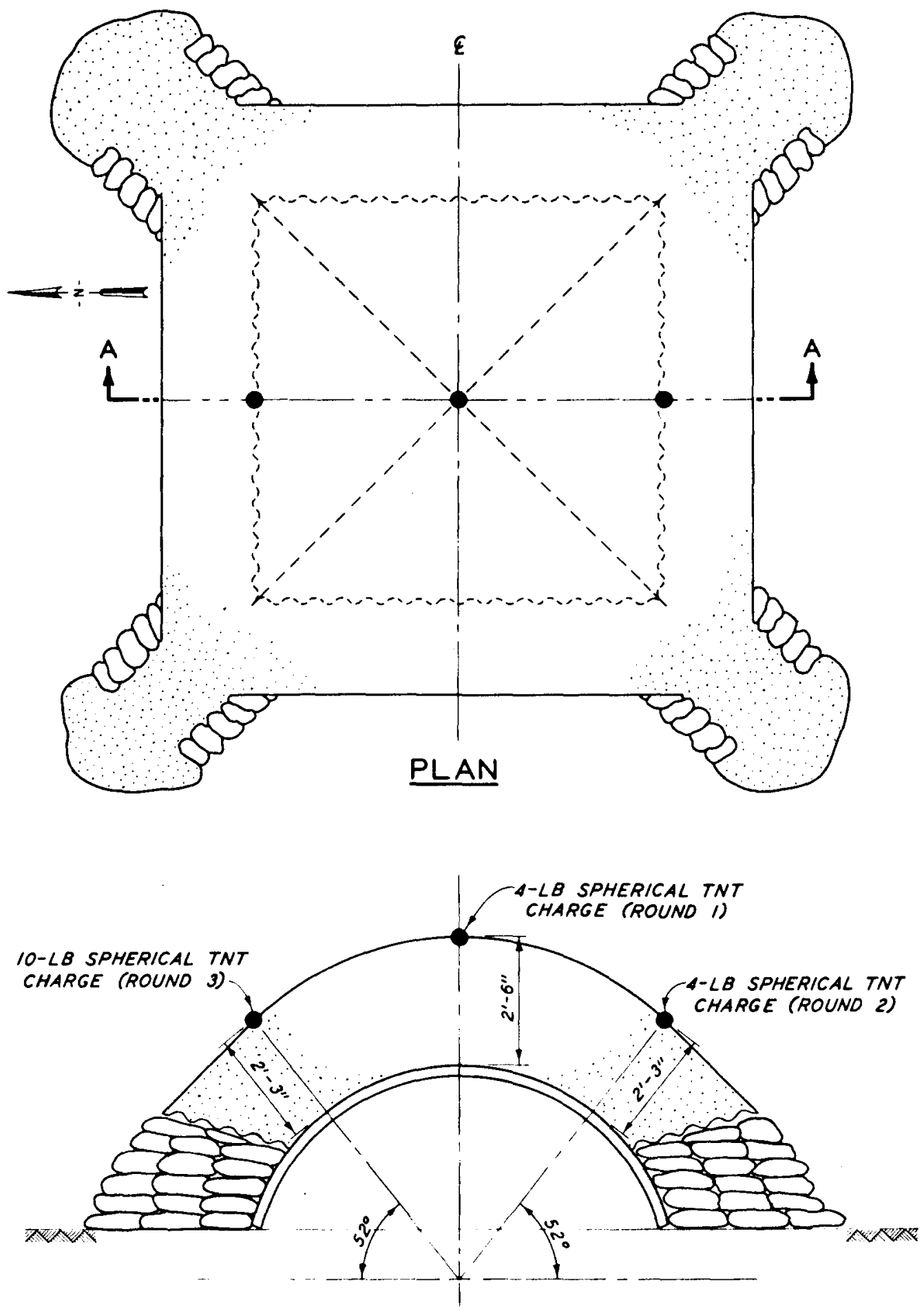

SECTION A-A

Figure 4.1 Charge sizes and locations for Phase I test series. 


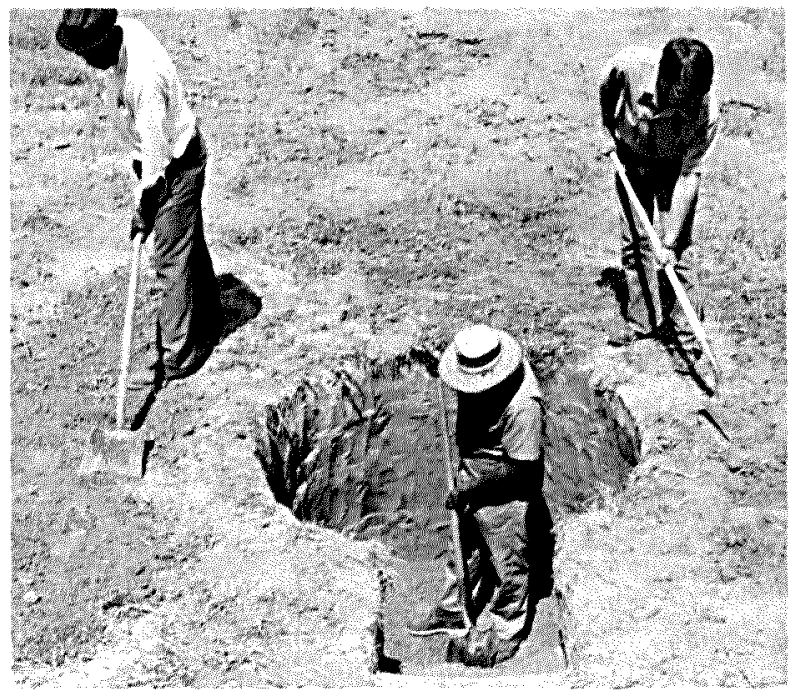

a. Excavation of fighting hole

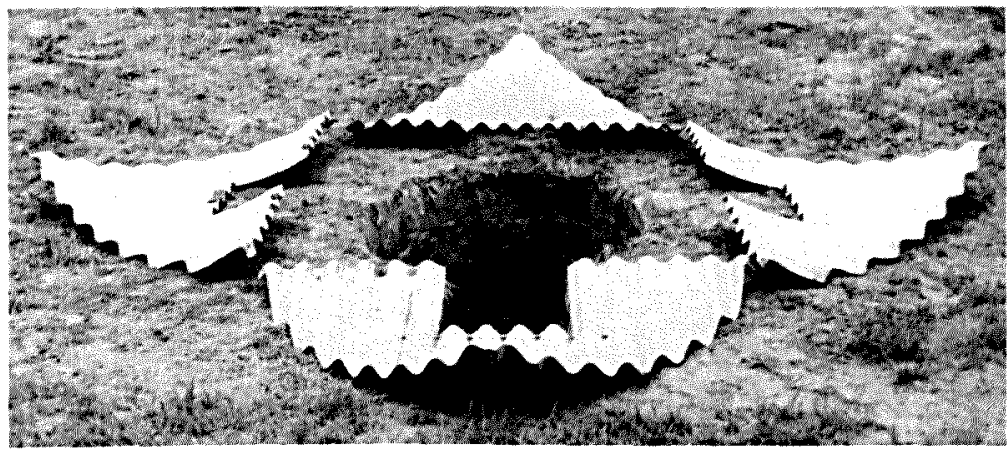

b. Quarter-sections of MICS positioned around perimeter of fighting hole

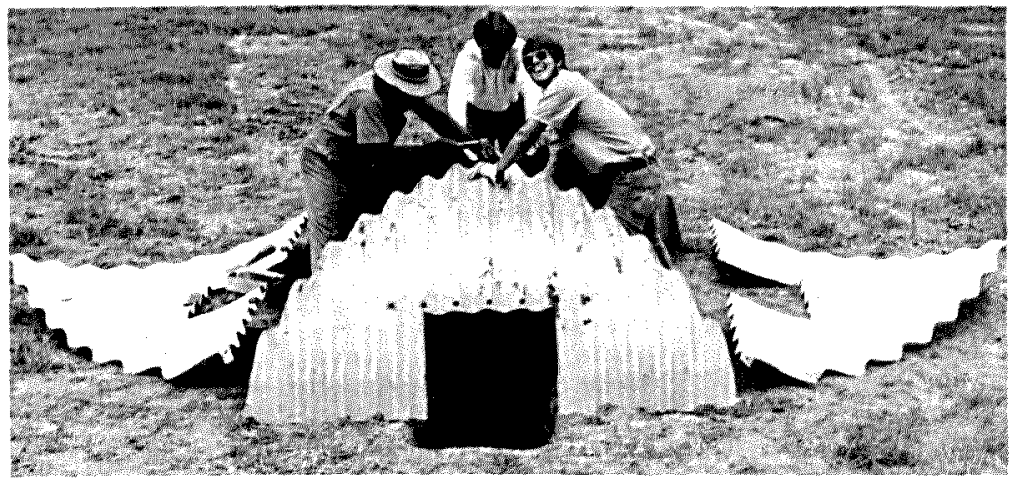

c. Attaching two quarter-sections of MICS

Figure 4.2 Installation of the Phase I test structure at BBTF (sheet 1 of 4 ). 


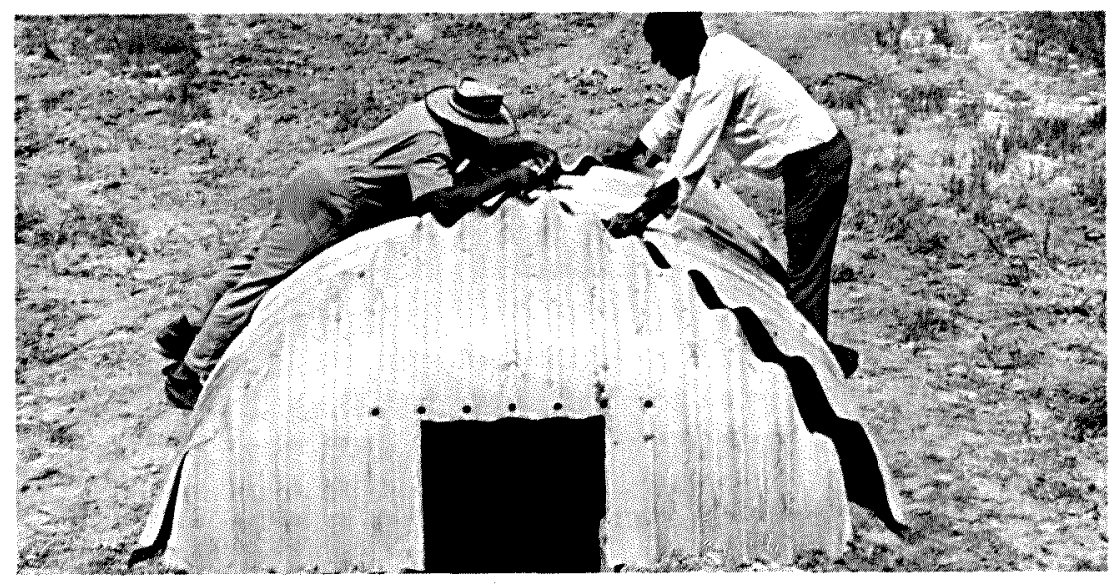

d. Attachment of last two quartersections at crown of MICS

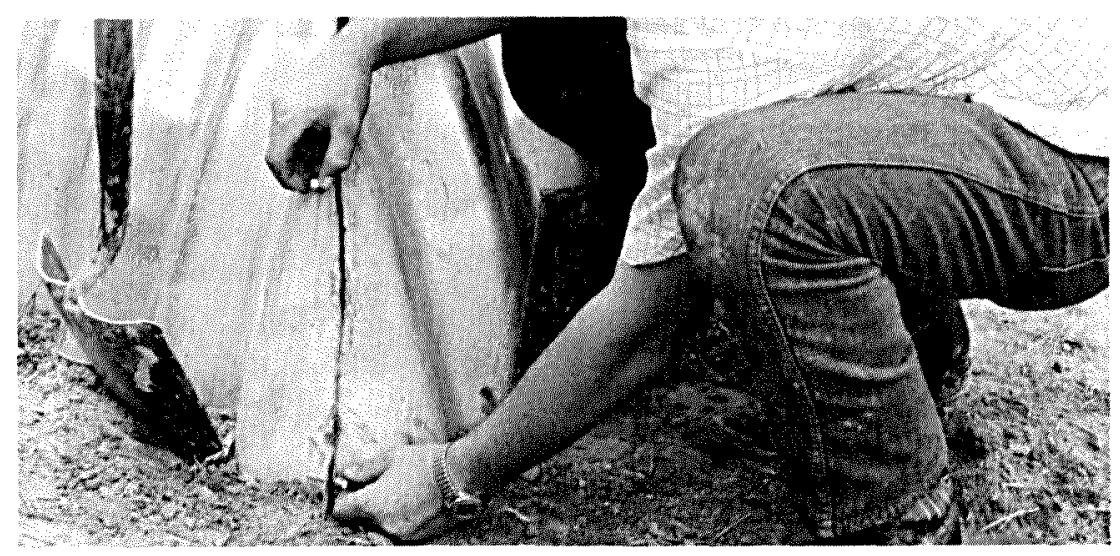

e. Attaching two adjacent quartersections of MICS at bottom

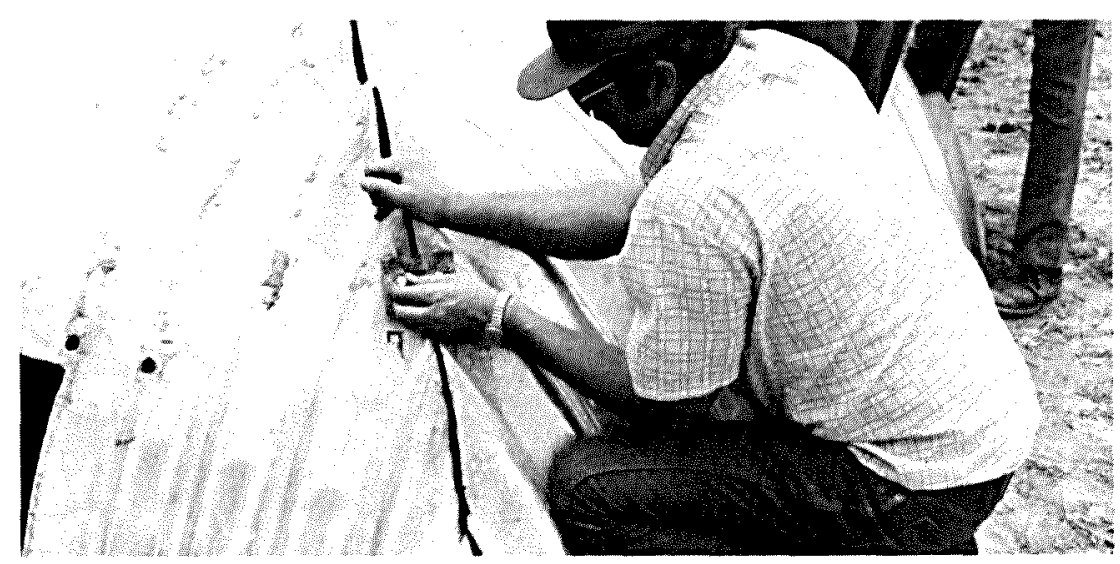

f. Attaching two adjacent quartersections with steel plates and bolts

Figure 4.2 (Sheet 2 of 4 ). 


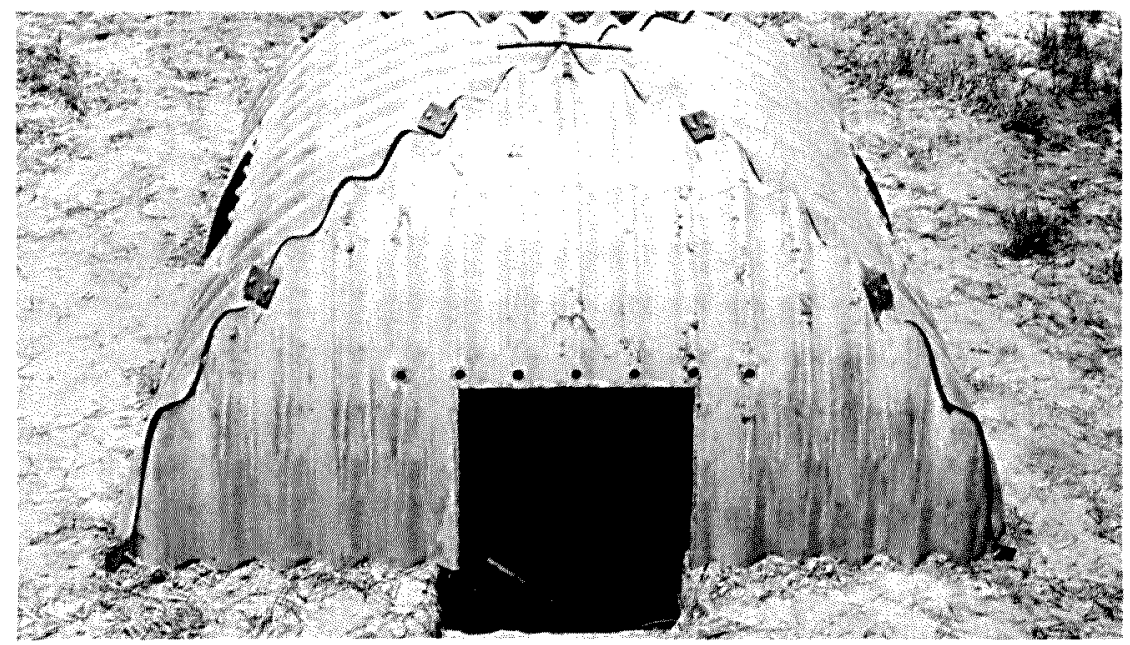

g. Completed MICS

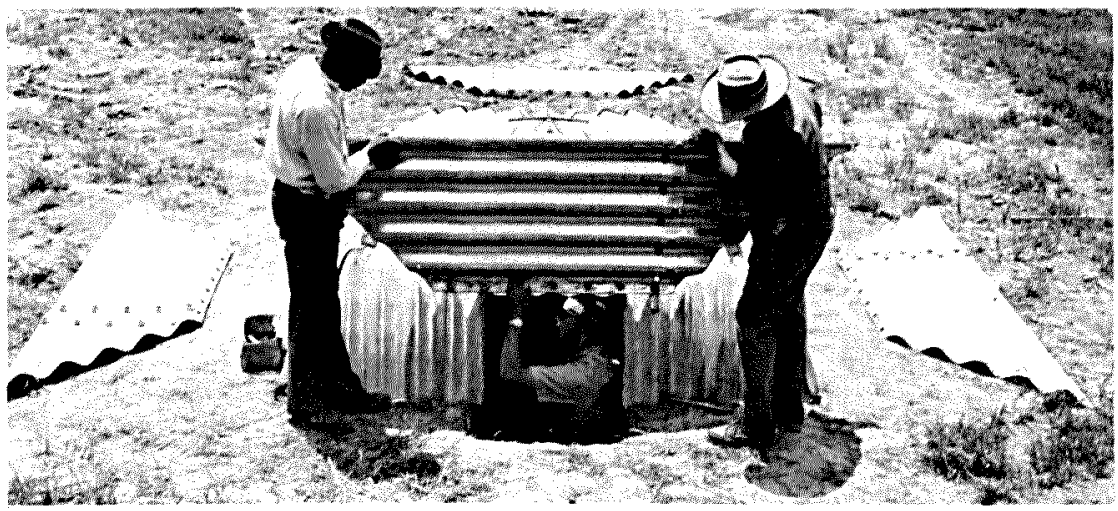

h. Attachment of an aperture beam

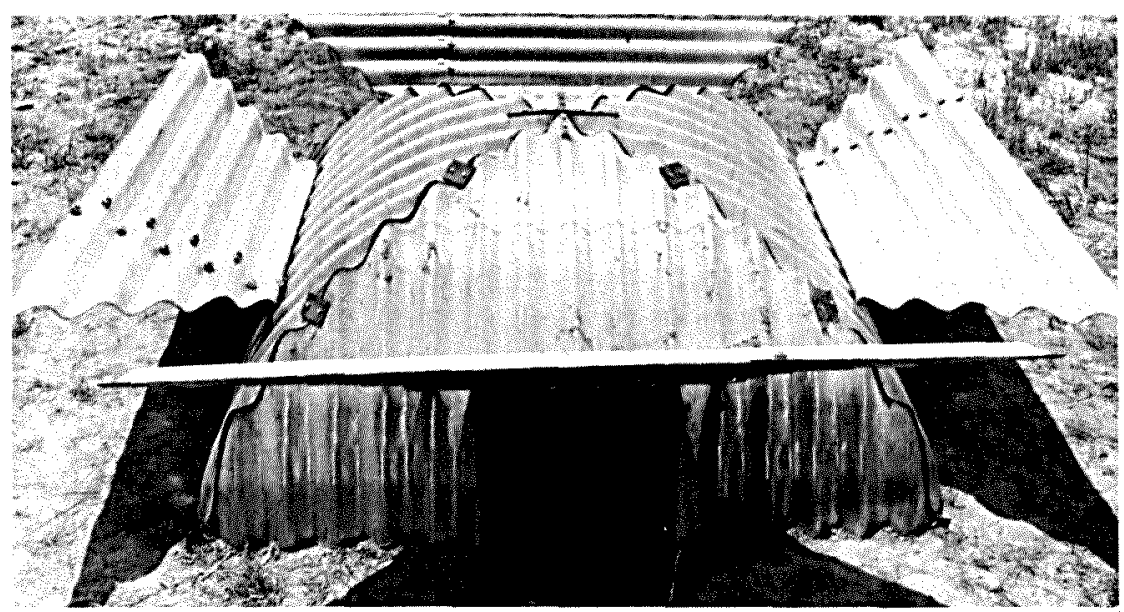

i. Completed assembly of prefabricated components

Figure 4.2 (Sheet 3 of 4 ). 


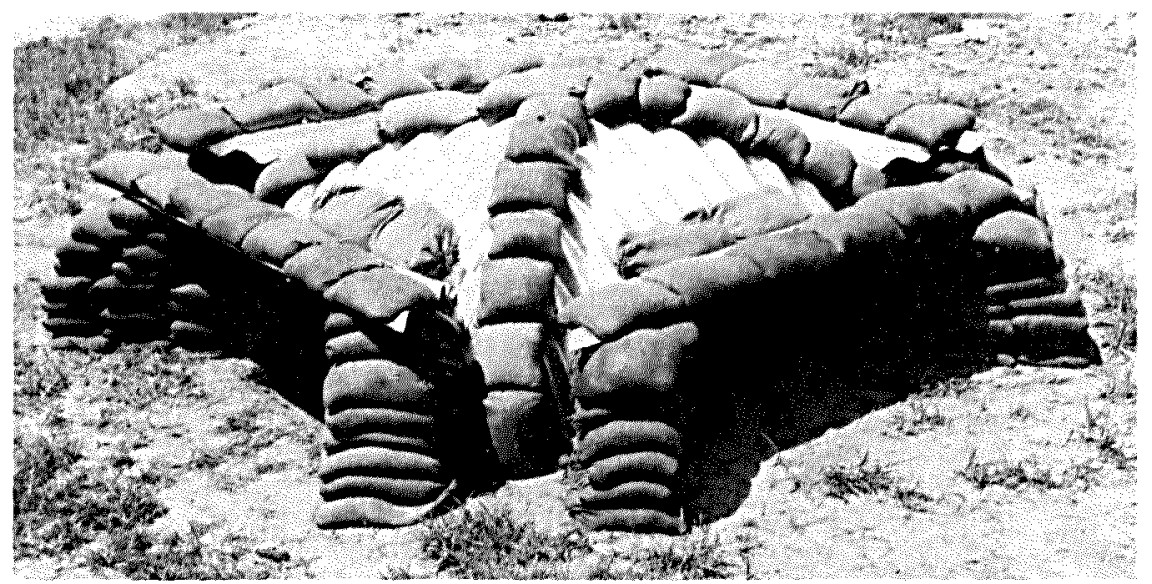

3. Completed assembly of prefabricated components with sandbags

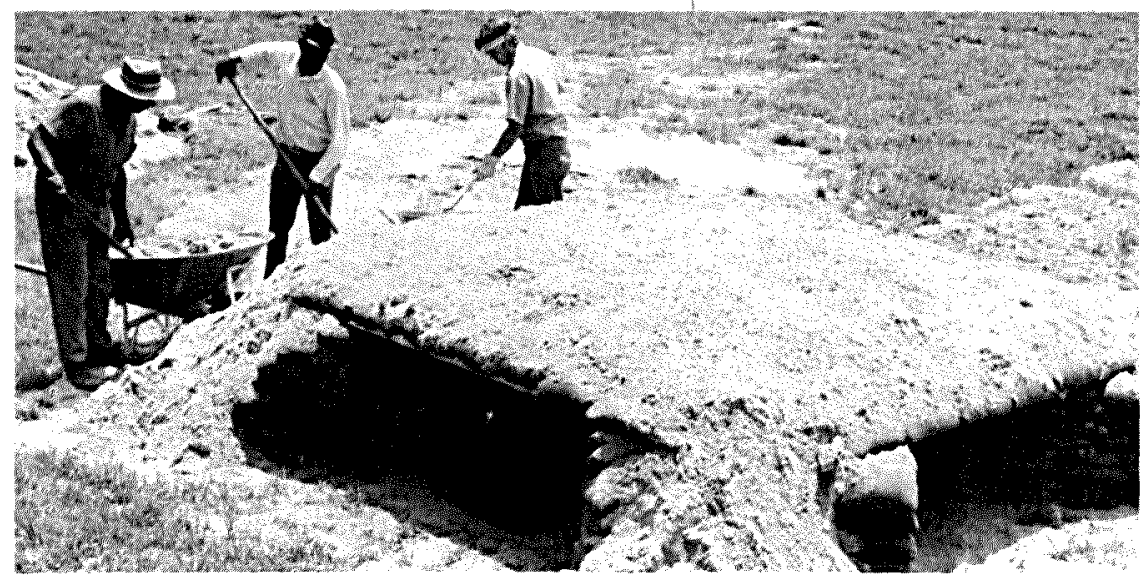

k. Placement of sand cover

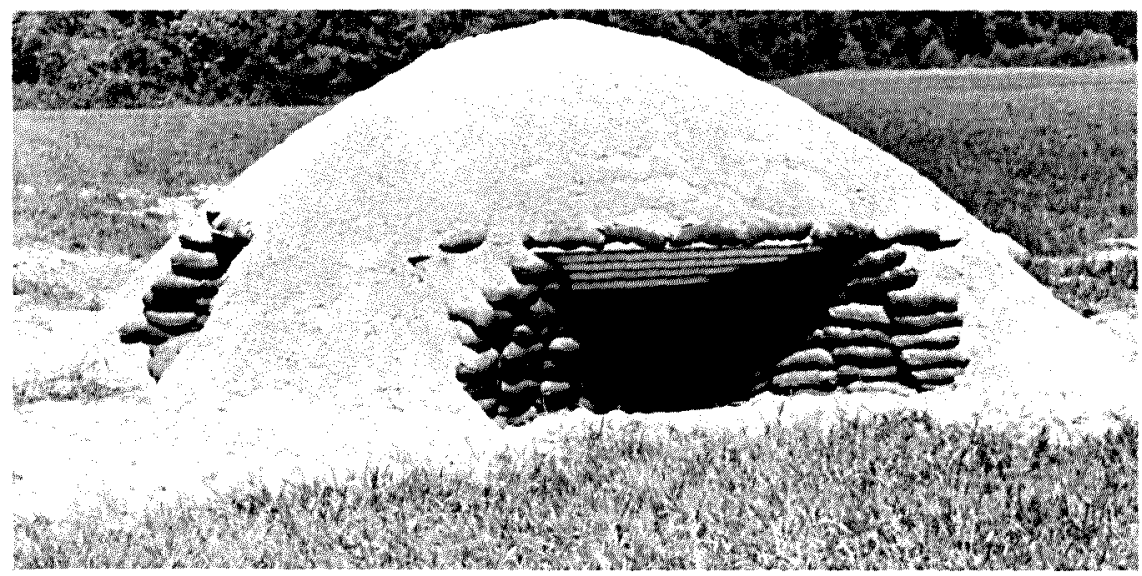

1. Completed bunker

Figure 4.2 (Sheet 4 of 4 ). 


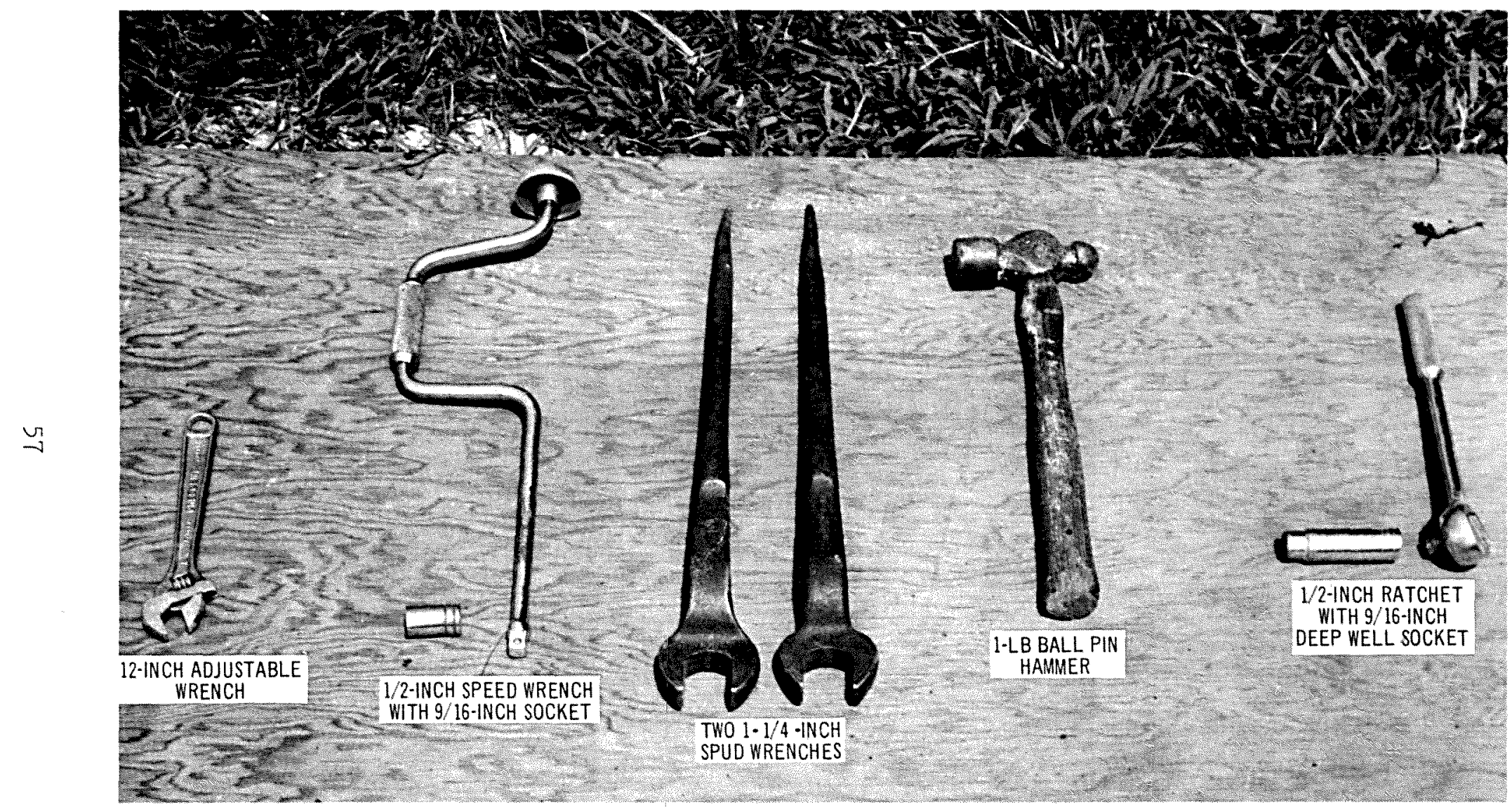

Figure 4.3 Hand-tools used in erecting Phase I test structure with the exception of three shovels and two wheelbarrows. 


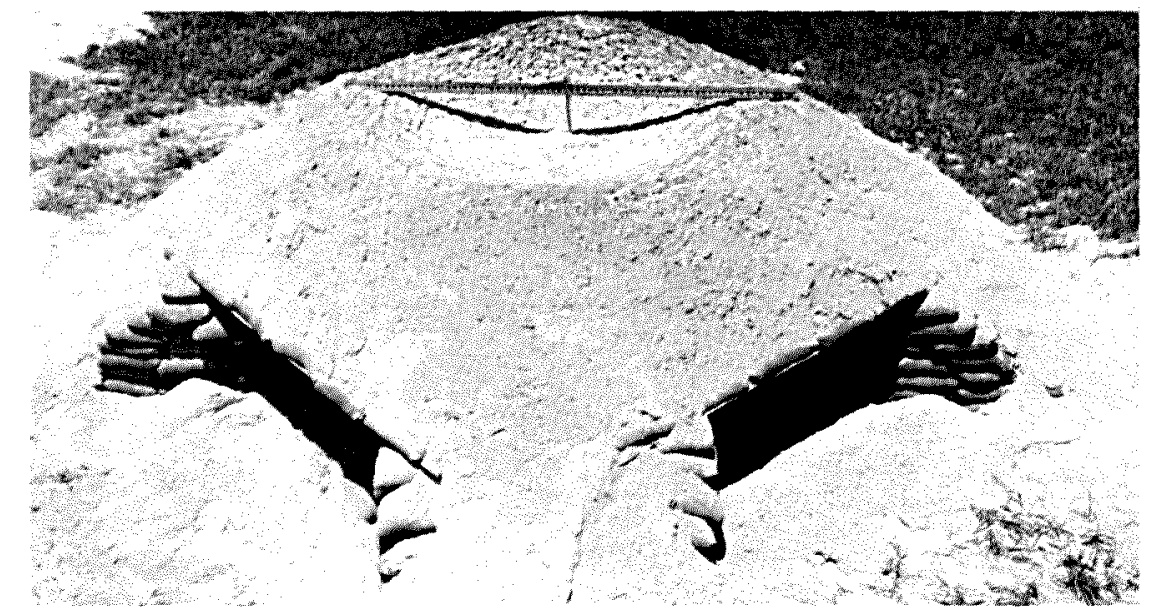

a. Crater formed by 4-pound charge detonated above MICS crown

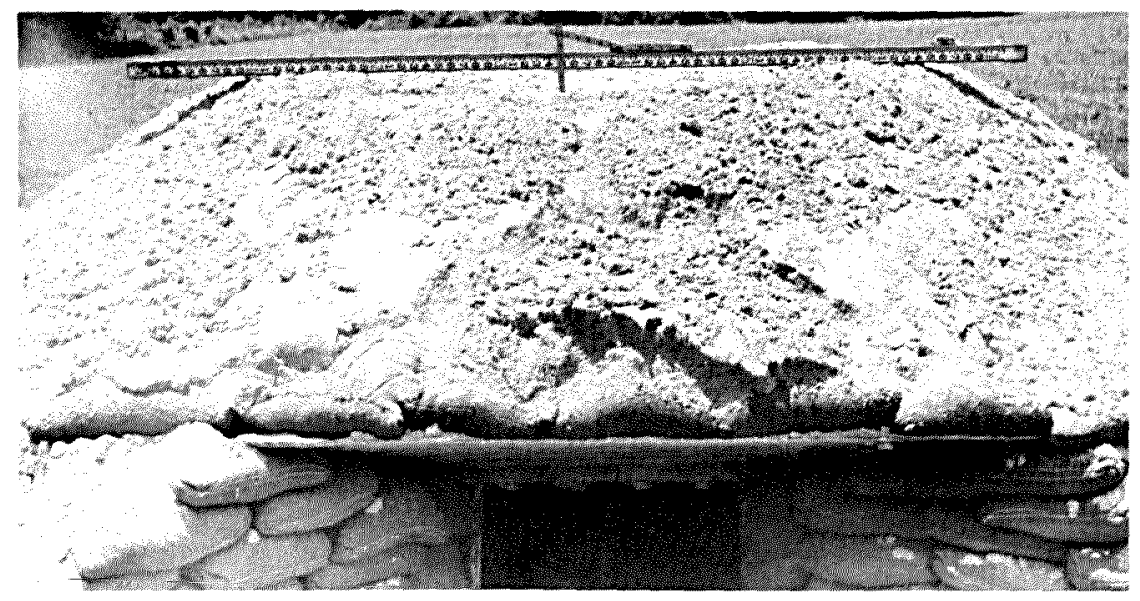

b. Saddle formed between peaks of crater

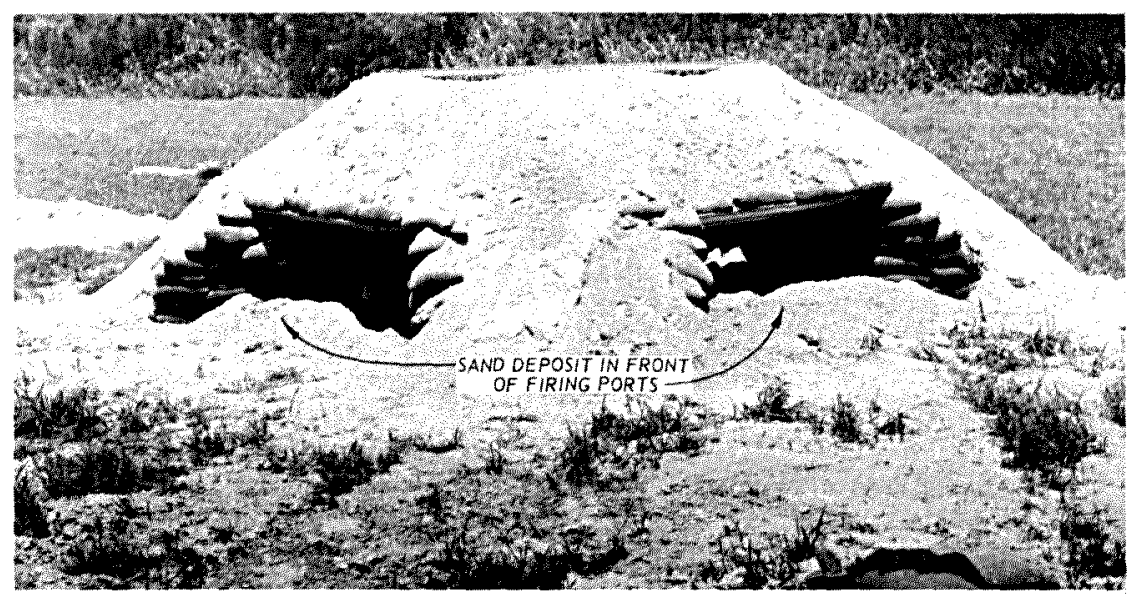

c. Sand deposited in front of two firing ports

Figure 4.4 Damage resulting from Phase I test series, Round I. 


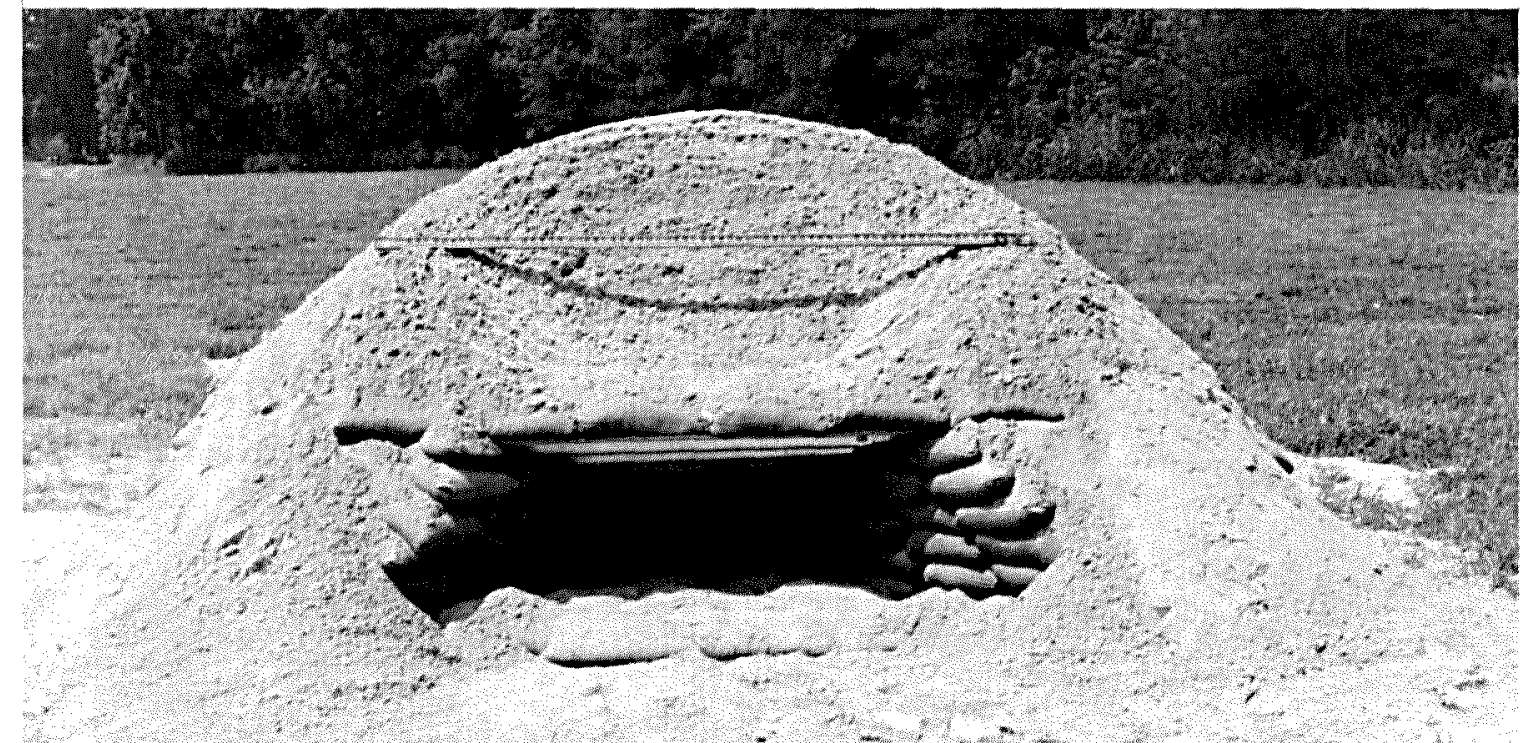

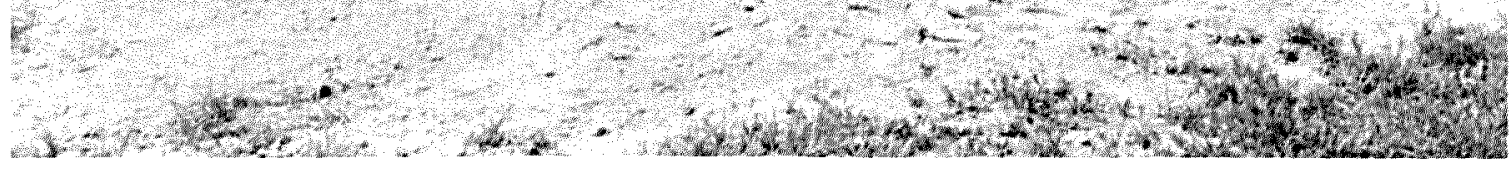
a. Diameter of crater approximately 6 feet

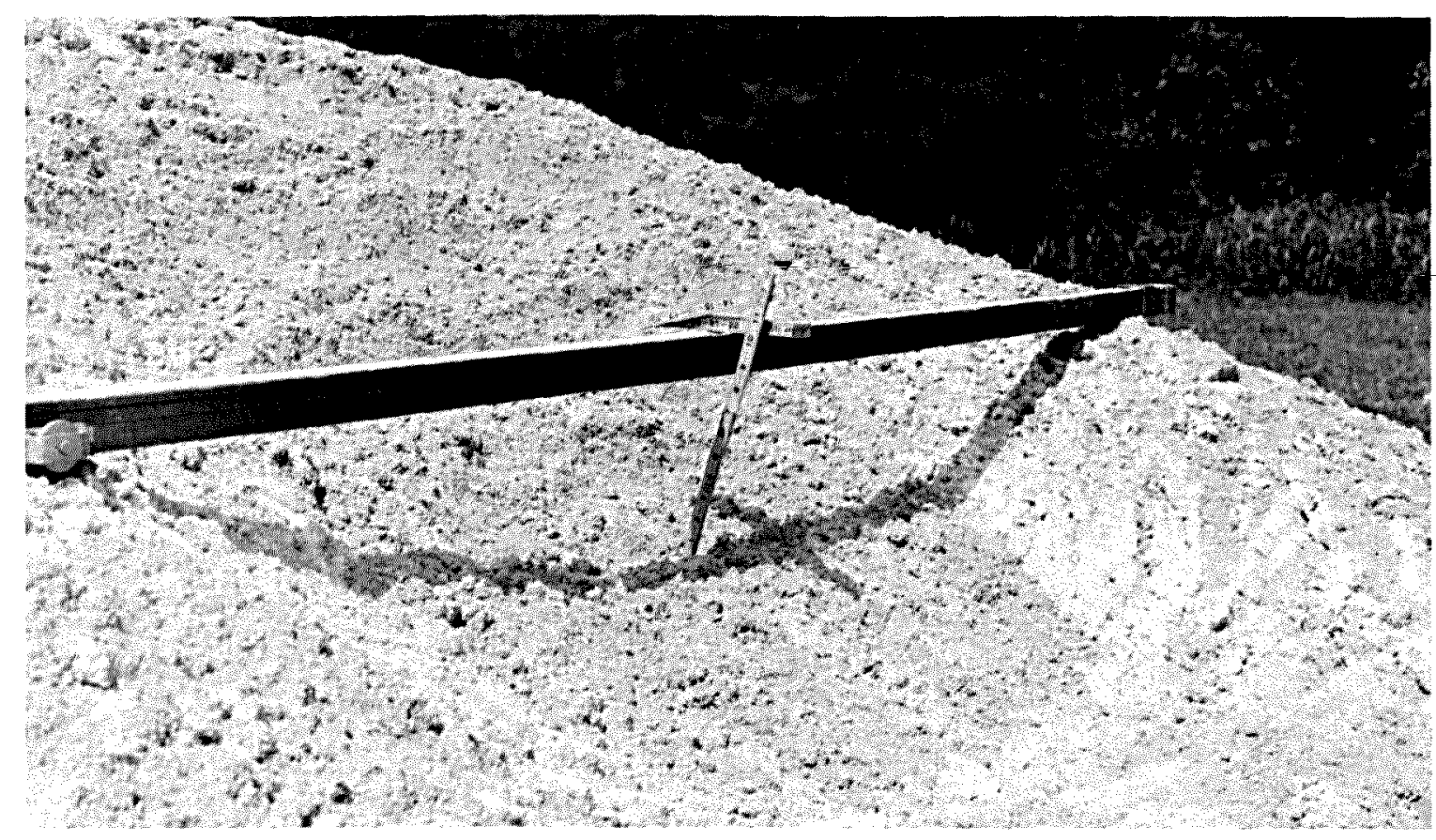

b. Depth of crater approximately $8-1 / 2$ inches

Figure 4.5 Damage resulting from Phase I test series, Round 2 (sheet 1 of 2 ). 


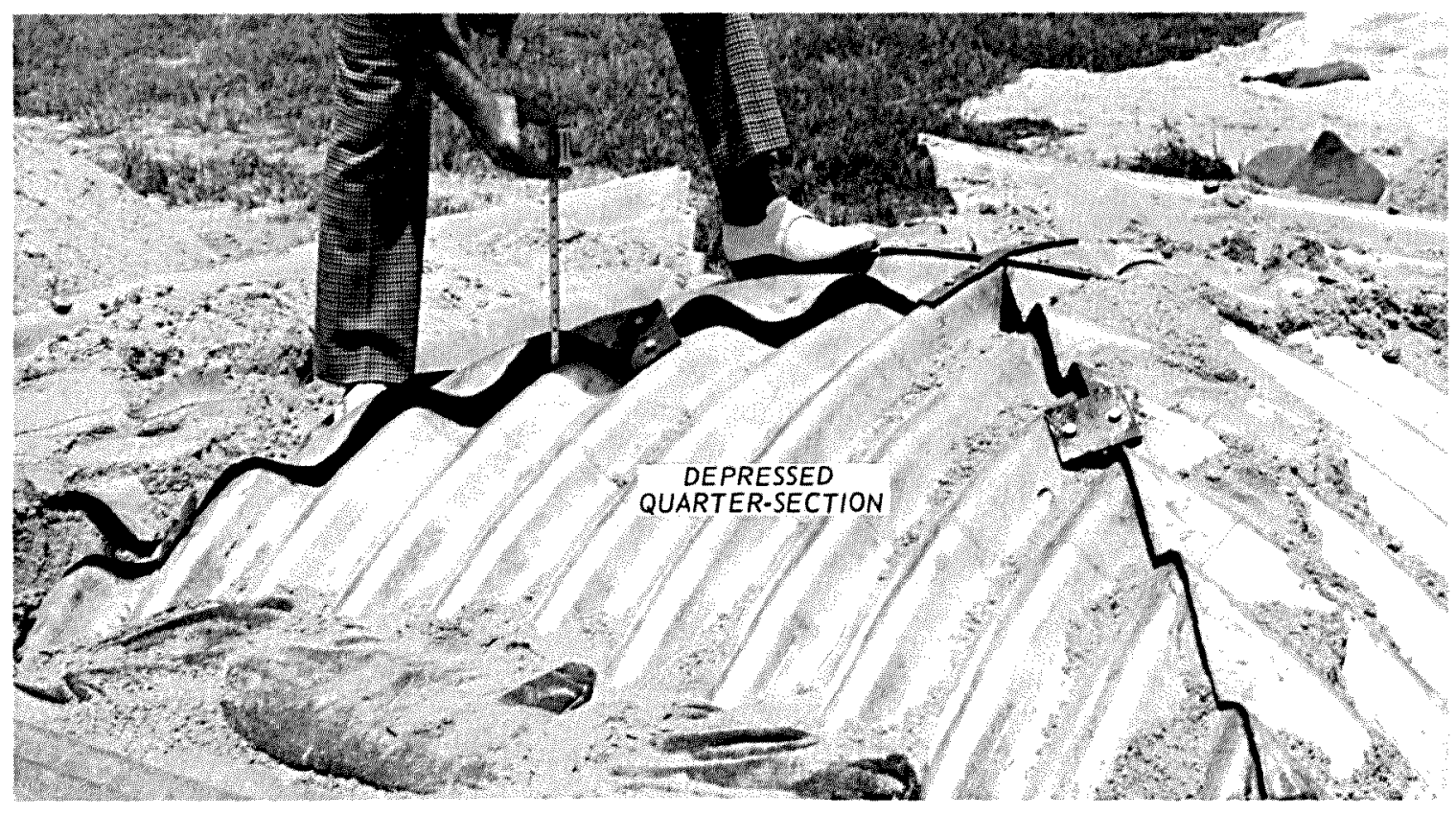

c. Damage to loaded quarter-section of MICS determined after removal of sand cover

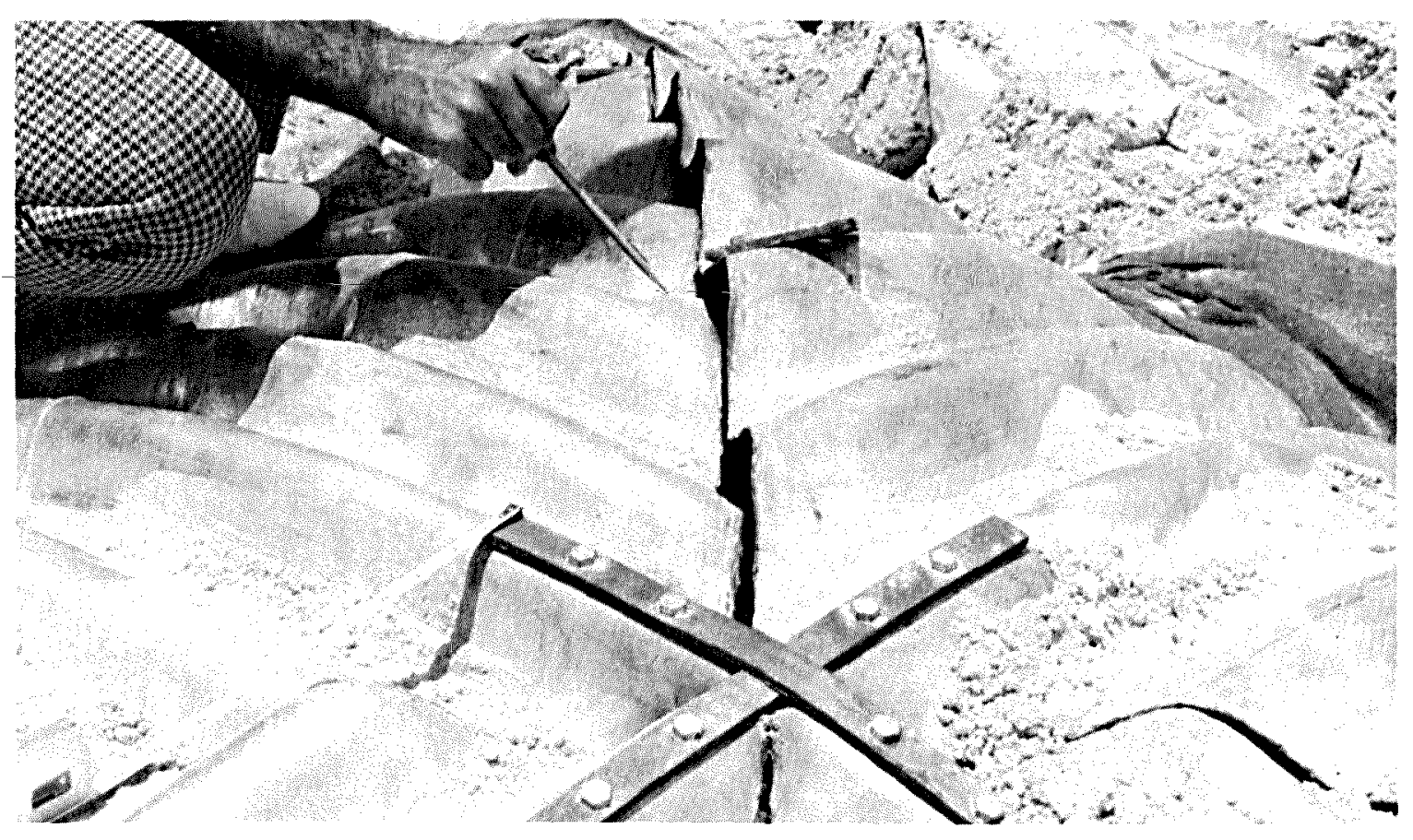

d. Deformed metal around a bolt hole

Figure 4.5 (Sheet 2 of 2 ). 


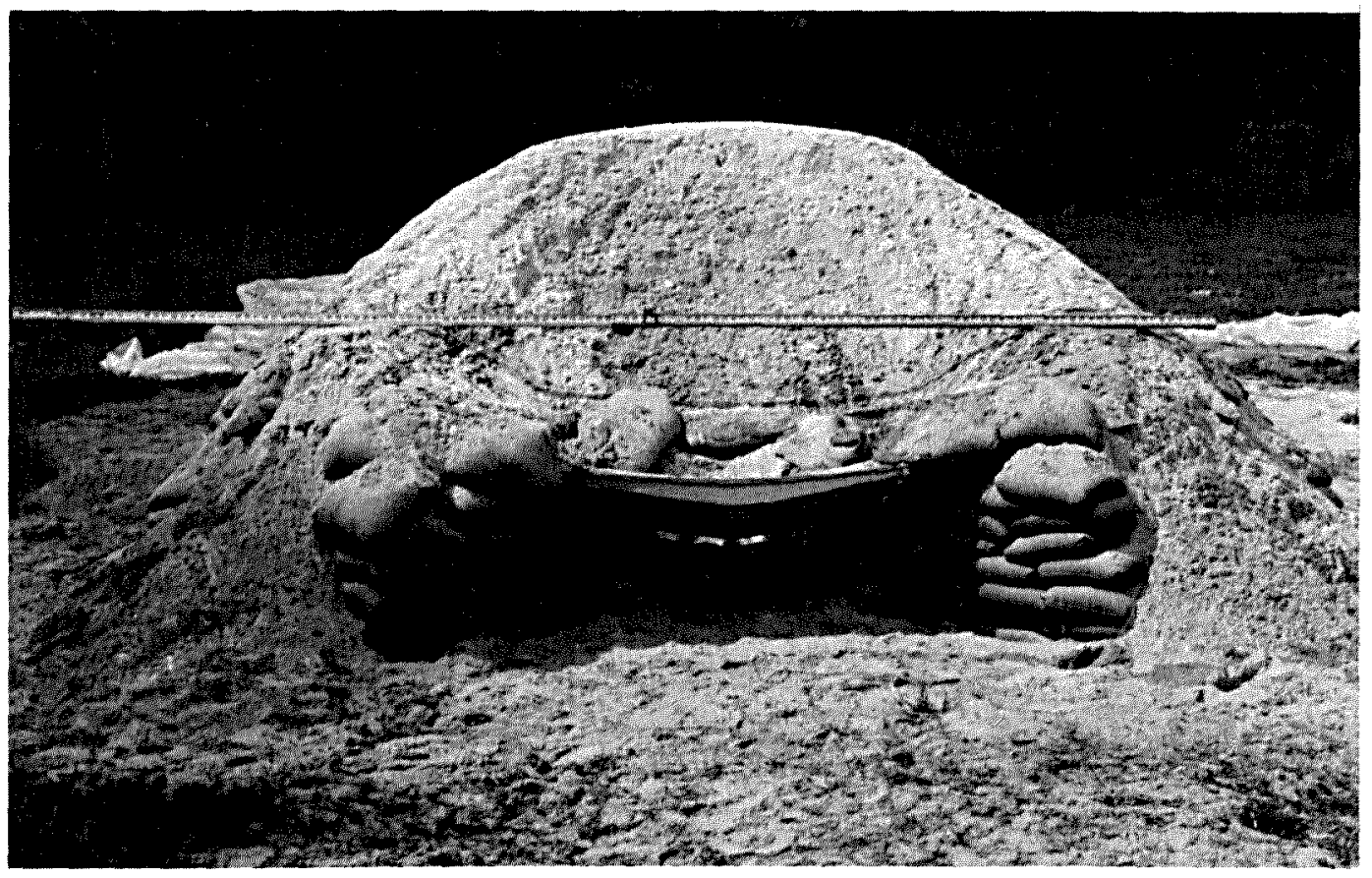

a. Apparent crater approximately 7 feet in diameter



b. Apparent crater depth approximately 9 inches

Figure 4.6 Damage resulting from Phase I test series, Round 3 (sheet 1 of 4 ). 


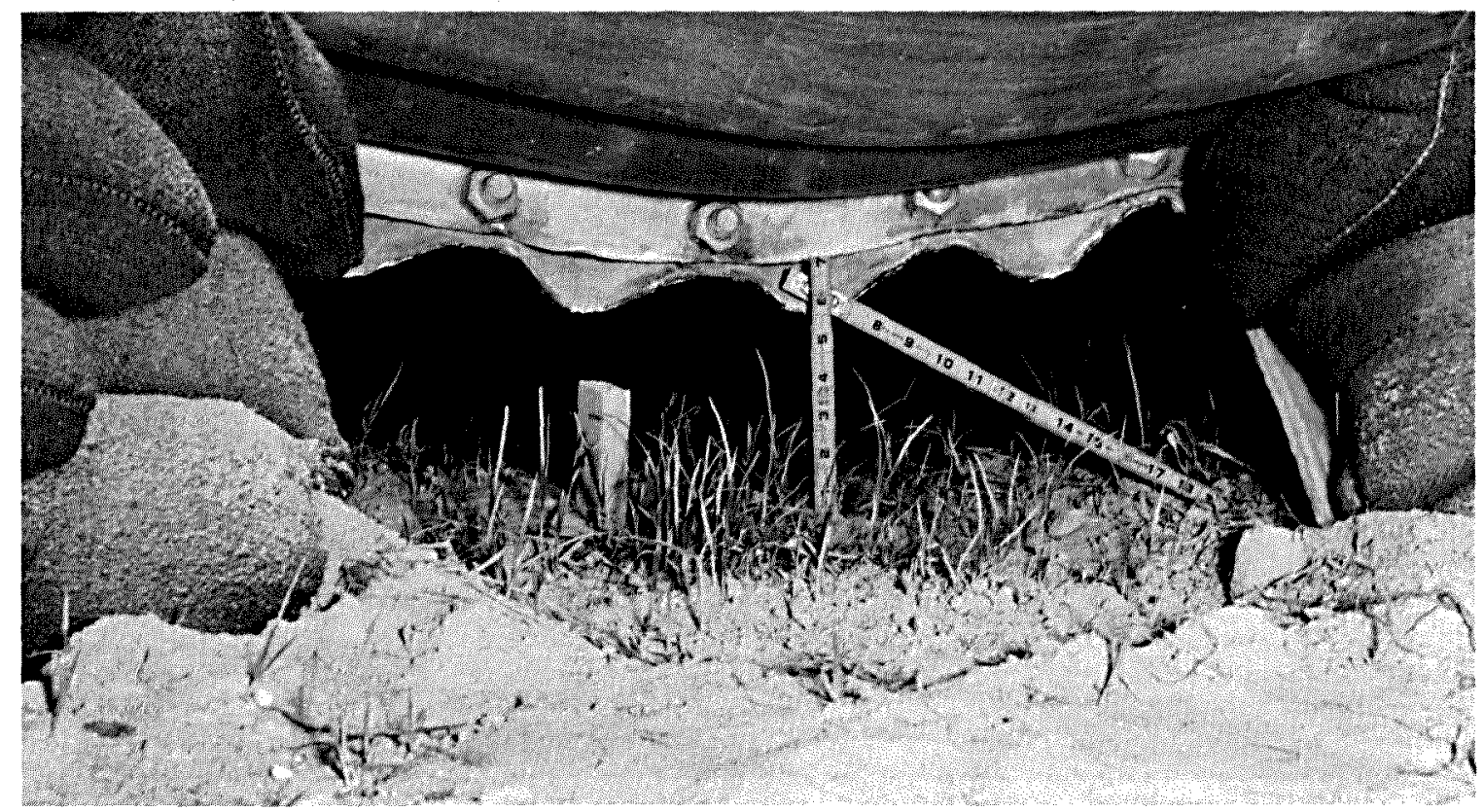

c. Aperture on loaded side of MICS

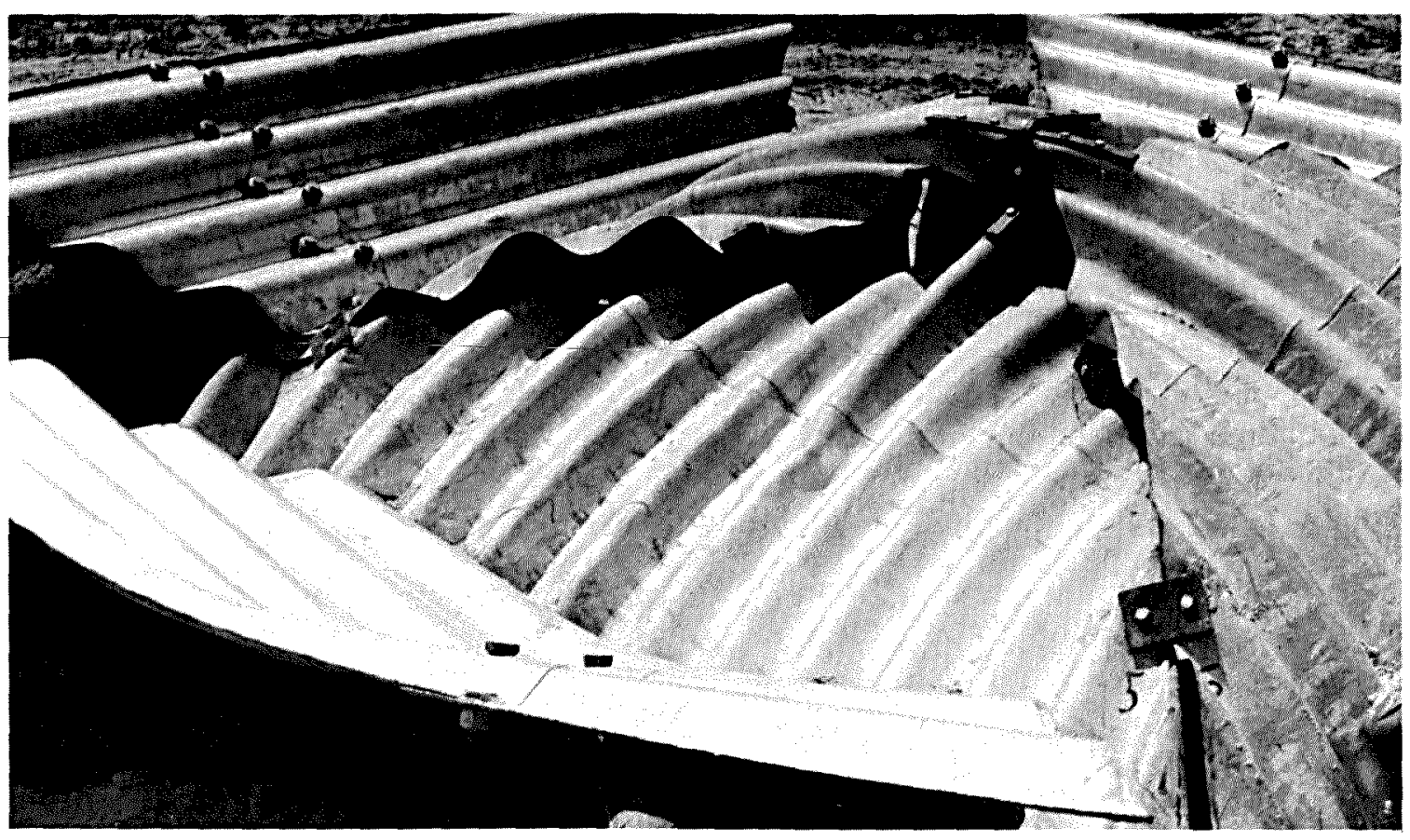

d. Depression of loaded side of MICS

Figure 4.6 (Sheet 2 of 4 ). 


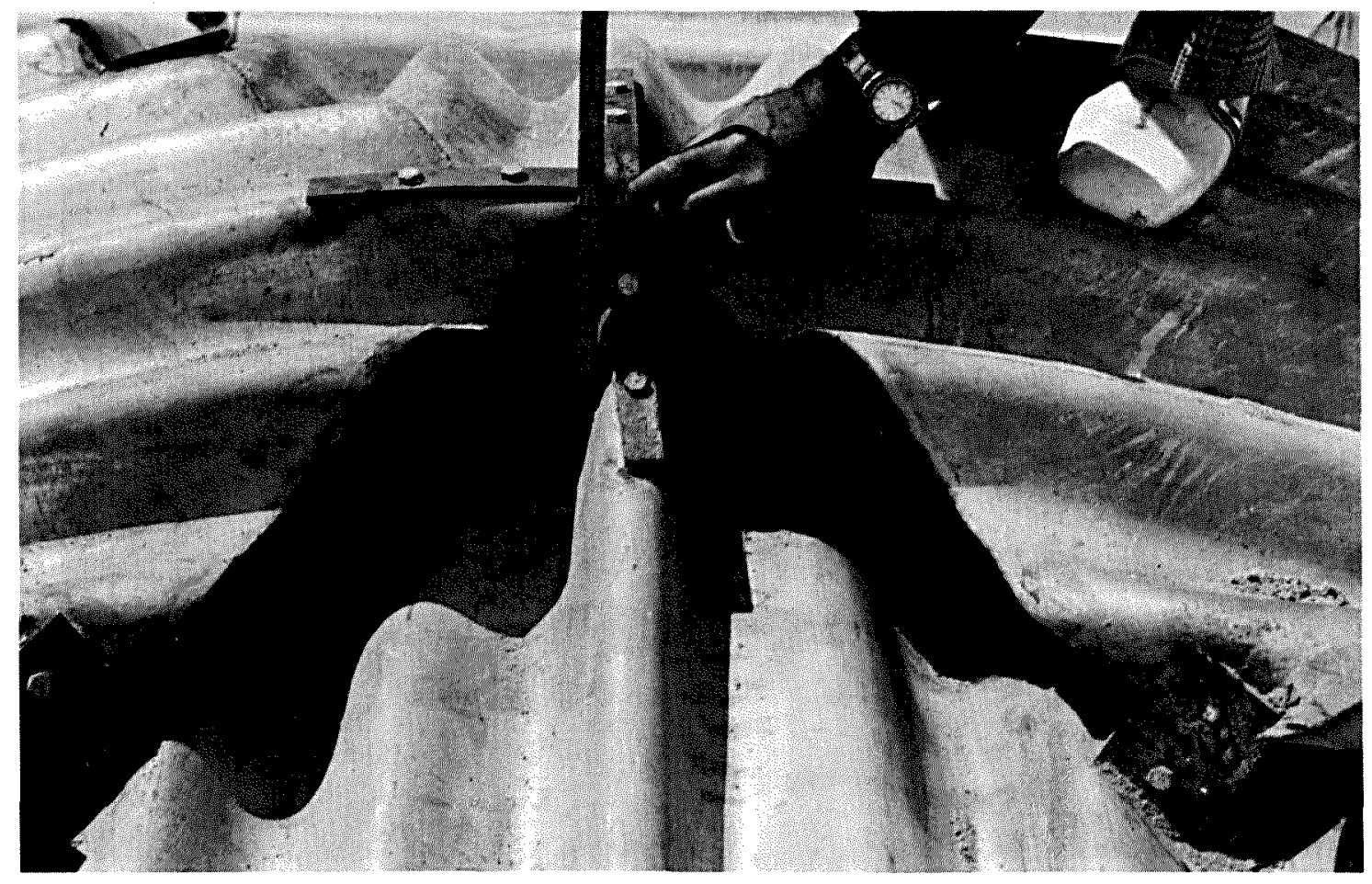

e. Crown of loaded quarter-section

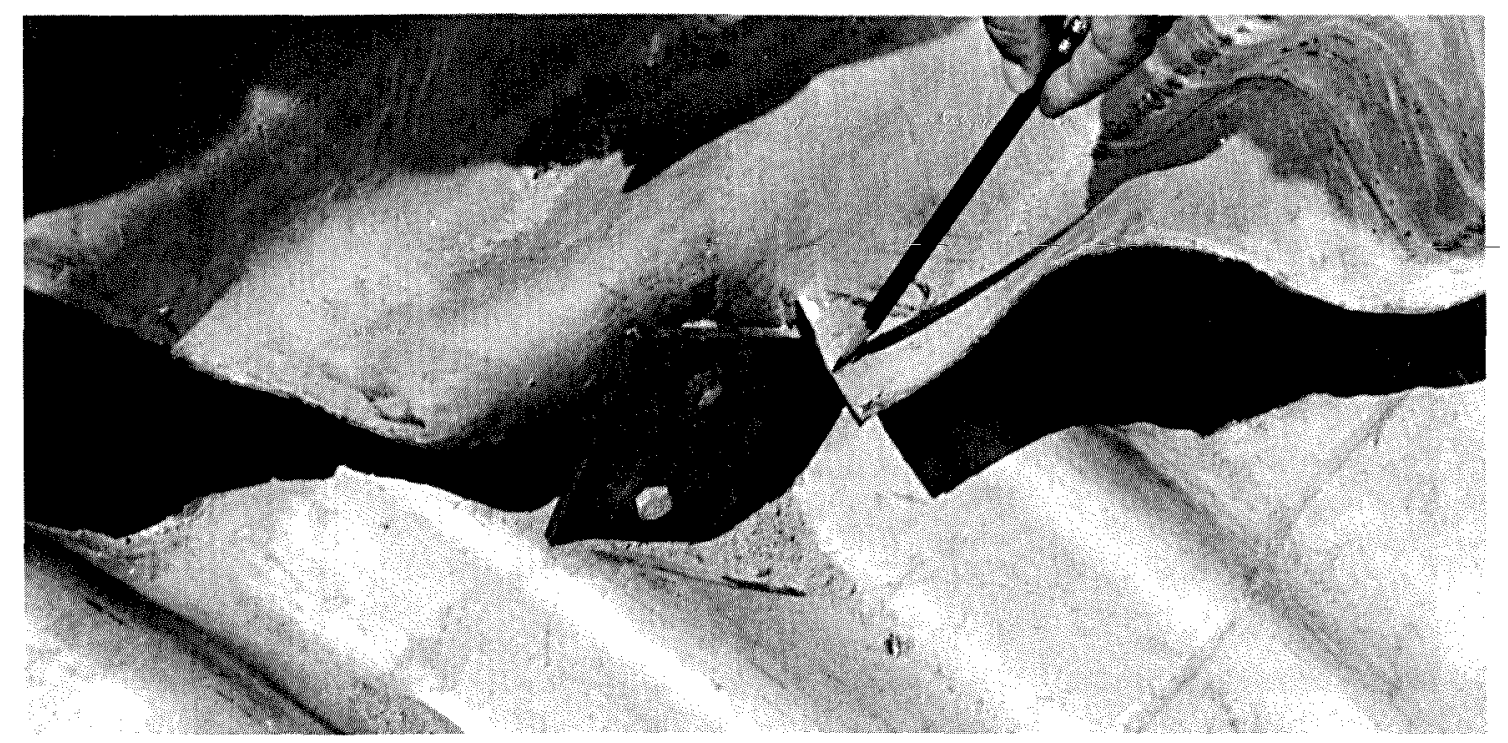

f. Shear failure around one set of connector plates

Figure 4.6 (Sheet 3 of 4 ). 


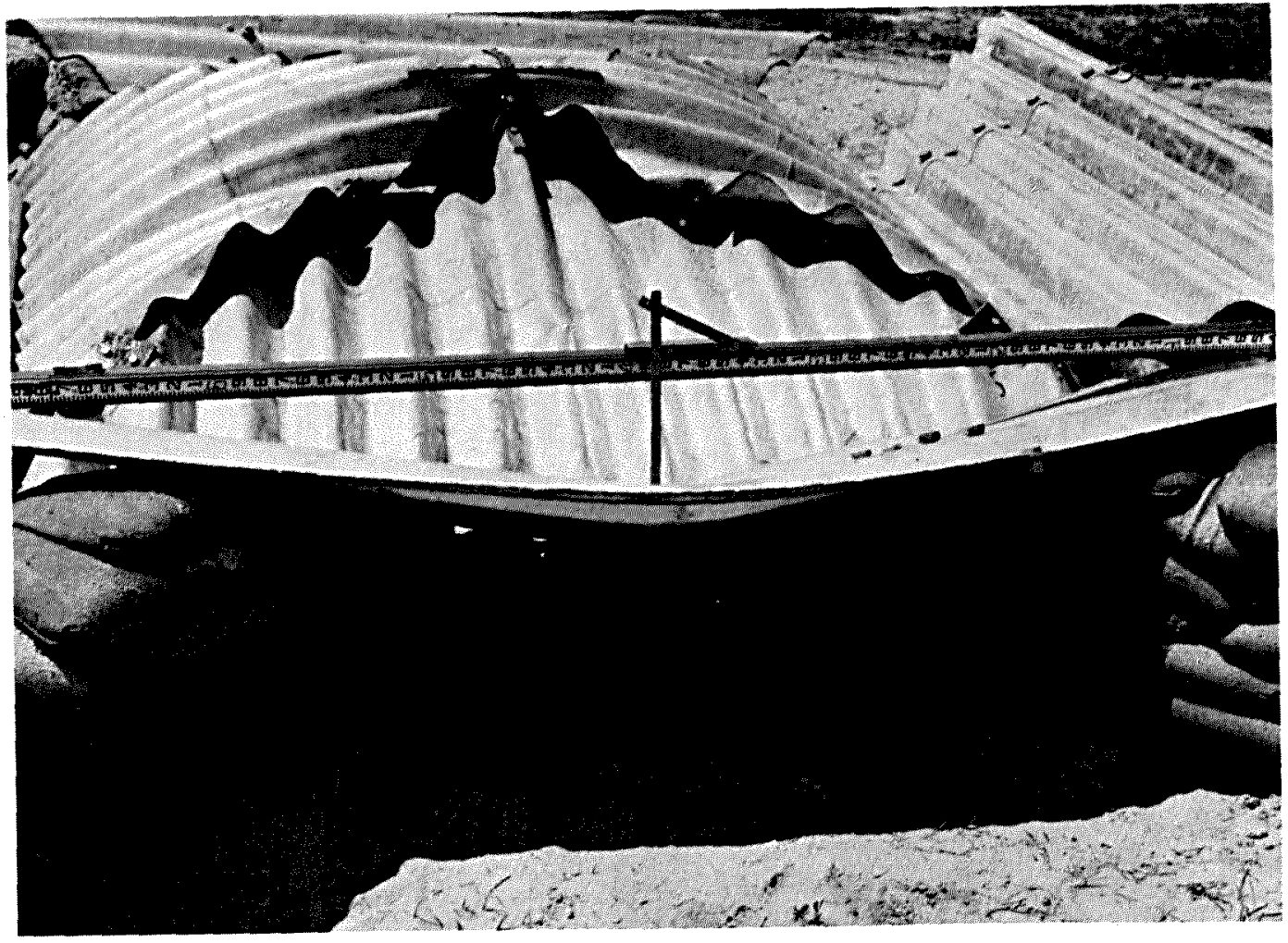

g. Permanent set in aperture beam

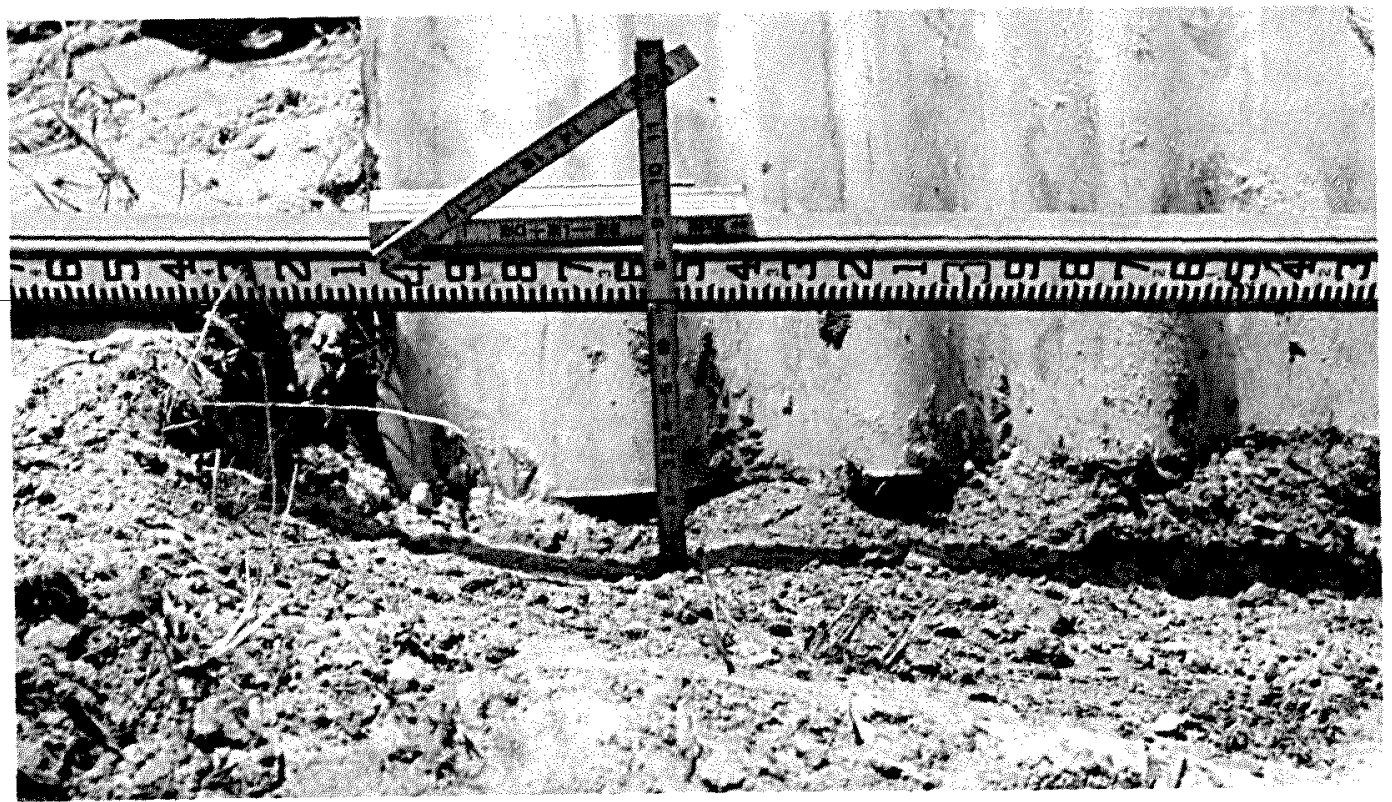

h. Base of loaded quarter-section punched into the ground Figure 4.6 (Sheet 4 of 4 ). 


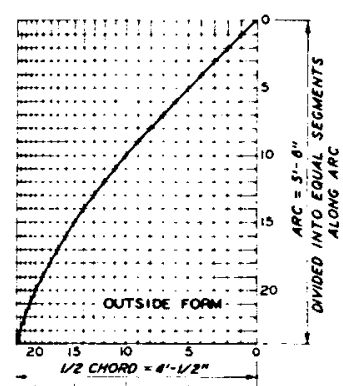

4
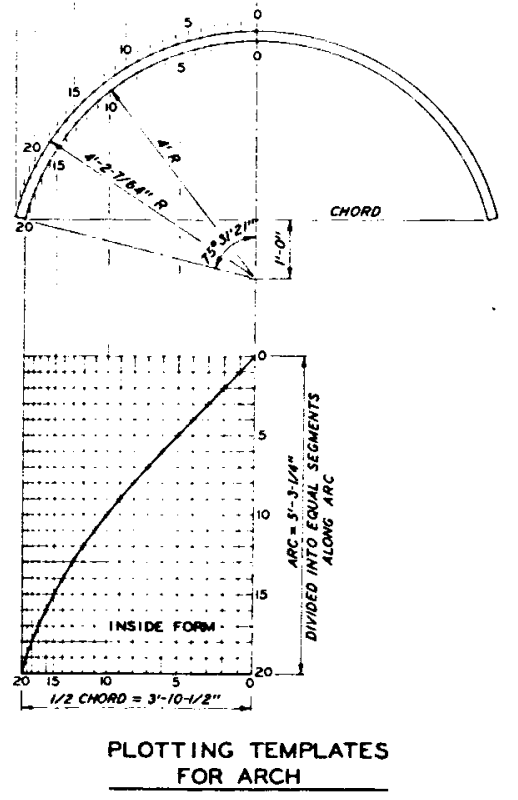

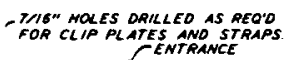
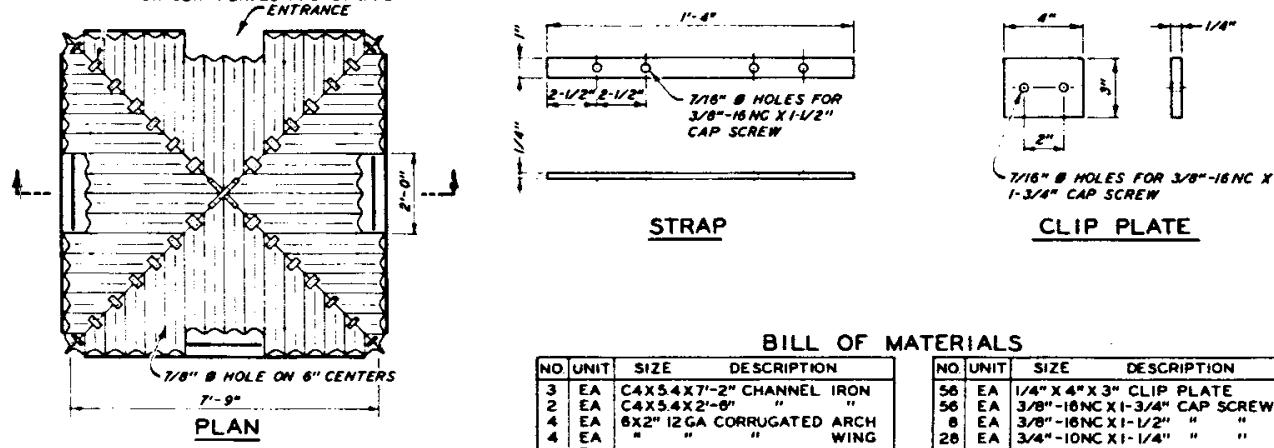

BILL OF MATERIALS
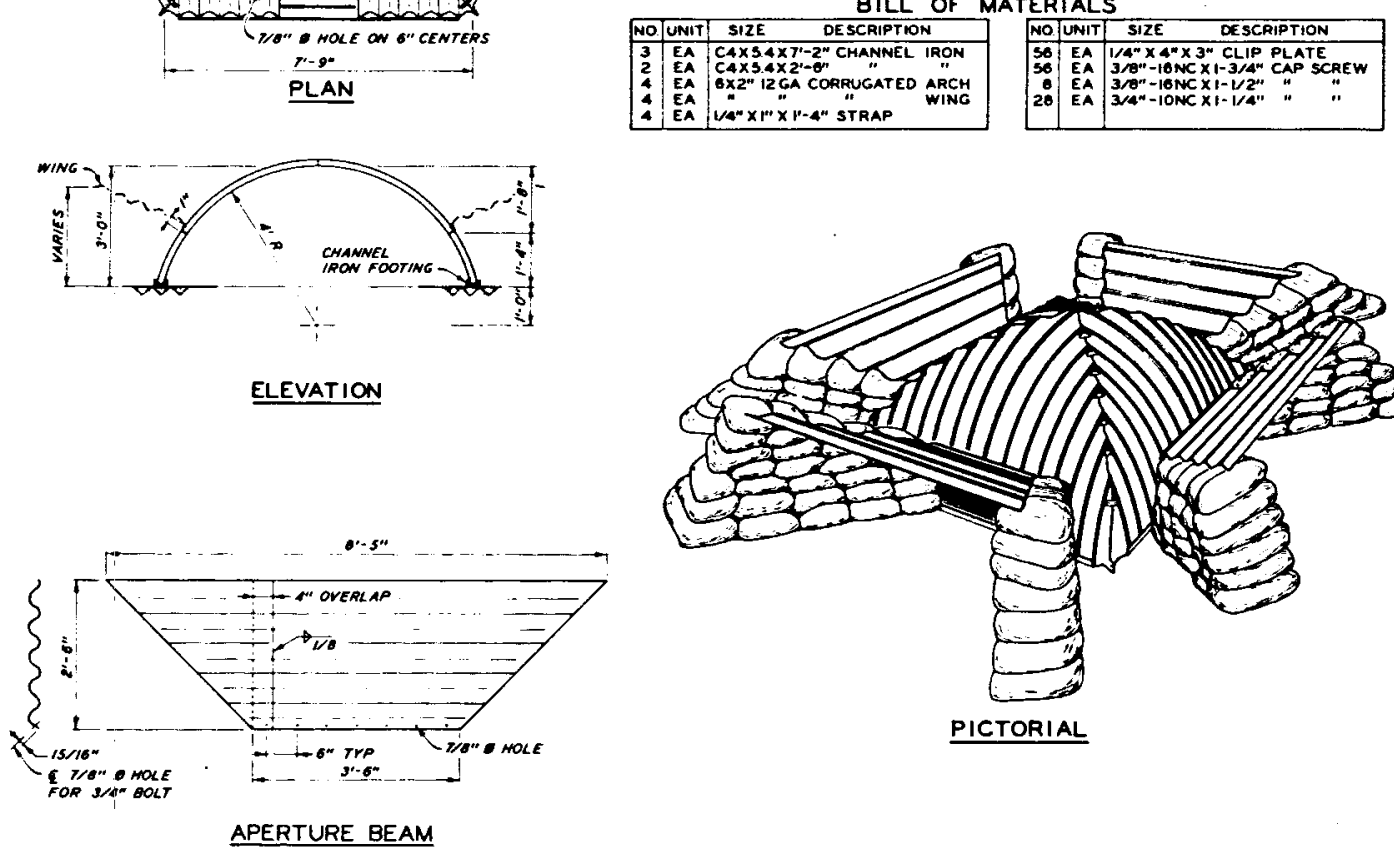

Figure 4.7 Detailed design drawings of Phase II test structure. 


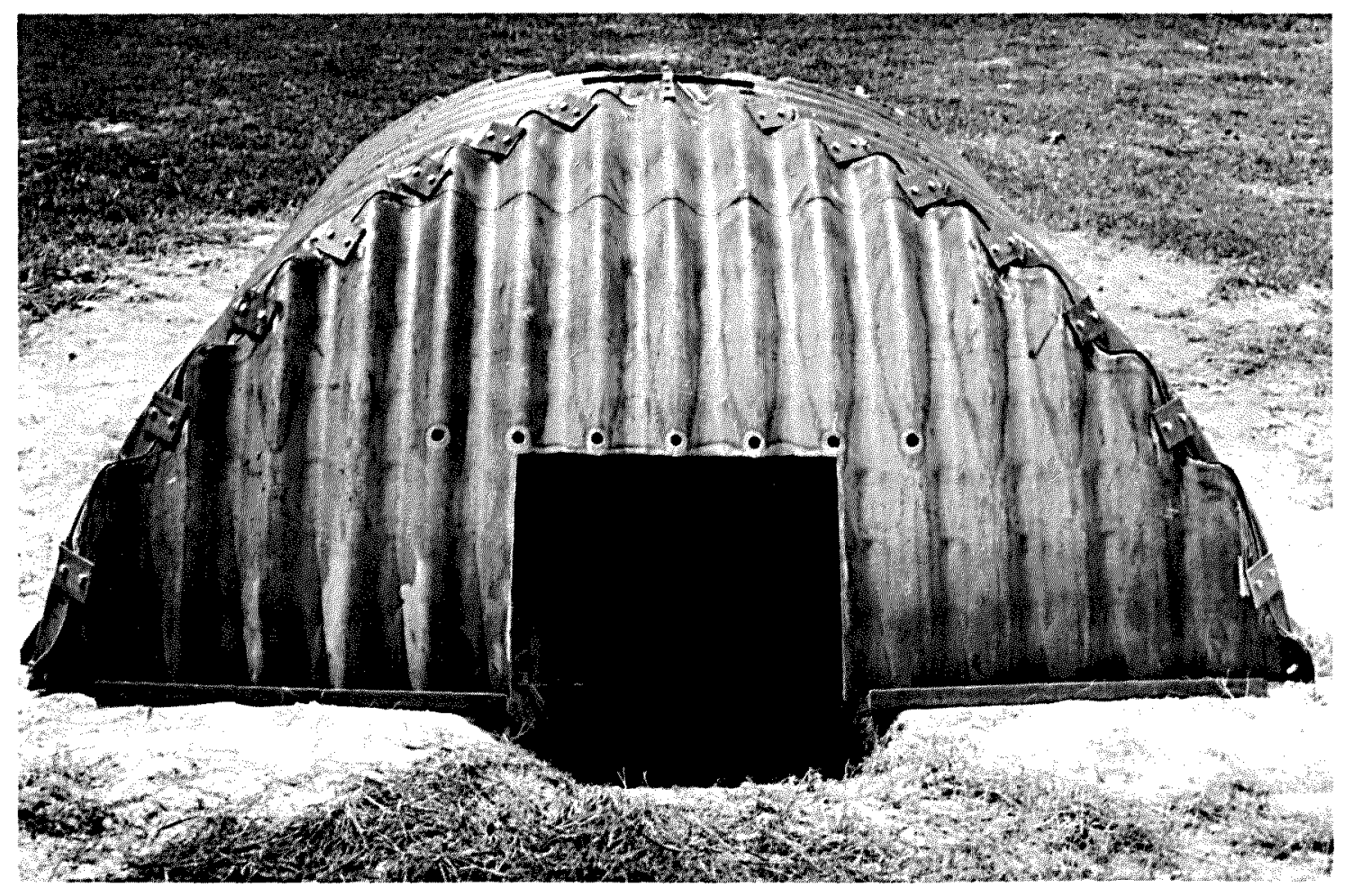

a. MICS

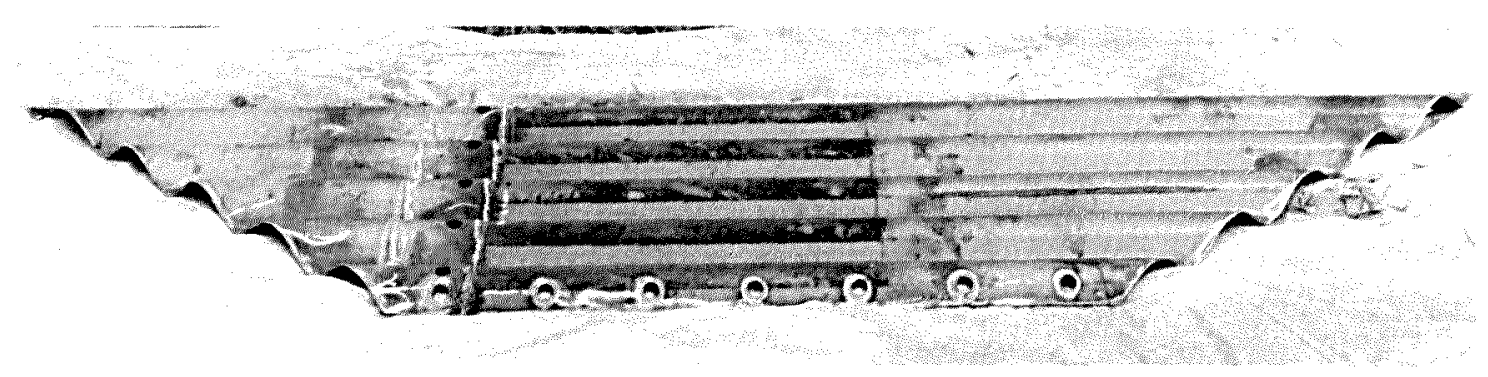

b. Aperture beam

Figure 4.8 MICS and typical aperture beam used in Phase II test series. 

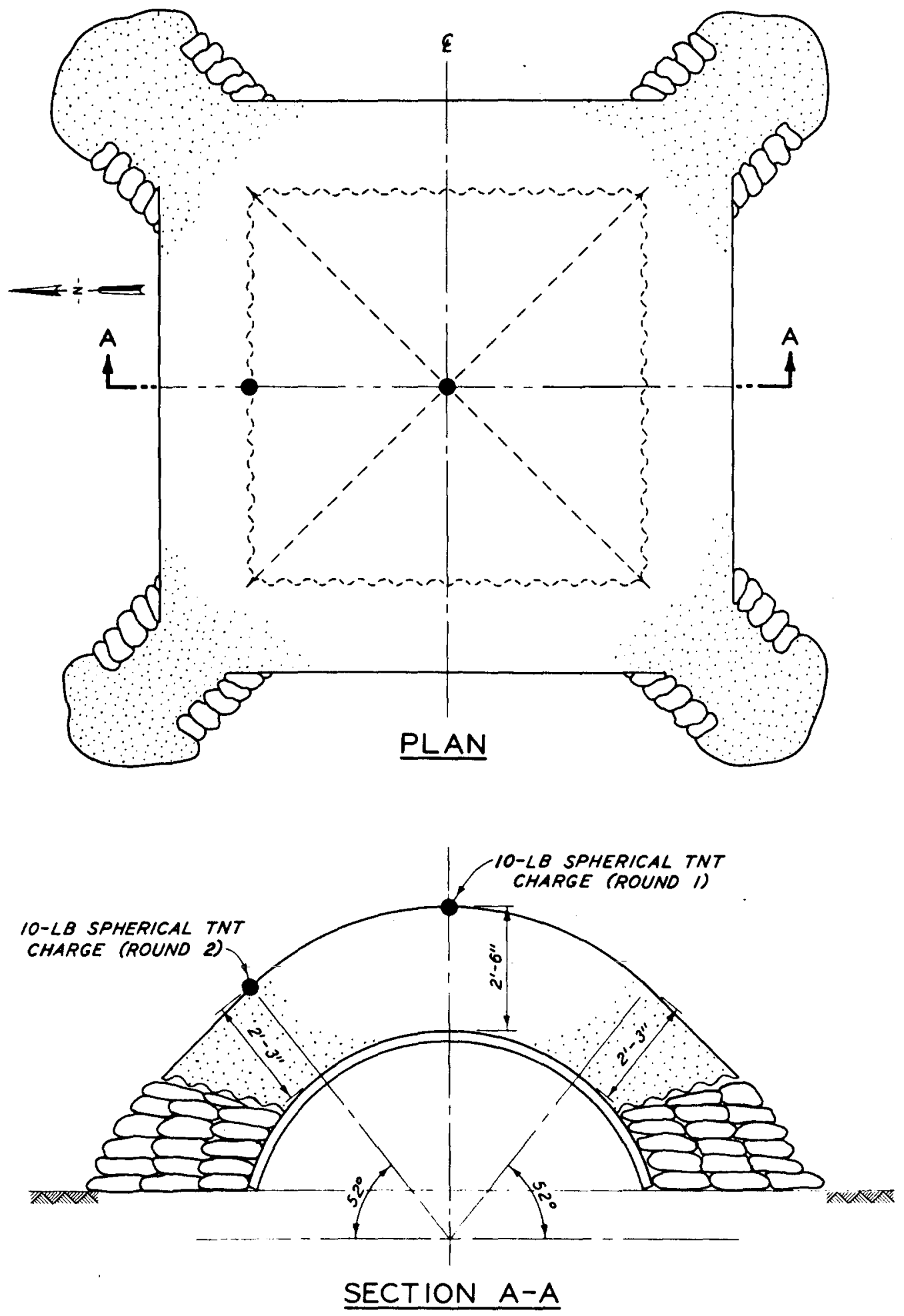

Figure 4.9 Charge sizes and locations of Phase II test series. 


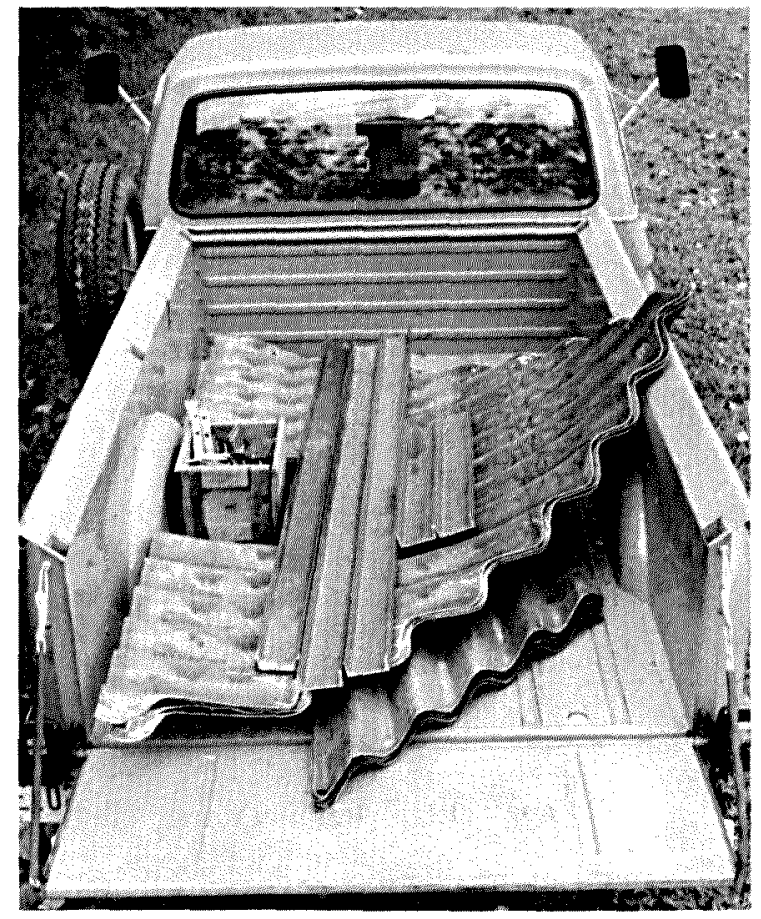

a. Components of test structure in back of pickup truck

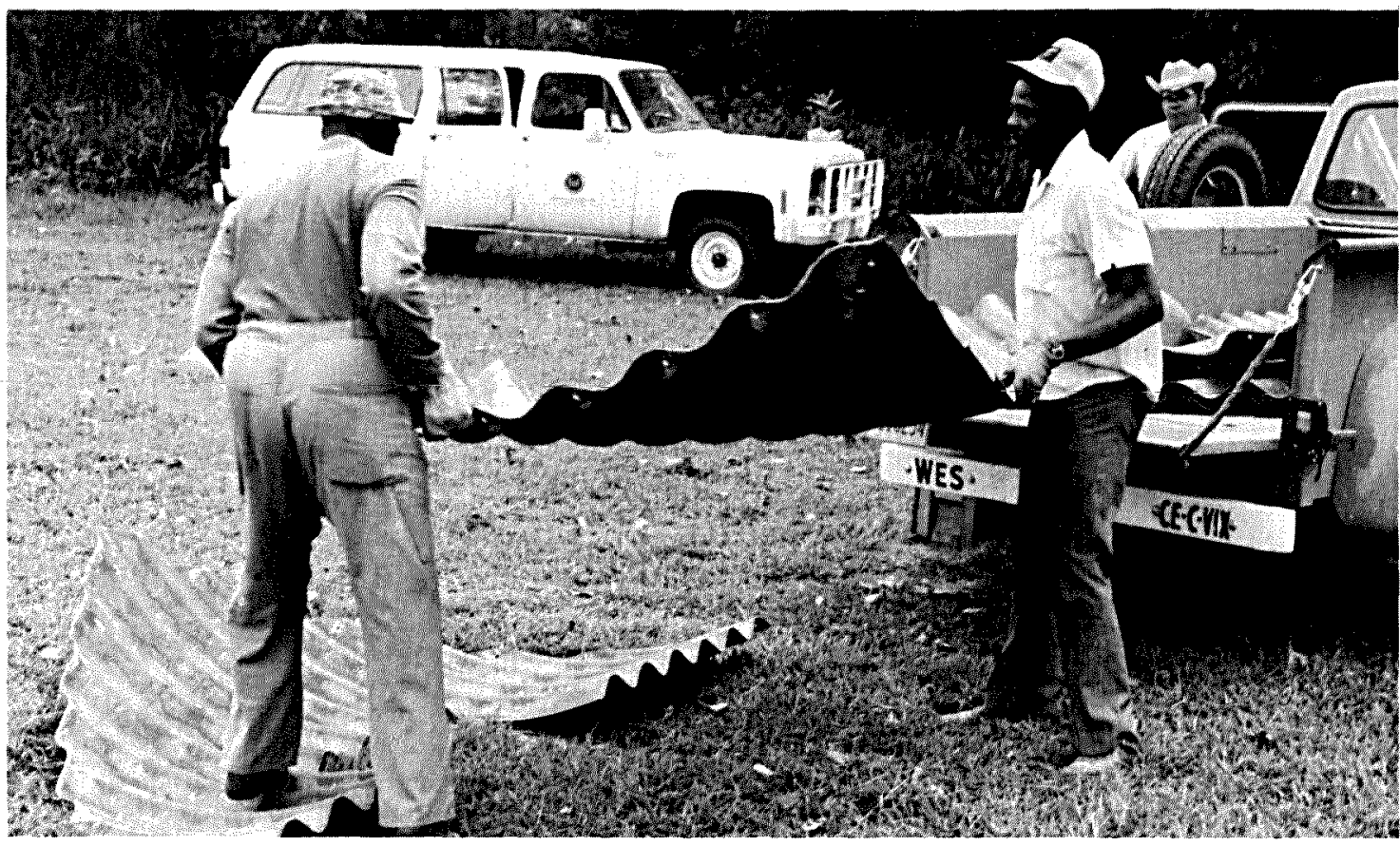

b. Unloading test structure components

Figure 4.10 Various stages of installation of Phase II test structure (sheet 1 of 2 ). 


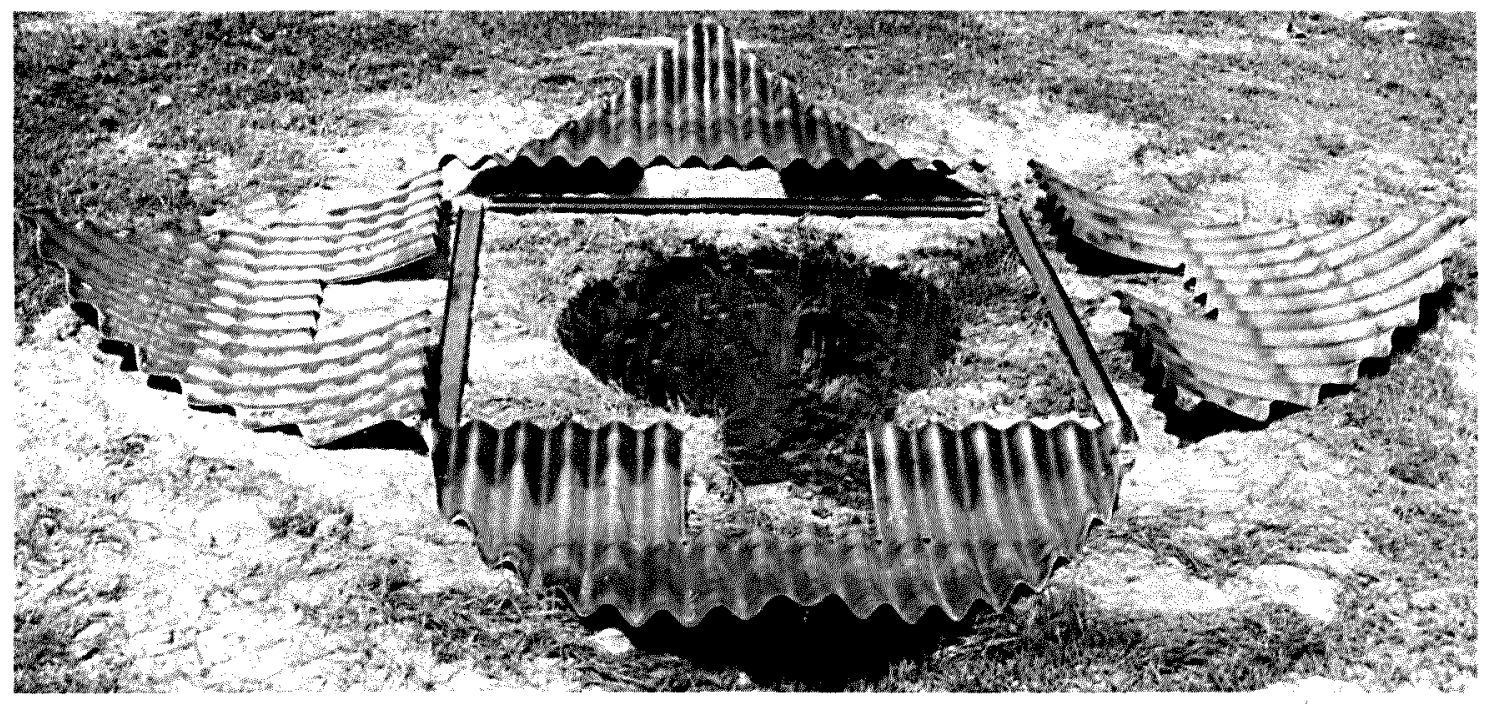

c. Footings and quarter-sections of MICS placed around perimeter of fighting hole

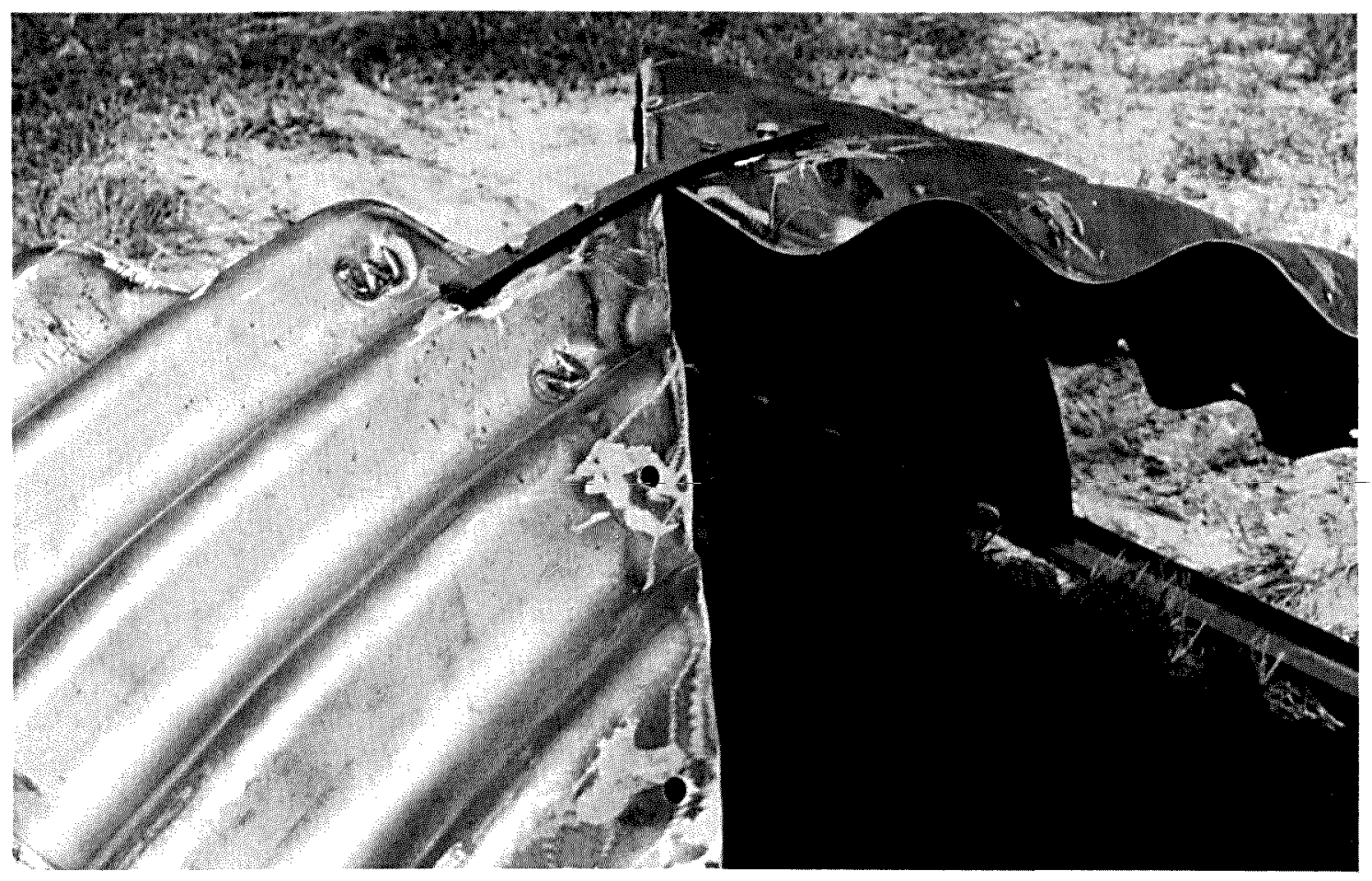

d. Two quarter-sections of MICS attached at crown

Figure 4.10 (Sheet 2 of 2 ). 


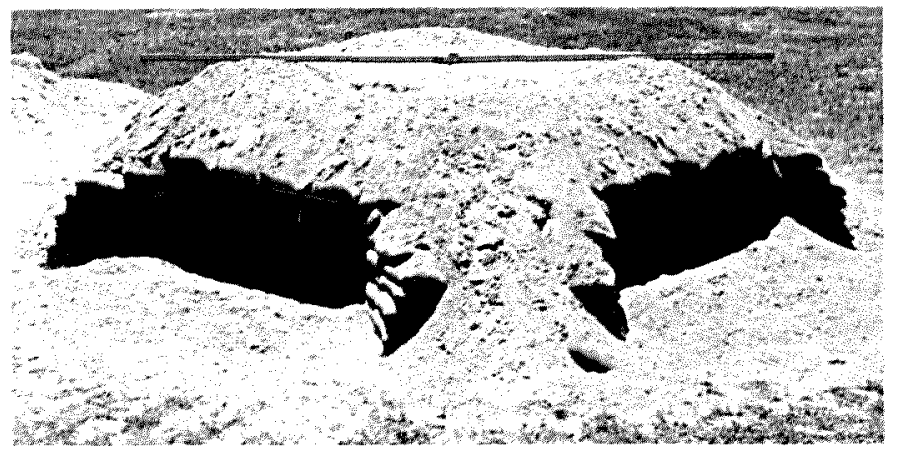

a. Crater formed by detonation of 10-pound charge above MICS crown

b. Saddle formed between peaks of crater. Note sand deposited in front of firing port
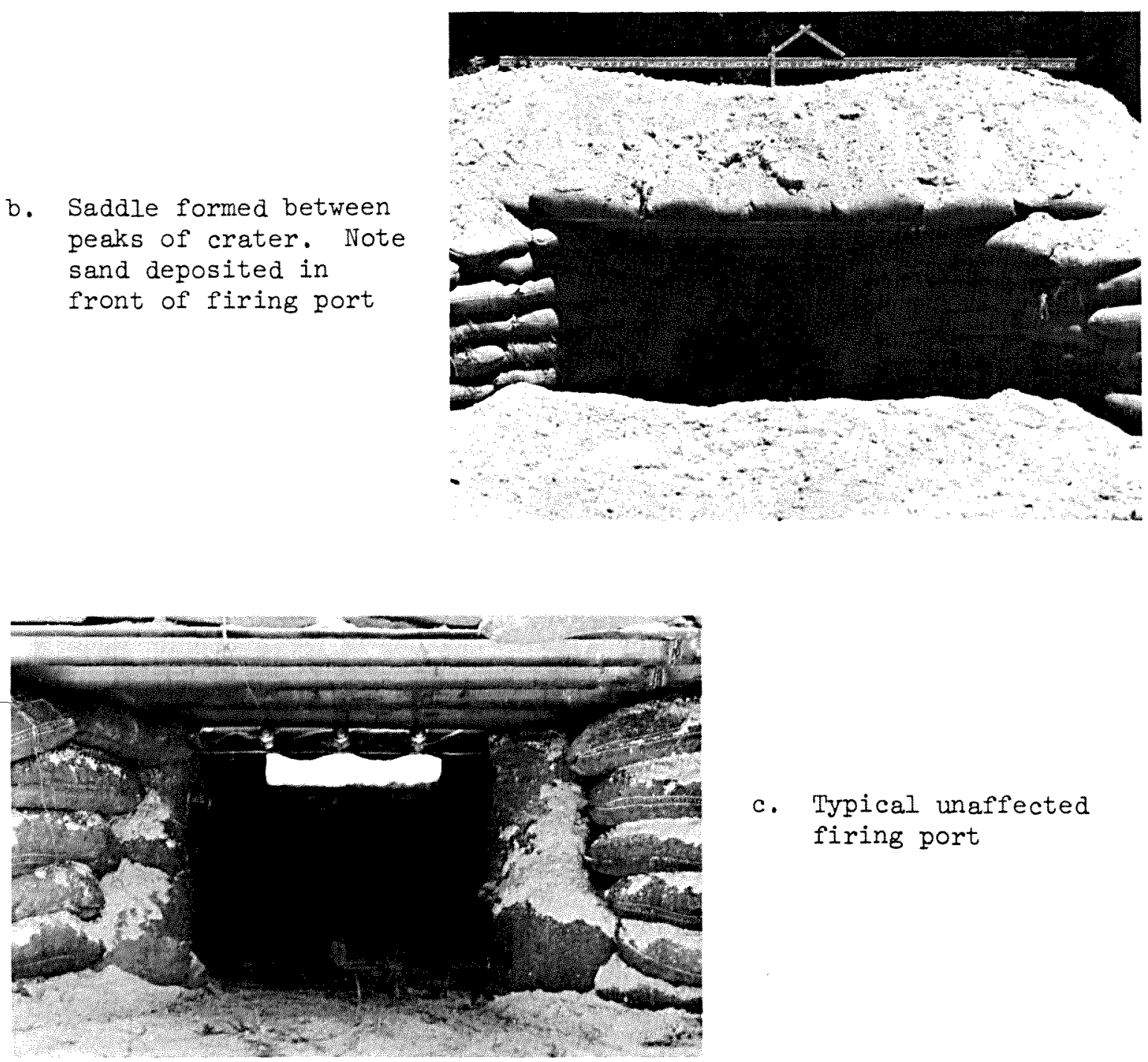

c. Typical unaffected firing port

Figure 4.11 Damage resulting from Phase II test series, Round 1 . 


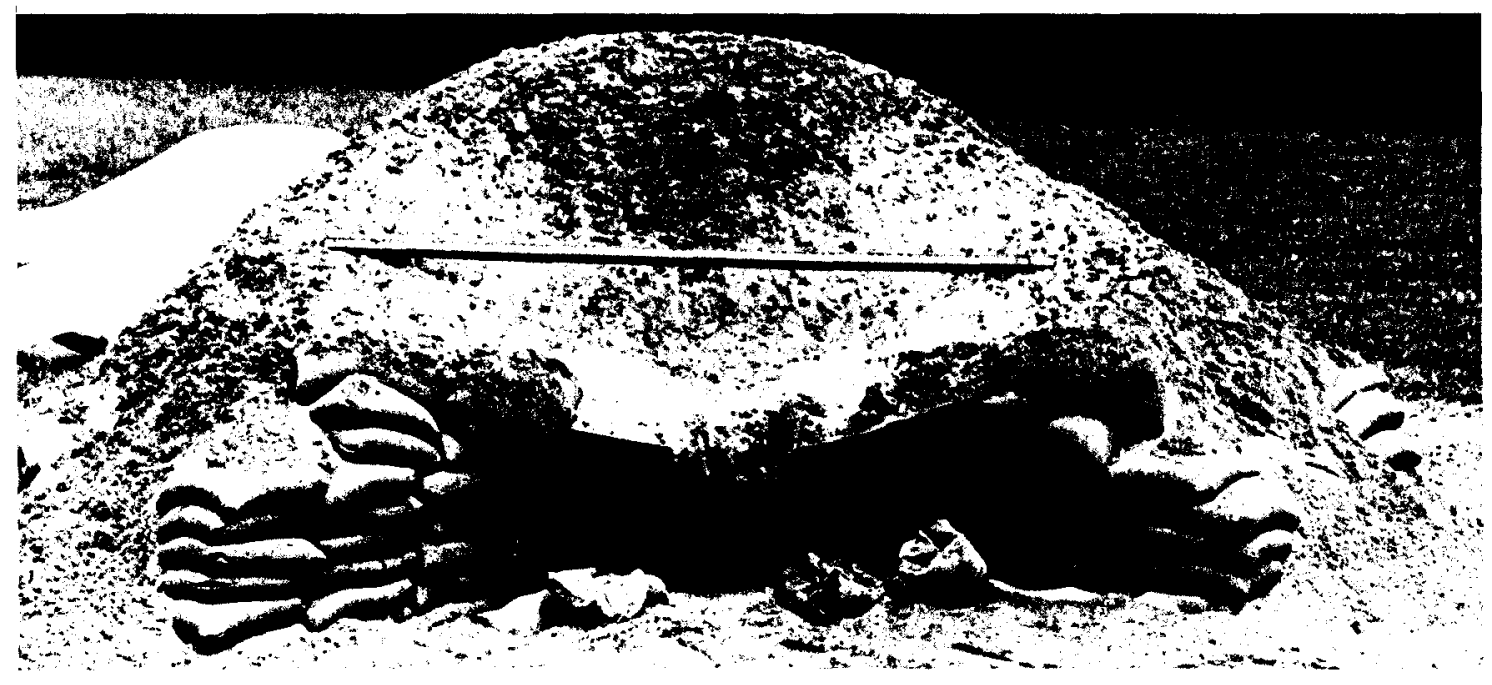

a. Apparent crater diameter was 7 feet

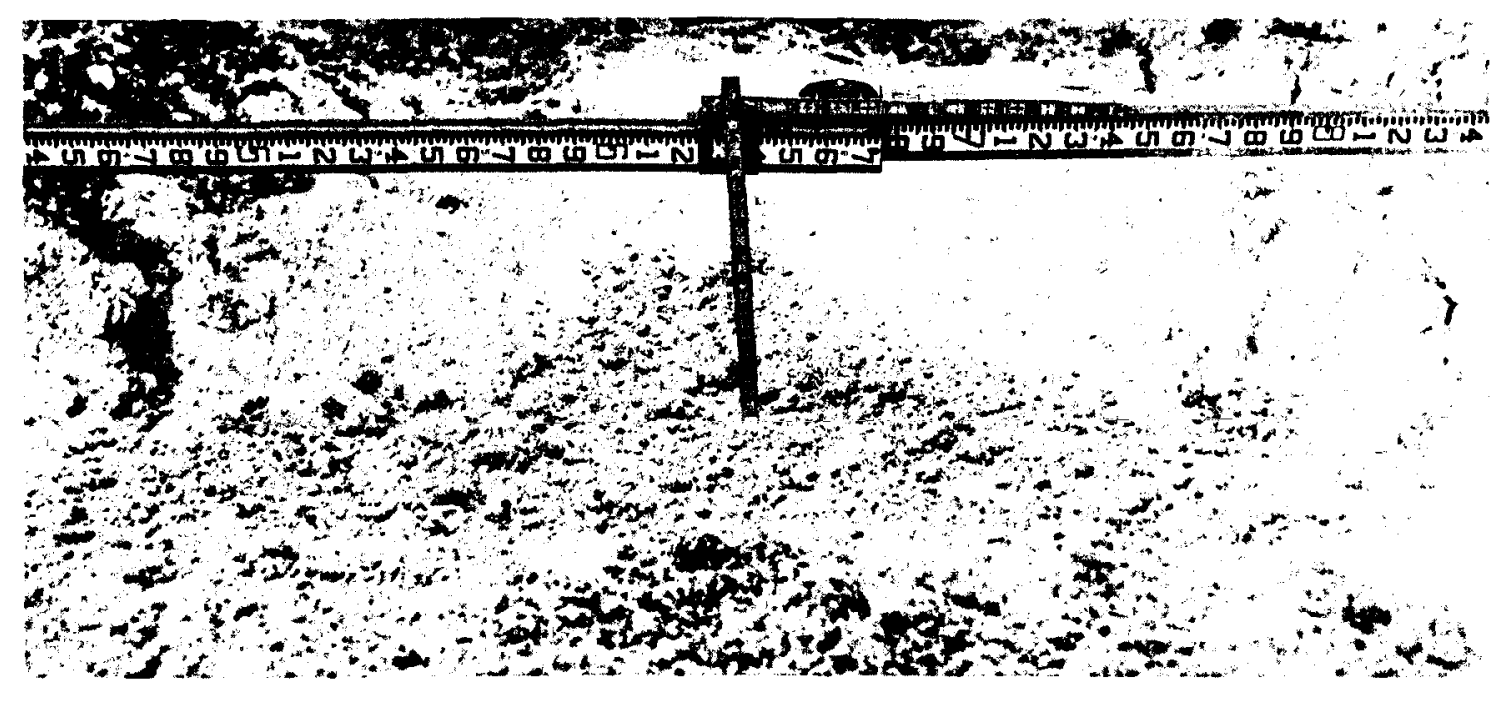

b. Apparent crater depth was $9-1 / 2$ inches

Figure 4.12 Damage resulting from Phase II test series, Round 2 (sheet 1 of 2 ). 


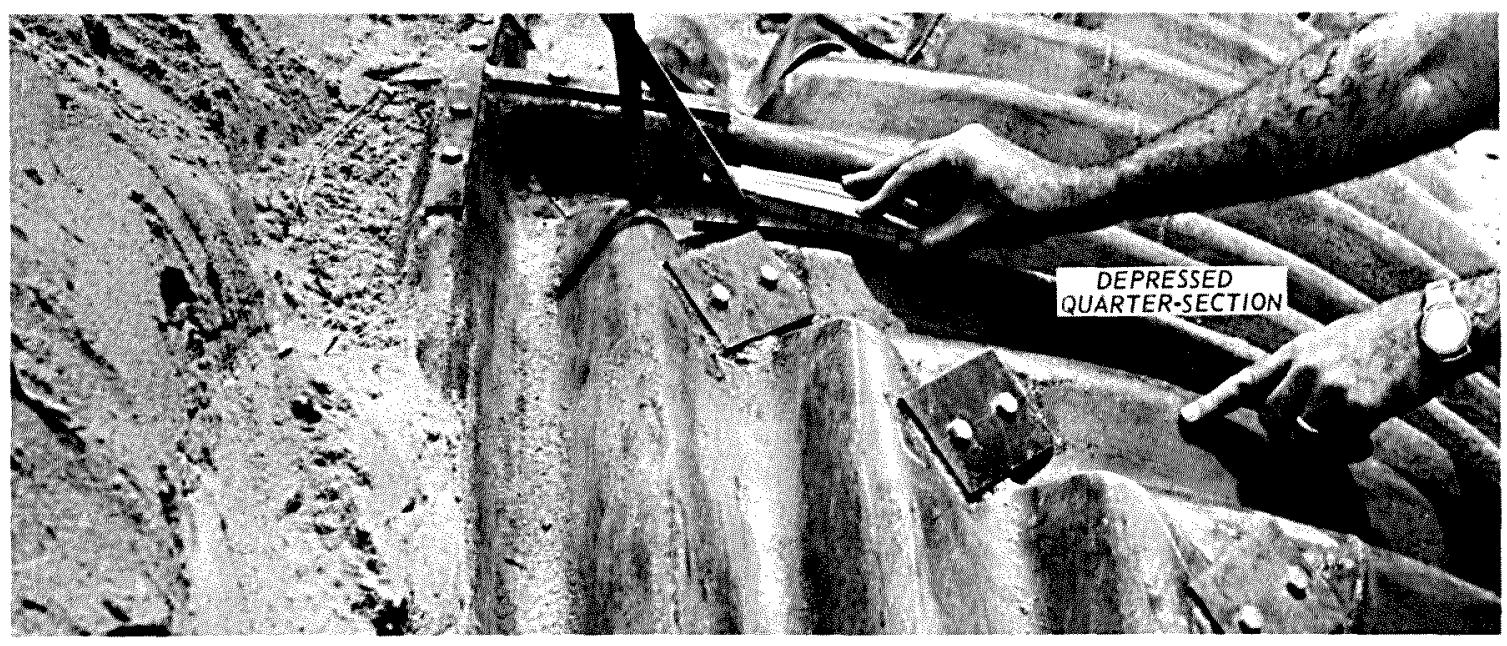

c. Depression of loaded quarter-section of MICS

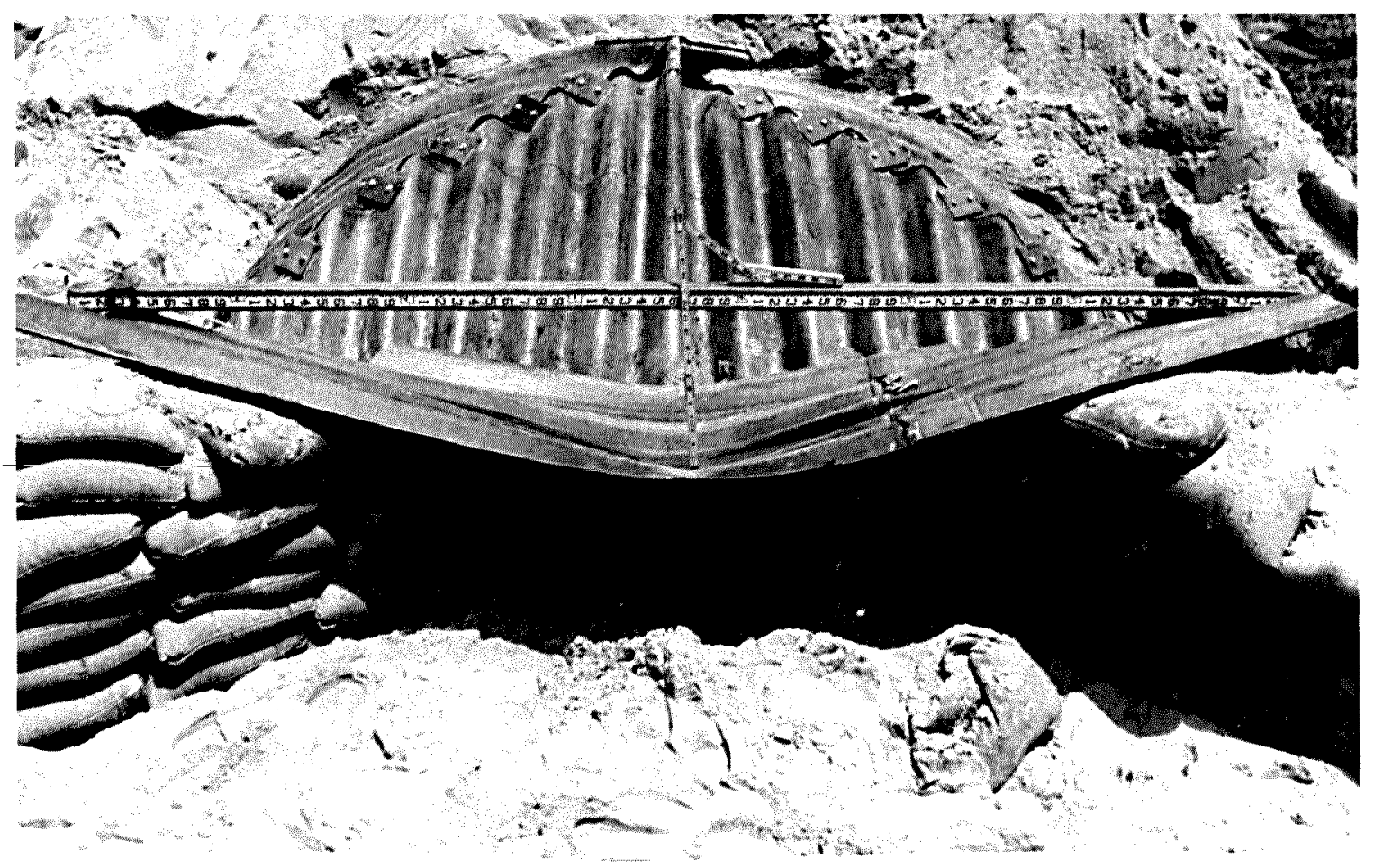

d. Permanent set of aperture beam

Figure 4.12 (Sheet 2 of 2 ). 
BILL OF MATERIALS
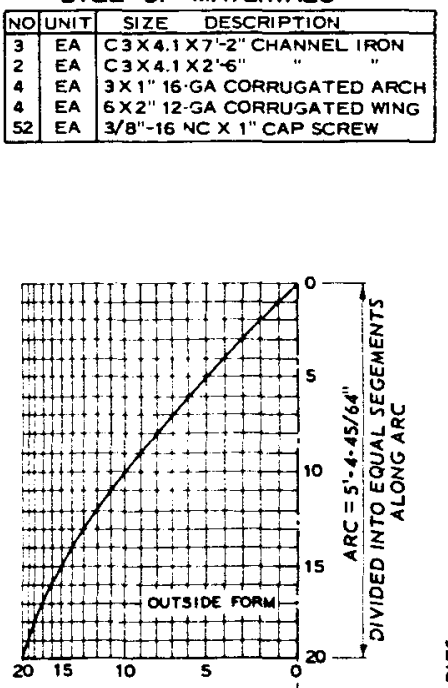

$1 / 2$ CHORD $=3^{\prime} \cdot 11 \cdot 1 / 2^{\prime \prime}$
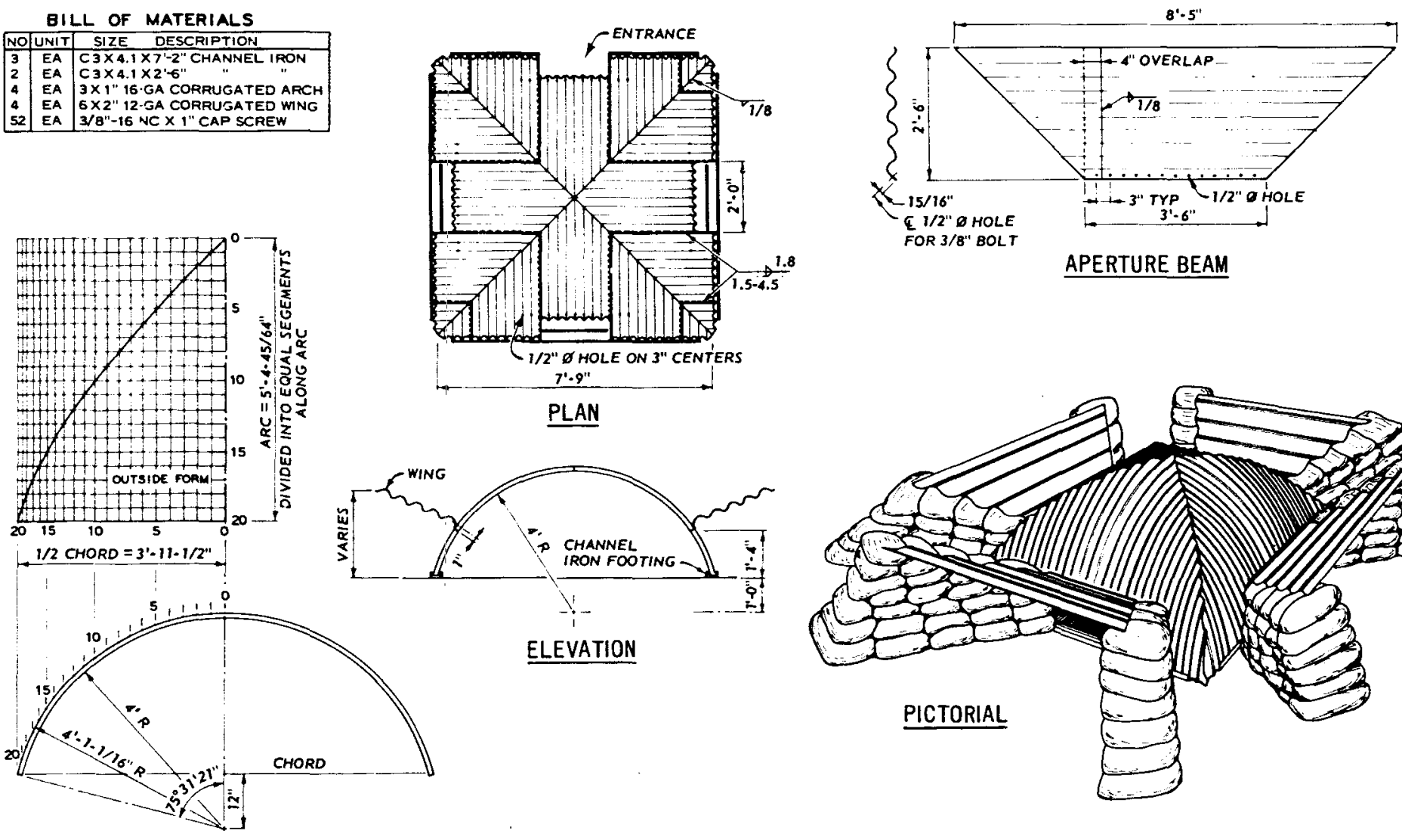

PLOTING TEMPLATE FOR ARCH

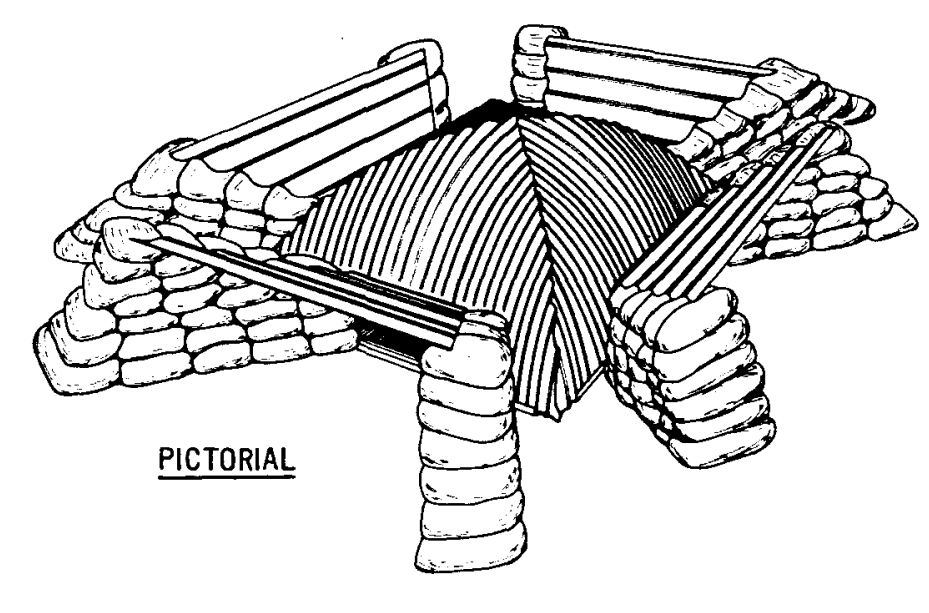

Figure 4.13 Detailed design drawings of Phase III test structure. 

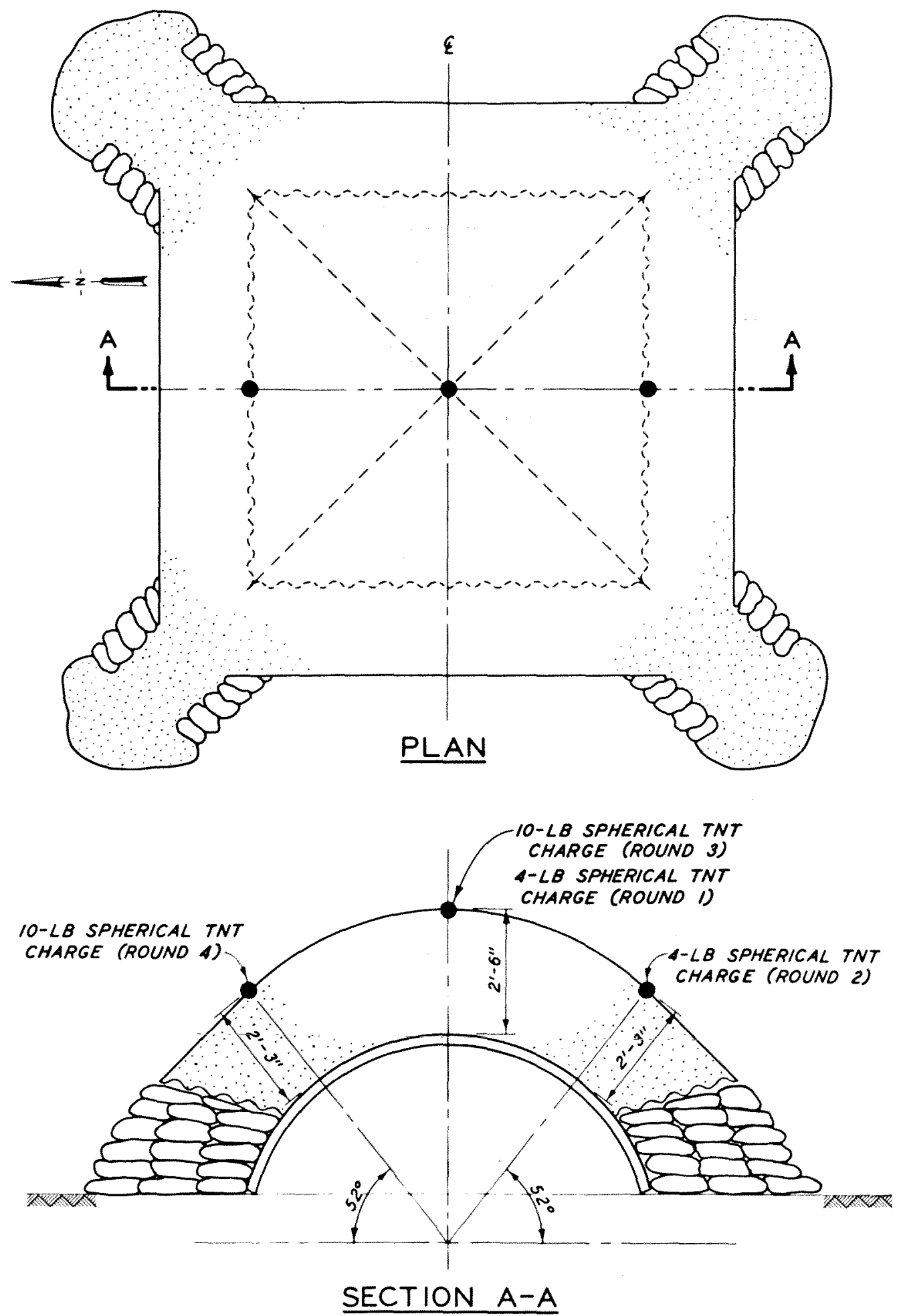

Figure 4.14 Charge sizes and locations for Phase III test series. 


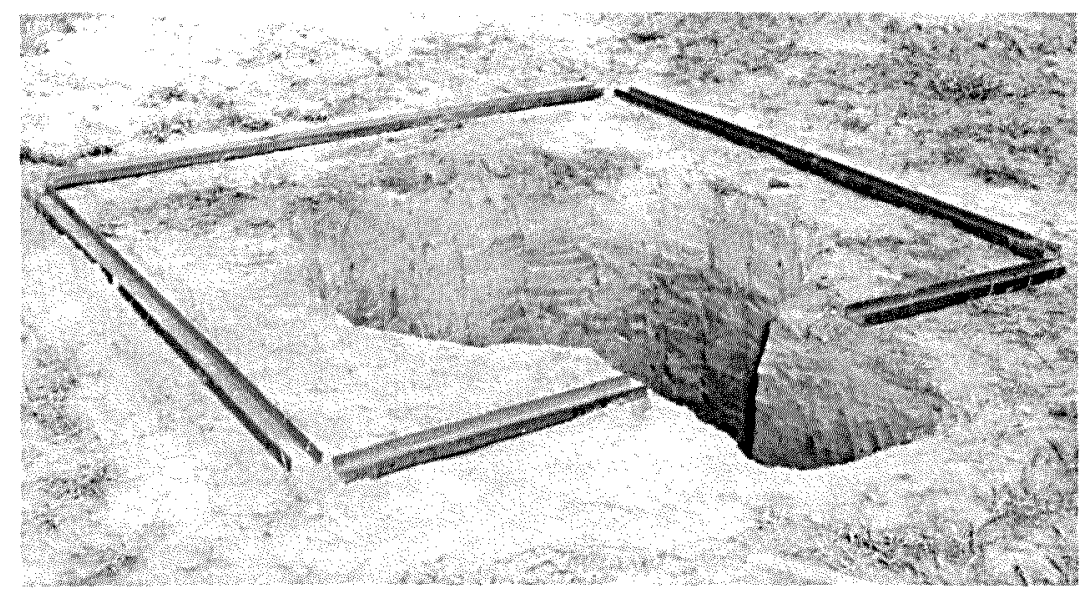

a. Footings placed around perimeter of fighting hole

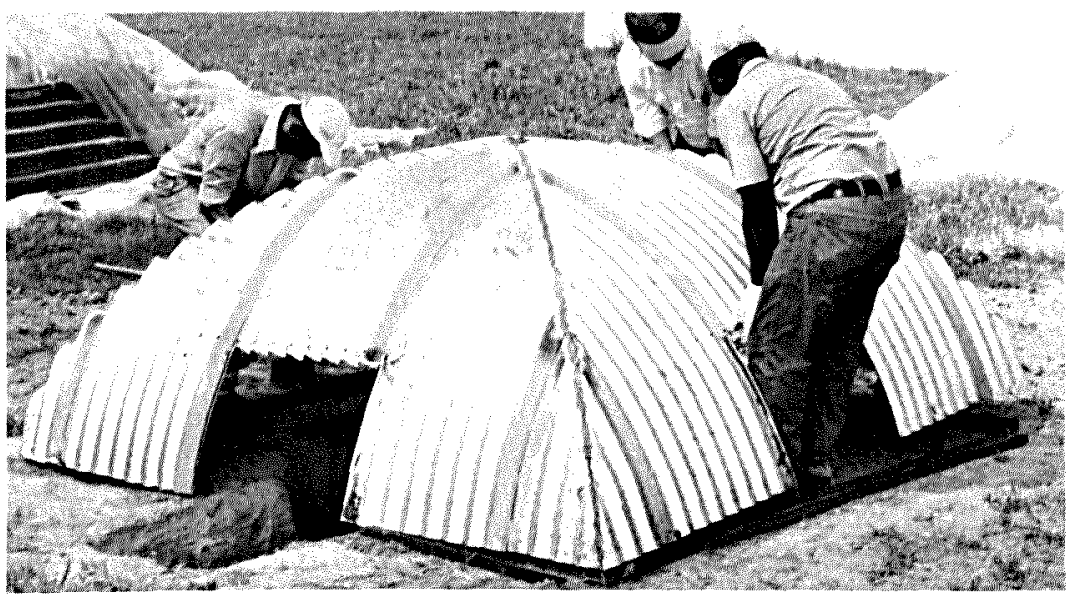

b. Three-man workcrew placing MICS

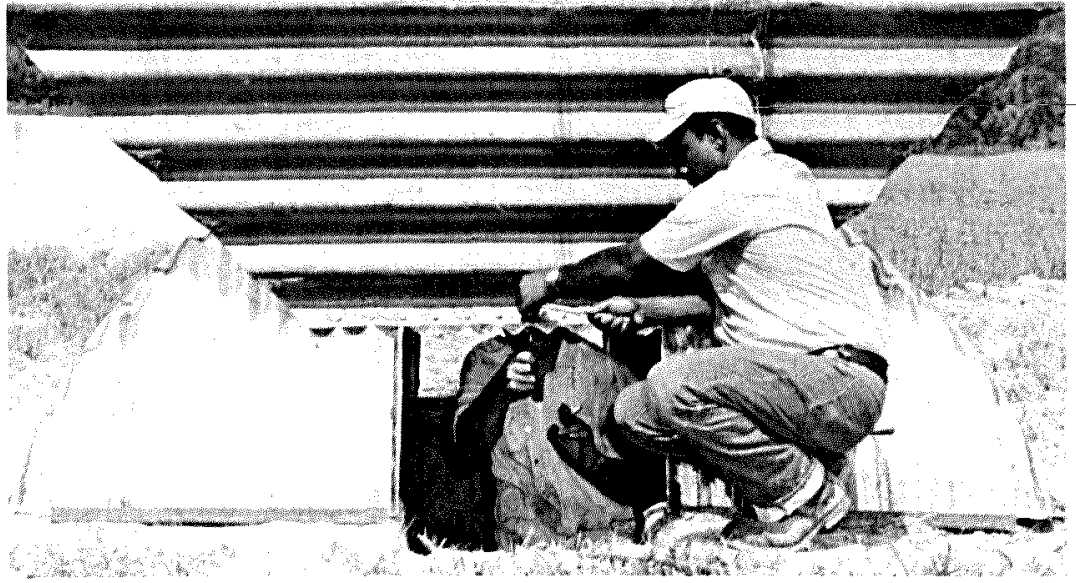

c. Attachment of aperture beams

Figure 4.15 Various stages of installation of Phase III test structure (sheet 1 of 2 ). 


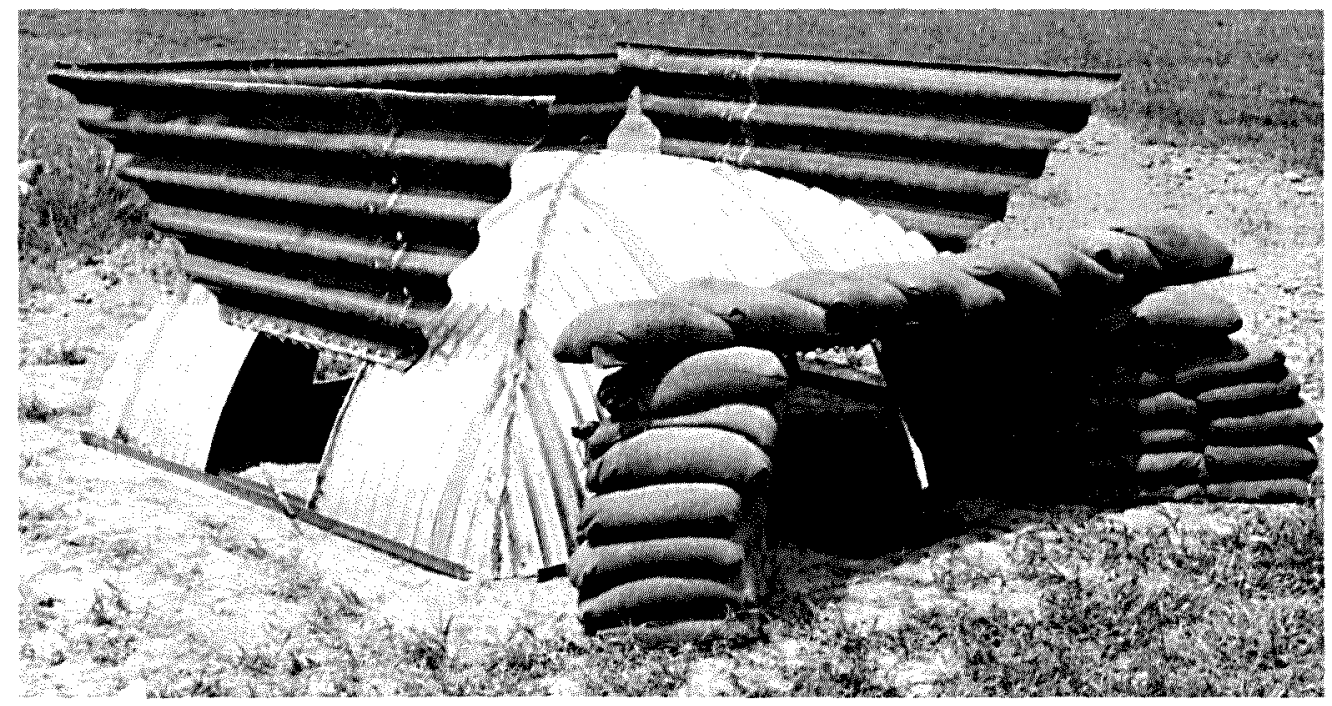

d. Sandbags placed over and under one aperture beam

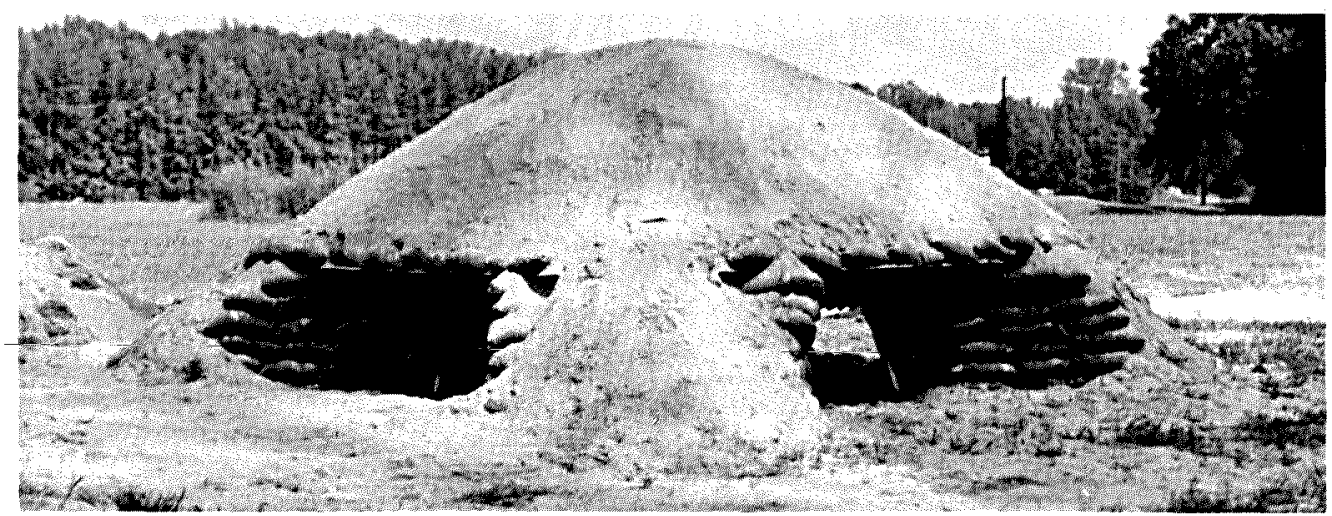

e. Sand cover placed over structure

Figure 4.15 (sheet 2 of 2 ). 


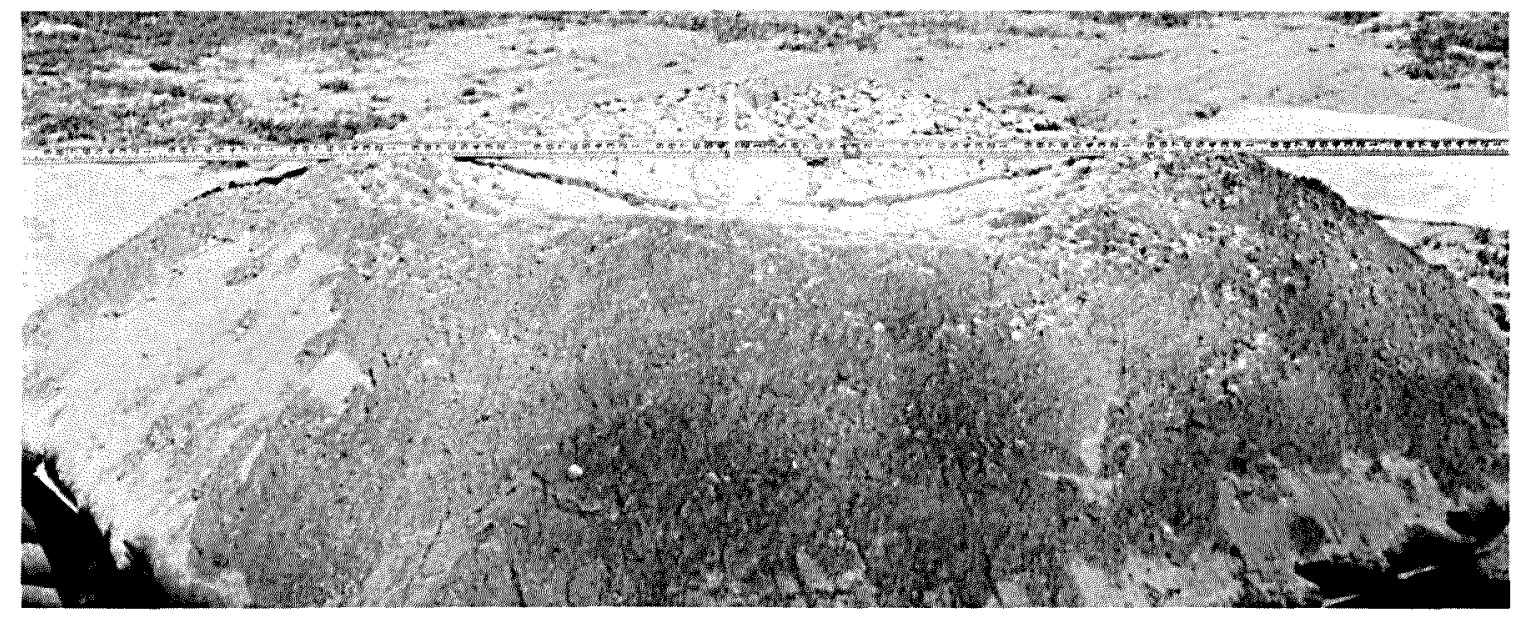

a. Apparent crater

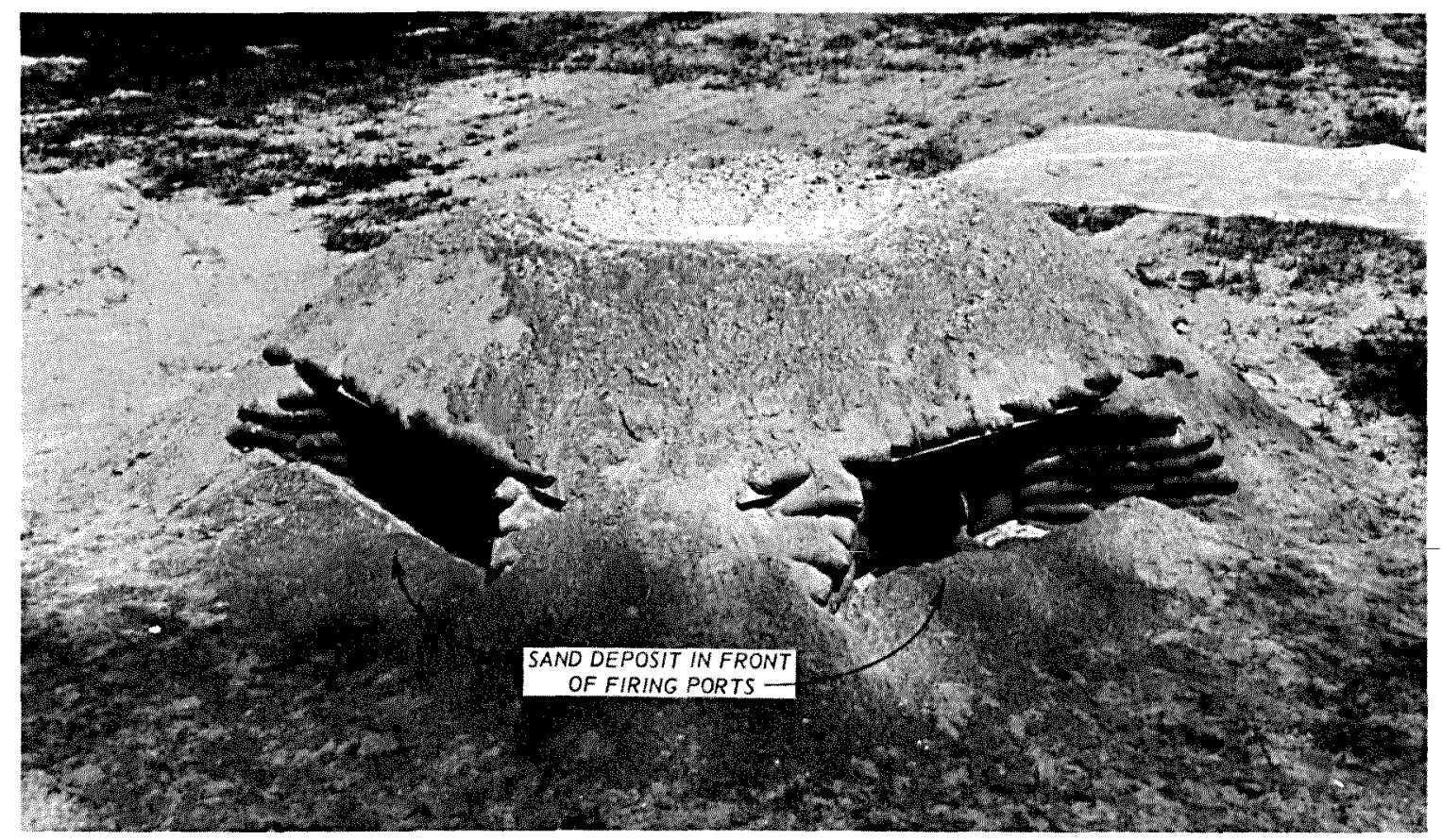

b. Sand deposited in front of firing ports

Figure 4.16 Damage resulting from Phase III test series, Round 1 . 


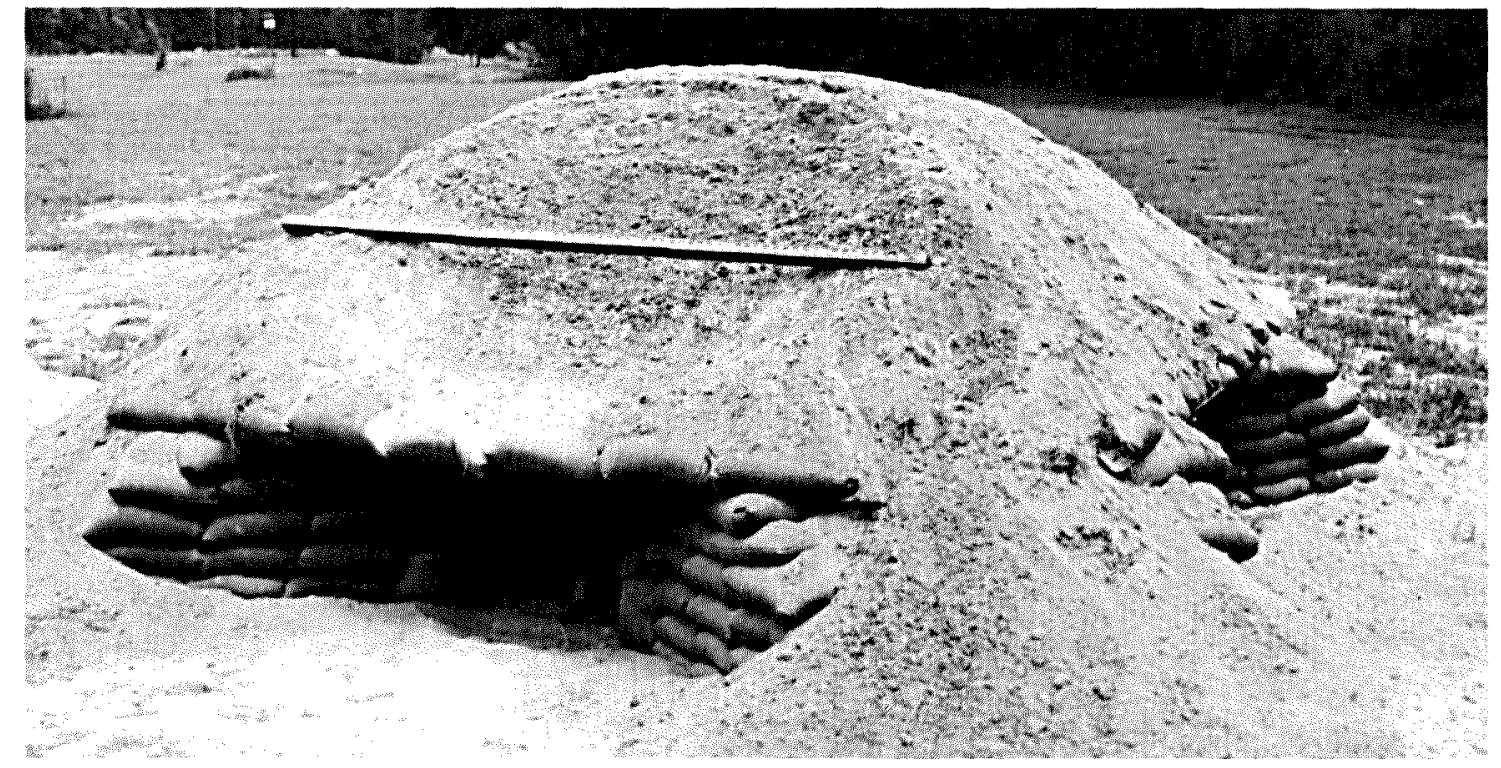

a. Crater formed by Round 2

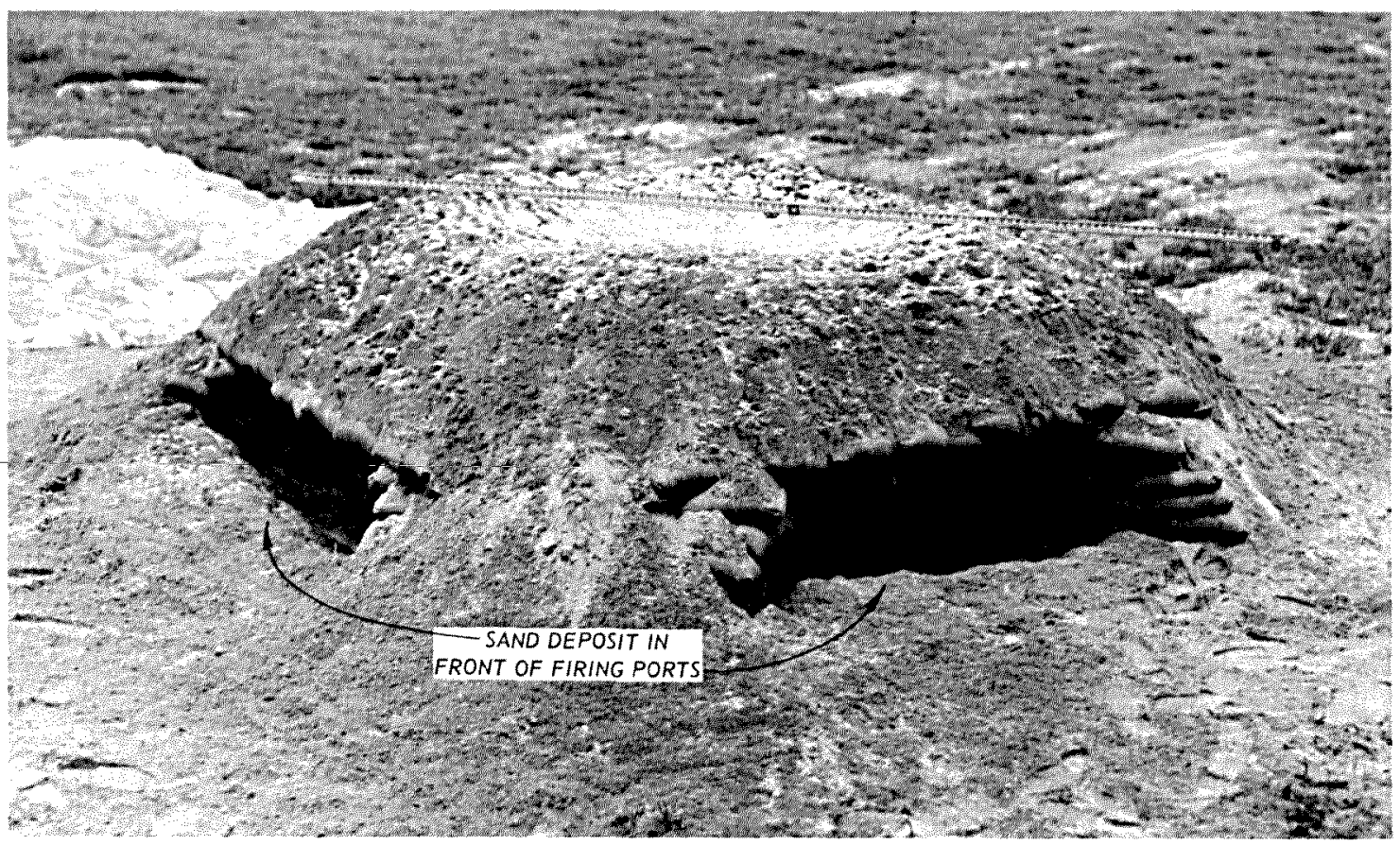

b. Crater formed by Round 3

Figure 4.17 Damage resulting from Phase III test series, Rounds 2 and 3. 


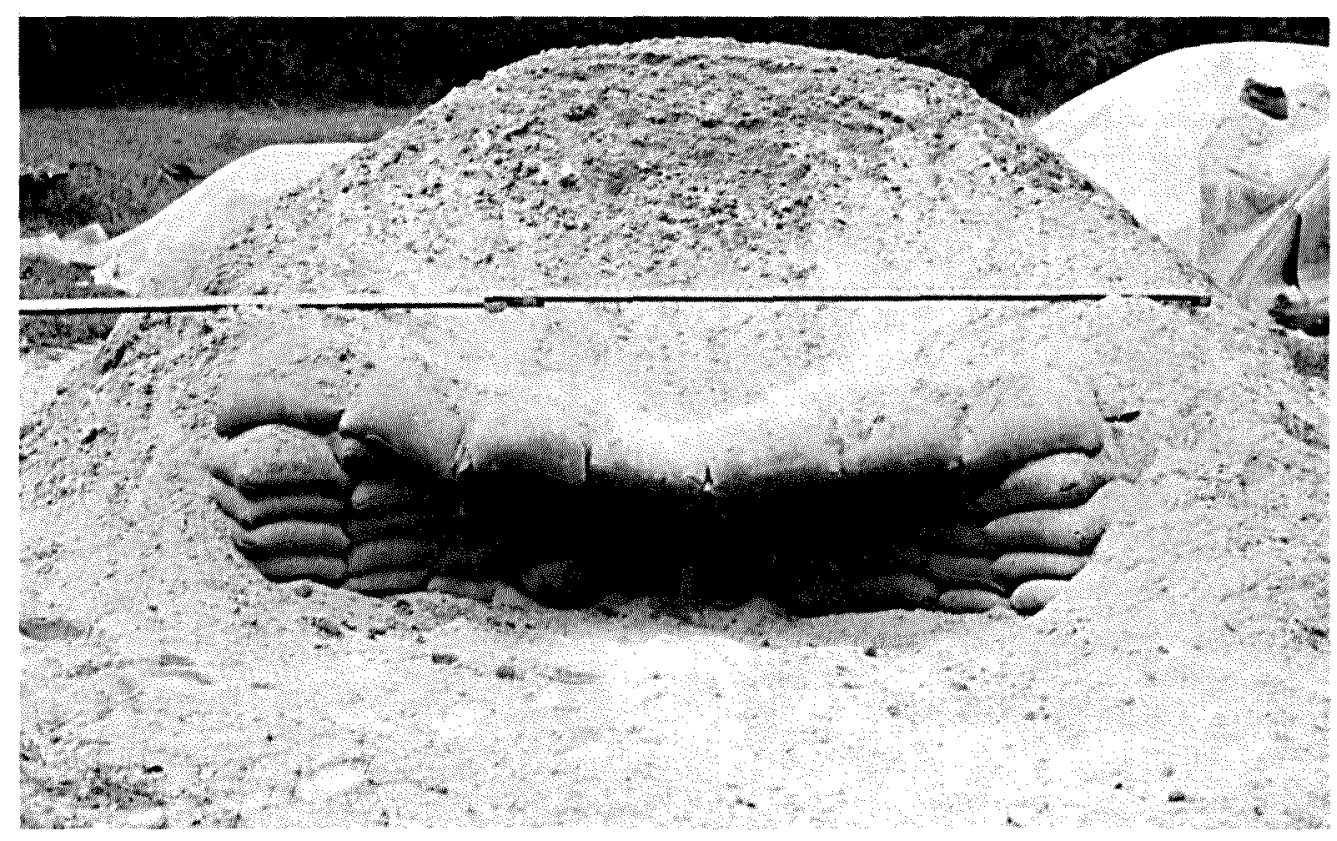

a. Apparent crater

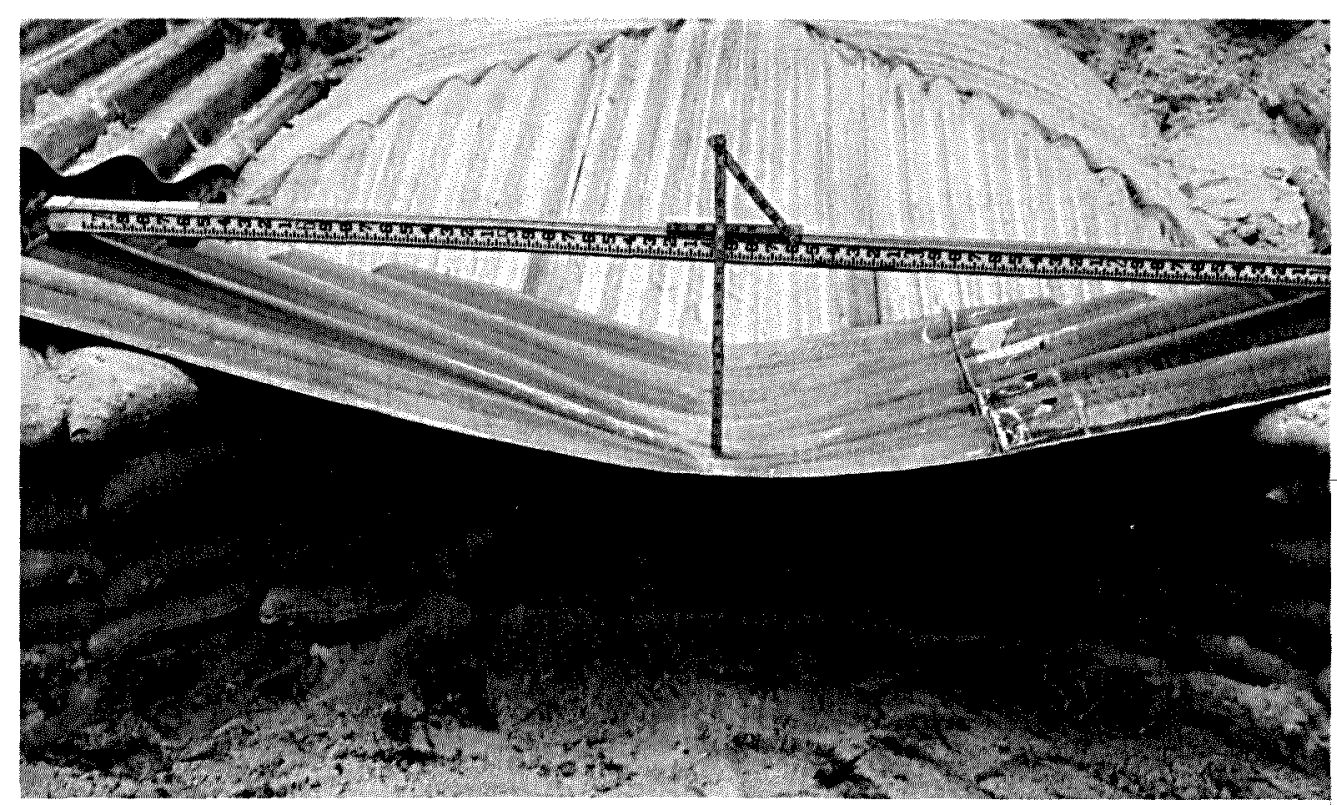

b. Permanent set of aperture beams

Figure 4.18 Damage resulting from Phase III test series, Round 4 (sheet 1 of 2 ). 


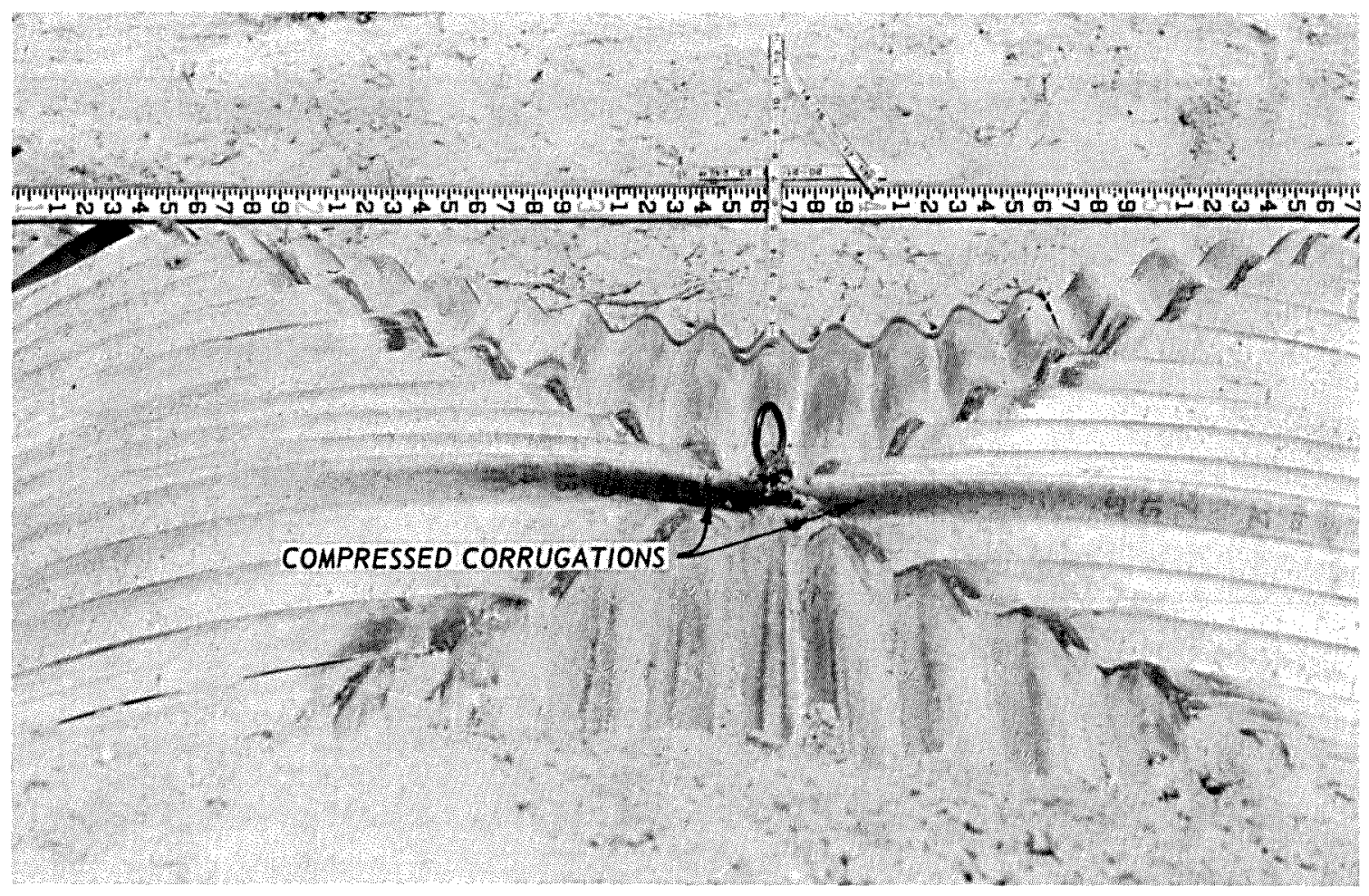

c. Permanent set of loaded quarter-section of MICS

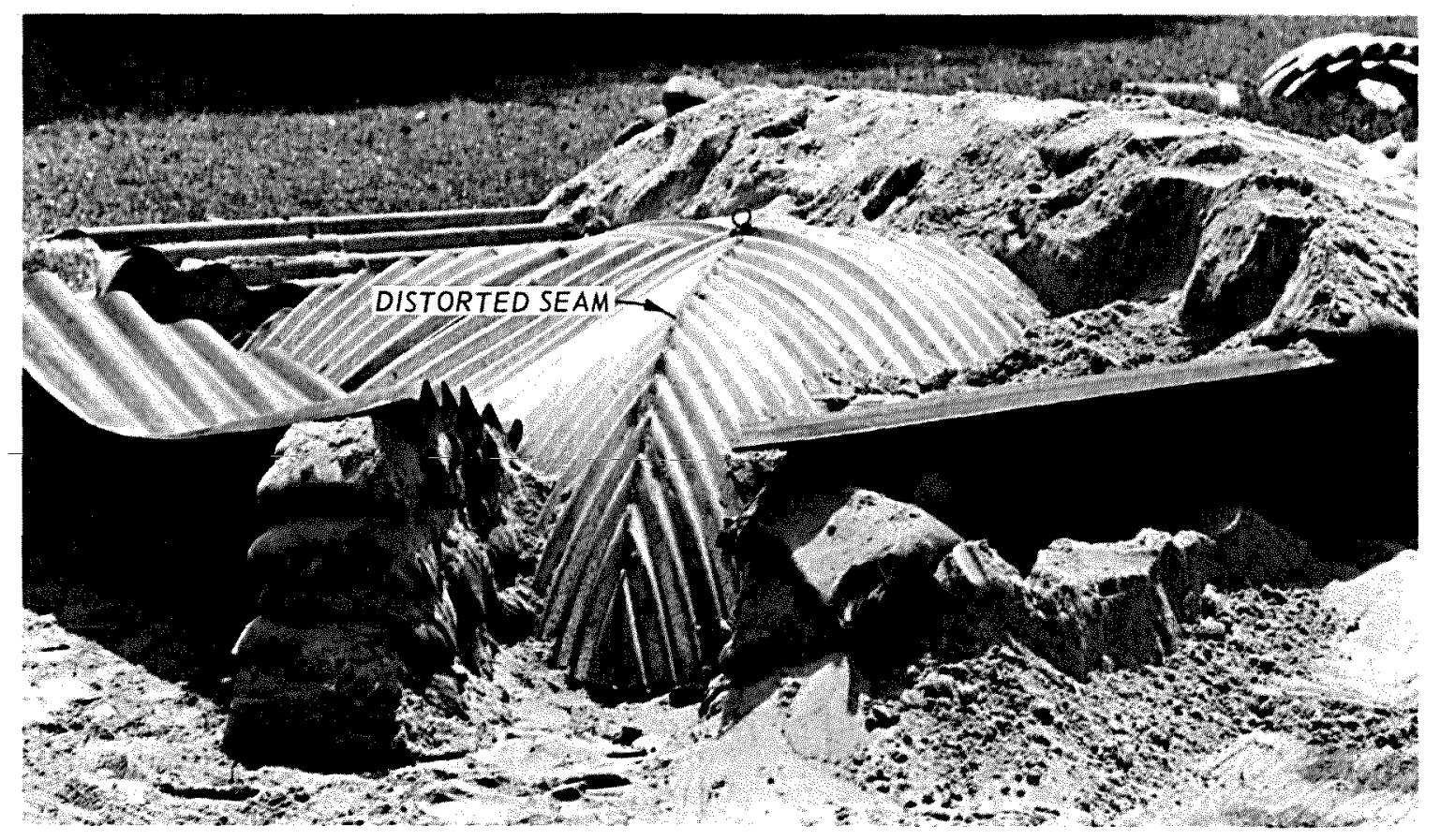

d. Typical distorted seam

Figure 4.18 (Sheet 2 of 2 ). 
CHAPTER 5

SELECTED DESIGNS AND RECOMMENDATIONS

\section{I SELECTED DESIGNS}

Two fighting hole cover designs were selected as a result of this investigation. These two designs were evaluated in both the Phase II and the Phase III test series. Detailed design drawings of these two fighting hole covers are shown in Figures 5.1 and 5.2 , respectively.

A comparison of the two selected designs with respect to the requirements necessary for evaluating their effectiveness is presented as follows:

a. Protection. The tests conducted at the WES BBTF demonstrated that both designs provided ample protection from the blast effects of 4- and 10-pound spherical TNT charges half buried in a loose sand cover that was 30 inches deep over the crown. Likewise, based on the discussion presented in Section 4.1, the two cover designs will provide protection from the blast effects of contact bursts, i.e. superquick fuzed $81-\mathrm{mm}$ and 4.2-inch mortars and 105-mm artillery $\mathrm{HE}$ rounds.

b. Fabrication. Both designs can be fabricated from standard materials using existing fabrication techniques. No attempt was made in this study to record the man-hours required for fabrication due to the fact that, for mass production, hardware such as stamps, molds, etc., would be used. Based on the fabrication procedure used in this study, it can be concluded that approximately the same number of man-hours is required for each design.

It should be pointed out that the remaining corrugated material from which two quarter-sections of the MICS for the Phase II and III test structures were fabricated is ample for fabrication of another quartersection that is welded along its center line. Figure $5.3 \varepsilon$ shows the remaining two parts of the material from which one quarter-section of the Phase III test structure was fabricated. Again, if these two parts are welded together, ample material is available for the fabrication of another quarter-section (Figure 5.3b). Although this procedure was 
not used in this study, it is believed that the resulting welded seam at the center line of the quarter-sections would not alter the protection provided by the Phase II and III test structures.

c. Functional. Both designs offer identical functional features. The usable floor area of the fighting-hole covers for personnel is the area of the fighting hole itself, i.e. 19.6 feet $^{2}$ for both designs. Also, both designs offer the same aperture dimensions for accommodating various weapons and offer the same fields of fire. For both structures, the geometry of the embrasure desired is dependent only on the sandbag arrangement used to support the aperture beams.

d. Transportability. Both designs can be delivered by air and/or truck. A box with minimum inside dimensions of 5 feet wide by 7 feet 9 inches long by 1 foot high would be necessary to containerize the component parts of the Phase II test structure, while a box with minimum inside dimensions 8 feet by 8 feet by 3 feet 2 inches high would be necessary to containerize the component parts of the Phase III test structure.

e. Constructability. Both designs can be field-erected without the aid of mechanical equipment. Three men with only hand-tools can erect both structures. It takes approximately $1-1 / 2$ hours longer to erect the Phase II test structure than the Phase III test structure. This is primarily due to the fact that the MICS of the Phase III test structure is intact when received in the field.

f. Cost. Cost of materials of the Phase II and Phase III test structures is presented in Tables 5.1 and 5.2 , respectively. It should be emphasized that the cost shown in these tables is based on the purchase price of the materials needed per test structure. For mass production commensurate with the fabrication technique used in this study, a reduction of at least 10 to 15 percent of the costs shown would be justified. For mass production commensurate with hardware such as stamps, molds, etc., further cost reductions are possible. 


\subsection{RECOMMENDATIONS}

Within the scope of the testing outlined in this report, the selected designs stand as a plausible, realistic means of providing hasty bunker protection. Additional testing and evaluation would, however, be advantageous to the overall development. Therefore, the following recommendations are made concerning the selected designs:

a. An investigation should be made into the optimum fabrication procedure for mass production and the resulting cost.

b. The selected designs should be troop-tested in the field. Of special interest are delivery methods, installations, and functional features relative to the aspects of a combat operation.

c. Live-fired weapons effects tests should be conducted to determine the protection level against various $H E$ weapons and the effects of various soil cover systems.

d. Live-fire tests should be conducted to verify the effectiveness of triggering screens with this bunker.

e. The response of Phase III design to nuclear airblast should be determined by subjecting it to simulated nuclear explosion events as they become available. Pressure fill times and the response of unlined fighting holes should also be documented in the same event. 
TABLE 5.1 COST OF MATERIAIS FOR THE PHASE II TEST STRUCTURE

\begin{tabular}{|c|c|c|c|c|c|c|c|c|c|c|}
\hline & \multirow[b]{2}{*}{$\begin{array}{c}\text { Description of } \\
\text { Comporent } \\
\text { Farts }\end{array}$} & \multicolumn{2}{|r|}{ MICS } & 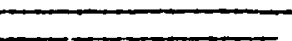 & \multicolumn{3}{|c|}{ Aperture Deems } & \multicolumn{3}{|c|}{ Footings } \\
\hline & & $\begin{array}{l}\text { Number } \\
\text { Required }\end{array}$ & $\begin{array}{l}\text { Besed on Fabricating } \\
\text { Tro-Quarter-Secticns } \\
\text { per Component Part }\end{array}$ & $\begin{array}{l}\text { Based on Fabricating } \\
\text { One-Quarter-Section } \\
\text { per Component Part }\end{array}$ & $\begin{array}{c}\text { Description of } \\
\text { Component } \\
\text { Partg }\end{array}$ & $\begin{array}{l}\text { Number } \\
\text { Requíred }\end{array}$ & $\cos t$ & $\begin{array}{c}\text { Description of } \\
\text { Component } \\
\text { Parts }\end{array}$ & $\begin{array}{l}\text { Number } \\
\text { Requ } \neq \text { red }\end{array}$ & Cost \\
\hline & $\begin{array}{l}\text { 6" } \times 12 \text { GA } \\
\text { N8 plate 10-rt } \\
\text { long rolied to } \\
4-\mathrm{ft} \text { radius }\end{array}$ & 4 & $\$ 288.90$ & $\$ 577.80$ & $\begin{array}{l}\text { 6" X 12 GA-3N } \\
\text { plate 12-It } \\
\text { leng }\end{array}$ & 1 & $\$ 143.00$ & $\begin{array}{l}\text { C4 } \times 5.4 \times 7^{\prime}- \\
2^{\text {" }} \text { channel } \\
\text { 1ron }\end{array}$ & 3 & $\$ 37.00$ \\
\hline$\infty$ & $\begin{array}{c}3^{n} \times 4 " x: / 4 " \\
\text { steel plate }\end{array}$ & 56 & 12.00 & 12.00 & $\begin{array}{l}6^{\prime \prime} \times 2 " 12 \mathrm{GA}- \\
7 \mathrm{~N} \text { plate } 12-\mathrm{ft} \\
\text { lonB }\end{array}$ & 1 & 238.00 & $\begin{array}{l}\text { c4 } \times 5.4 \times 2 \text { - } \\
6 " \text { channel 1ron }\end{array}$ & 2 & 28.64 \\
\hline$F$ & $\begin{array}{l}14^{\prime \prime} \times 1 " \times 1{ }^{\prime} \times \\
4 \cdot \text { steel strap }\end{array}$ & 4 & 1.00 & 1.00 & $\begin{array}{l}3 / 4 "-10 \text { Nc } \times 1-1 / 4 " \\
\text { cap screw }\end{array}$ & 28 & - & - & -- & - \\
\hline & $\begin{array}{l}3 / 8^{\prime \prime}-16 \text { Gic } x \\
1-1 / 2^{\prime \prime} \text { cap screr }\end{array}$ & 8 & 0.24 & 0.24 & - & - & - & - & - & - \\
\hline & $\begin{array}{l}3 / 8^{\prime \prime}-16 \mathrm{NC} x \\
1-3 / 4^{\prime \prime} \text { cap screv }\end{array}$ & 56 & 2.50 & 2.50 & - & - & - & - & - & - \\
\hline & & TOTAL COST & $\$ 304.64$ & $\$ 593.54$ & & & $\$ 381.00$ & & & $\$ 65.64$ \\
\hline
\end{tabular}

eror mass production, a reduction of 20 to 15 percent 'or those costs shown would be justirled. 
TABLE 5.2 COST OF MATERIALS FOR THE PHASE III TEST STRUCTURE ${ }^{\circ}$

\begin{tabular}{|c|c|c|c|c|c|c|c|c|c|}
\hline \multicolumn{4}{|c|}{ MICS } & \multicolumn{3}{|c|}{ Aperture Beams } & \multicolumn{3}{|c|}{ Foot1ngs } \\
\hline $\begin{array}{c}\text { Description of } \\
\text { Component } \\
\text { Parts }\end{array}$ & $\begin{array}{c}\text { Number } \\
\text { Required }\end{array}$ & $\begin{array}{l}\text { Based on Fabricating } \\
\text { Two-Quarter-Sections } \\
\text { per Component Part }\end{array}$ & $\begin{array}{l}\text { Based on Fabricating } \\
\text { One-Quarter-Section } \\
\text { Der Component Part }\end{array}$ & $\begin{array}{c}\text { Description of } \\
\text { Component } \\
\text { Parts } \\
\end{array}$ & $\begin{array}{c}\text { Nunber } \\
\text { Required } \\
\end{array}$ & $\cos t$ & $\begin{array}{c}\text { Description of } \\
\text { Component } \\
\text { Parts }\end{array}$ & $\begin{array}{c}\text { Number } \\
\text { Required } \\
\end{array}$ & Cost \\
\hline \multirow{4}{*}{$\begin{array}{l}\text { 3" } \times l^{\prime \prime}-15 \mathrm{GA} \\
\text { sheet 10-ft long } \\
\text { rolled to a } \\
\text { 4-ft radius }\end{array}$} & 4 & $\$ 258.00$ & $\$ 516.00$ & $\begin{array}{l}6 " \times 2 "=12 \mathrm{GA} \\
3 \mathrm{~N} \text { plate } 12-\mathrm{ft} \\
\text { long }\end{array}$ & 1 & $\$ 143.00$ & 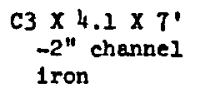 & 3 & $\$ 28.17$ \\
\hline & & & & $\begin{array}{l}6^{\prime \prime} \times 2^{\prime \prime}-12 \mathrm{GA} \\
7 \mathrm{~N} \text { plate } 12-\mathrm{ft} \\
\text { long }\end{array}$ & 1 & 238.00 & $\begin{array}{l}\text { C3 } \times 4.1 \times 21 \\
-6 " \text { channel } \\
\text { Iron }\end{array}$ & 2 & 3.28 \\
\hline & & & & $\begin{array}{l}3 / 8^{\prime \prime}-16 N C \times 1 " \\
\text { cap screv }\end{array}$ & 52 & 2.00 & - & - & - \\
\hline & TOTAL COST & $\$ 258.00$ & $\$ 516.00$ & & & $\$ 383.00$ & & & $\$ 31.45$ \\
\hline
\end{tabular}

\footnotetext{
For mass production, a reduction of 10 to 15 percent of those costs shown vould be Justifled.
} 

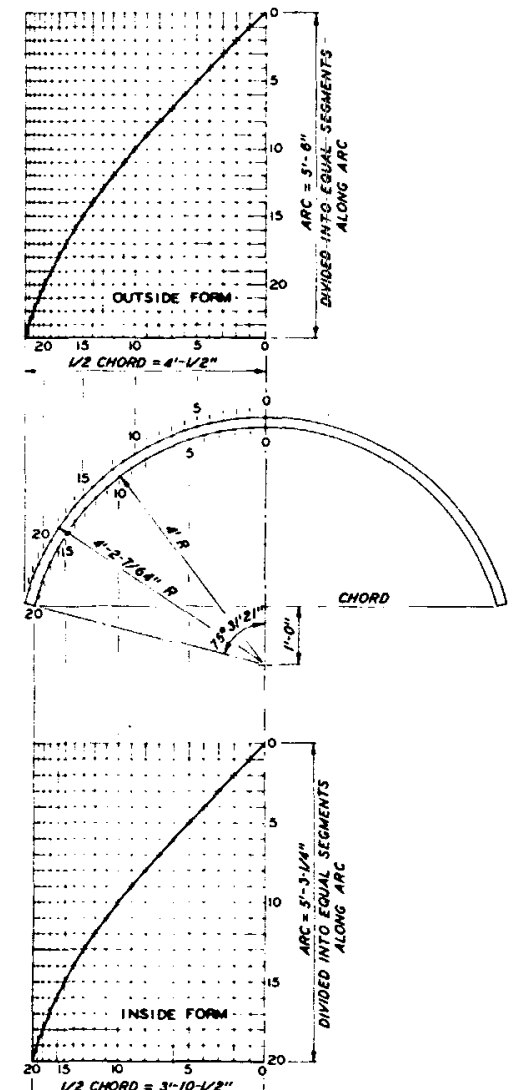

PLOTTING TEMPL.ATES FOR ARCH
THO" MOLES ORILLO AS REQD
FOR CLIP PL ATES ANO STRAPS
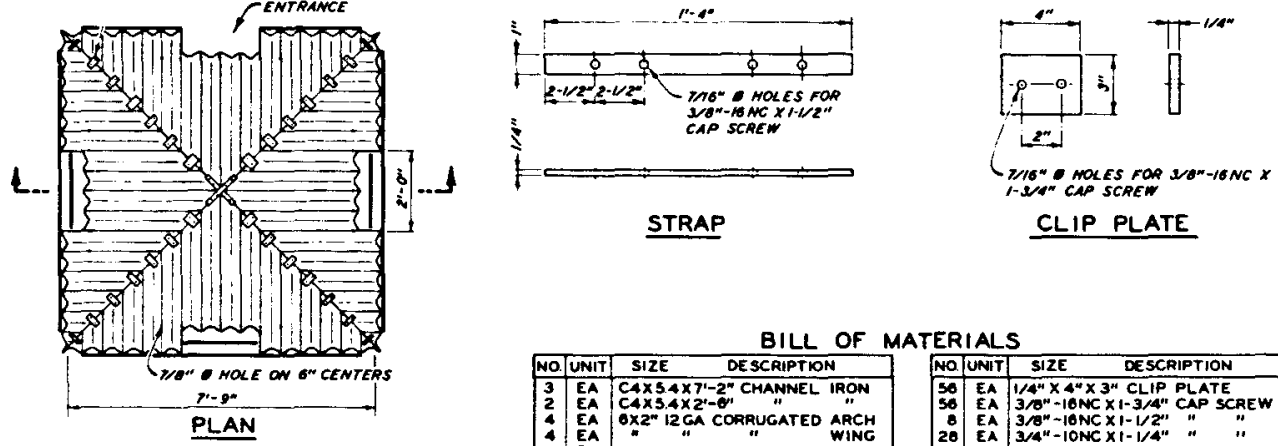

BILL OF MATERIALS
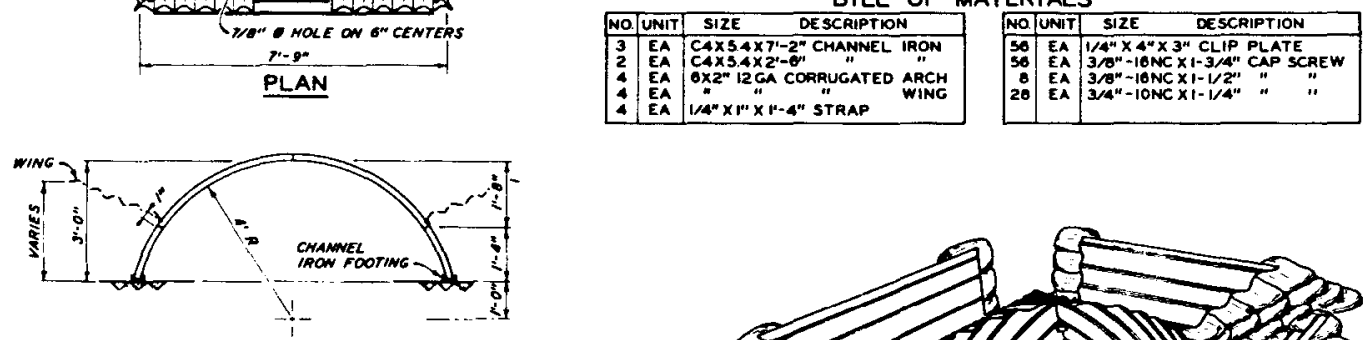

ELEVATION


Figure 5.1 Detailed design drawings of Phase II test structure. 


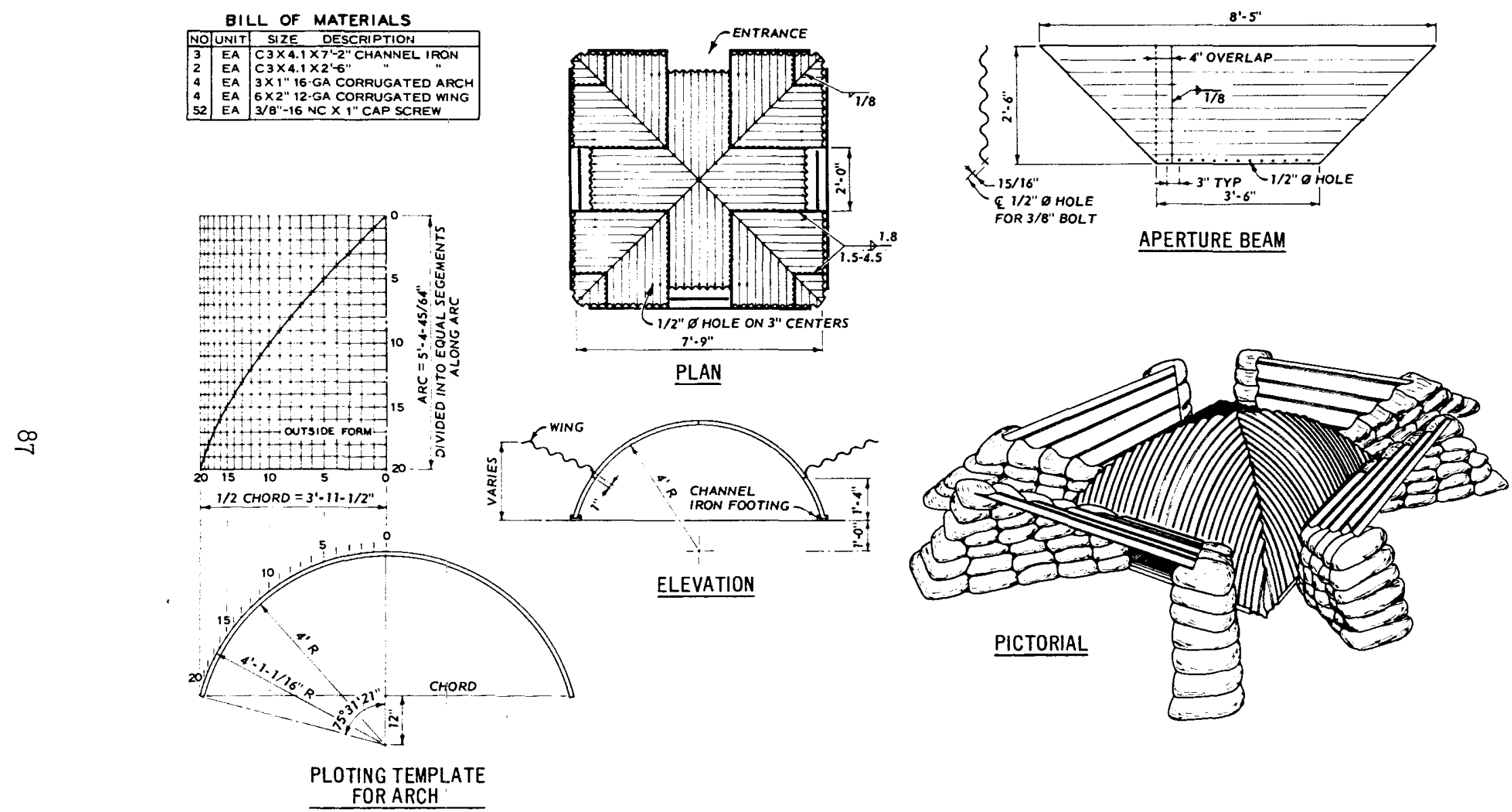

Figure 5.2 Detailed Drawings of Phase III test structure. 


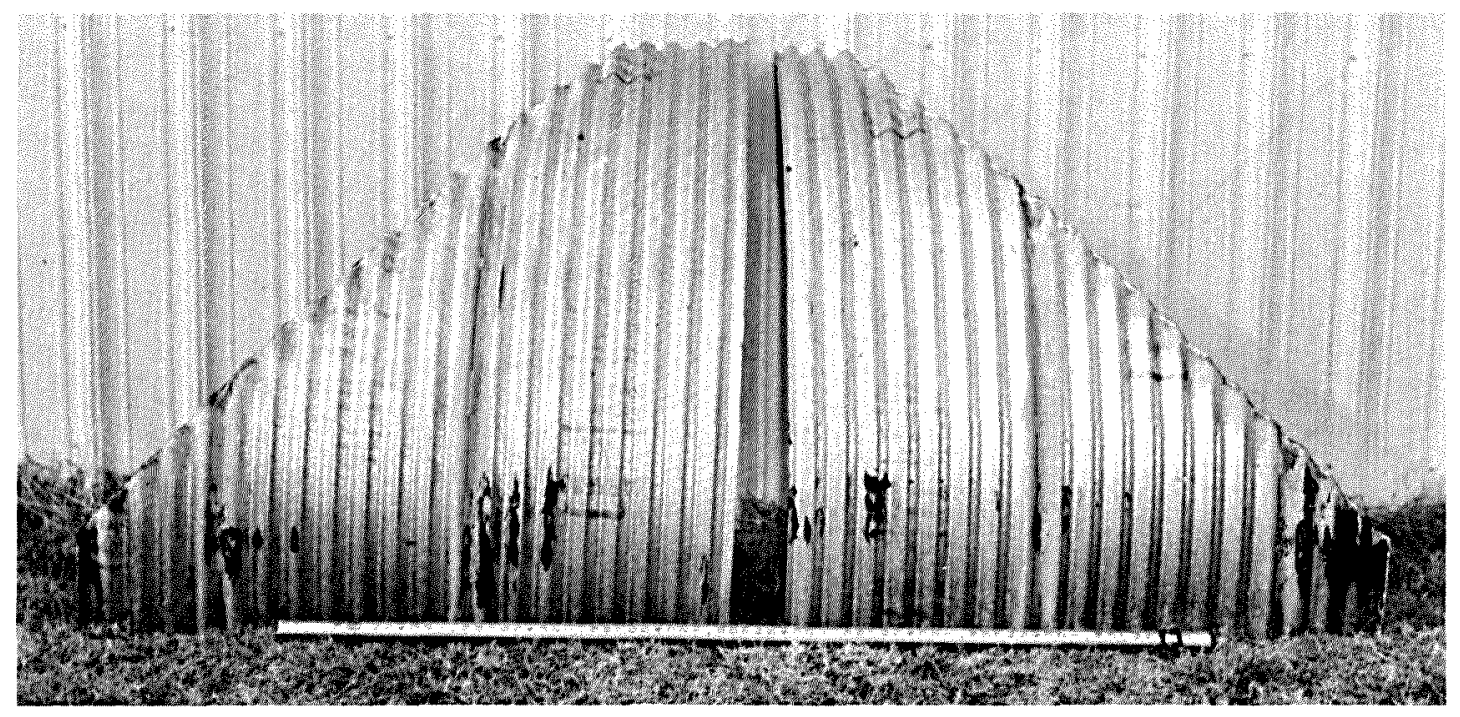

a. Remaining corrugated material from which one quarter-section of MICS of the Phase II test structure was fabricated



b. Quarter-section template of MICS showing ample material available for fabricating an additional quarter-section

Figure 5.3 Utilization of remaining corrugated material for fabrication of additional quarter-sections of MICS. 


\section{REFERENCES}

1. Carre, G. L., "Design, Construction, and Evaluation of Protective Military Structures," Technical Report N-68-1, Aug 1968, U. S. Army Engineer Waterways Experiment Station, CE, Vicksburg, Miss.

2. Hoot, B. B. et al, "Evaluation of Field Fortifications," Technical Report No. N-74-5, Aug 1974, U. S. Army Engineer Waterways Experiment Station, CE, Vicksburg, Miss.

3. American Iron and Steel Institute, "Handbook of Steel Drainage and Highway Construction Products," Apr 1967, New York, N. Y.

4. Hoot, B. B., "Portable Bunker Tests and Evaluation," Technical Report No. N-71-6, Jun 1971, U. S. Army Engineer Waterways Experiment Station, CE, Vicksburg, Miss. 
In accordance with $70-2-3$, paragraph $6 c(1)(b)$, dated 15 Pebruary 1973, a facoinlle catalog card in Ilbrary of Congress format is reproduced below.

Ball, James William

Development and evaluation of corrugated metal fightIng hole cover designs, by James W. Ball. Vicksburg,

U. S. Army Engineer Waterways Experiment Station, 1976. 89 p. illus. $27 \mathrm{~cm}$. (U. S. Waterways Experiment Station. Technical report $\mathrm{N}-76-6)$

Prepared for Office, Chief of Engineers, U. S. Army, Washington, D. C., under Project No. 4A762719AT30, Task 01 .

References: p. 89 .

1. Bunkers (Fortifications). 2. Corrugated metal shel1s. 3. Expedient construction. 4. Multiple Intersecting Cylindrical Shells. 5. Protective structures. 6. Subsurface structures. I. U. S. Army. Corps of Engineers. (Series: U. S. Waterways Experiment Station, Vicksburg, Miss. Technical report $\mathrm{N}-76-6$ ) TA7. W34 no. N-76-6 